\title{
Analytical and experimental study of FRP honeycomb sandwich panels with sinusoidal core
}

\author{
Justin Mark Robinson \\ West Virginia University
}

Follow this and additional works at: https://researchrepository.wvu.edu/etd

\section{Recommended Citation}

Robinson, Justin Mark, "Analytical and experimental study of FRP honeycomb sandwich panels with sinusoidal core" (2001). Graduate Theses, Dissertations, and Problem Reports. 1164.

https://researchrepository.wvu.edu/etd/1164

This Thesis is protected by copyright and/or related rights. It has been brought to you by the The Research Repository @ WVU with permission from the rights-holder(s). You are free to use this Thesis in any way that is permitted by the copyright and related rights legislation that applies to your use. For other uses you must obtain permission from the rights-holder(s) directly, unless additional rights are indicated by a Creative Commons license in the record and/ or on the work itself. This Thesis has been accepted for inclusion in WVU Graduate Theses, Dissertations, and Problem Reports collection by an authorized administrator of The Research Repository @ WVU. For more information, please contact researchrepository@mail.wvu.edu. 


\title{
ANALYTICAL AND EXPERIMENTAL STUDY OF FRP HONEYCOMB SANDWICH PANELS WITH SINUSOIDAL CORE
}

\author{
Justin Robinson \\ Thesis submitted to the \\ College of Engineering and Mineral Resources \\ at West Virginia University \\ in partial fulfillment of the requirements \\ for the degree of \\ Master of Science \\ in \\ Civil and Environmental Engineering
}

Julio F. Davalos, Ph.D., Chair

Pizhong Qiao, Ph.D., Co-Chair

Karl E. Barth, Ph.D.

Department of Civil and Environmental Engineering

Morgantown, West Virginia

2001

Keyword: fiber-reinforced plastics, honeycomb sandwich panel, sinusoidal core, experimental testing, finite element modeling, elastic equivalence 


\section{Abstract \\ Analytical and Experimental Study of FRP Honeycomb Sandwich Panels with Sinusoidal Core}

\section{Justin Robinson}

Fiber reinforced plastic (FRP) composite materials and structures have been increasingly used in highway bridge applications. Recent applications have demonstrated that FRP honeycomb sandwich panels with sinusoidal core can be effectively and economically used for highway bridge deck systems. In this study, analytical and experimental characterizations are presented for a FRP honeycomb panel with sinusoidal core geometry in the plane and extending vertically between face laminates. To verify the accuracy of the a closed-form solution, several honeycomb sandwich beams with sinusoidal core waves either in the longitudinal or transverse directions are tested in bending and torsion. Also, a deck panel is tested under both symmetric and asymmetric patch loading. Finite element models are further developed to simulate the actual sandwich geometry and also to simplify the structure as an equivalent three-layer laminate. The explicit and FE predictions are compared with experimental results. The present analysis and characterization procedures can be used in design applications and optimizations of honeycomb structures. 


\title{
D edicated to the M emory of my loving brother
}

\author{
$\mathrm{N}$ athan $\mathrm{R}$ obinson
}




\section{ACKNOWLEDGEMENTS}

First I would like to thank God for the many opportunities and gifts that He has bestowed upon me. I would also like to express my greatest appreciation to my wife, Tracy, my son, Mark, and the rest of my family, who have supported and encouraged me throughout my studies.

I would also like to offer my thanks to my advisor and friend Dr. Julio Davalos. His support and direction through all aspects of research and life have been invaluable. I also must thank Dr. Pizhong Qiao for all his hard work and assistance with this project.

My appreciation goes to Jennifer Righman for all her help with the experimental testing. Also, the assistance offered by Dana Humberson is greatly appreciated. I would like to thank Dr. Karl Barth for his participation in my advisory committee, and Dr. Ever Barbero for spending extra time teaching me many aspects of composite materials.

I would like to thank Dr. Jerry Plunkett for his technical advice and KSCI for providing the experimental test samples. This study was partially funded by the NCHRP-IDEA, Project 66. All other financial help is greatly appreciated. 


\section{TABLE OF CONTENTS}

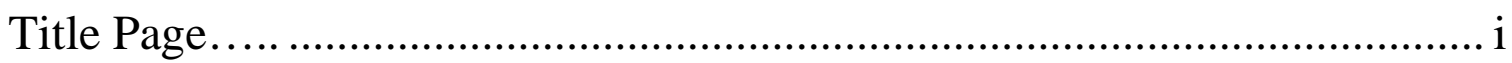

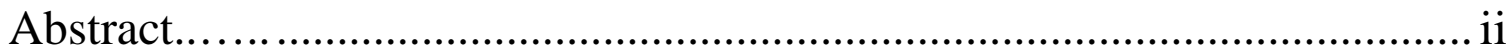

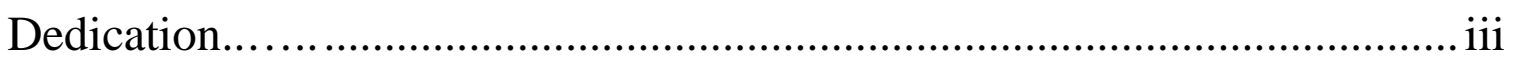

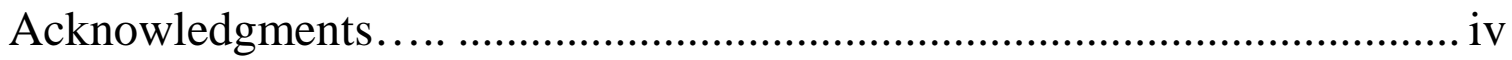

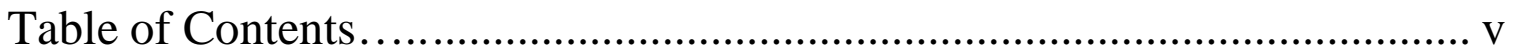

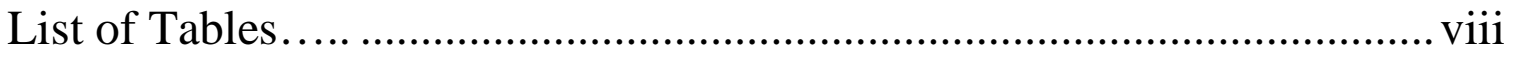

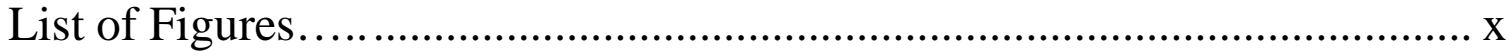

Chapter 1: Introduction ........................................................................... 1

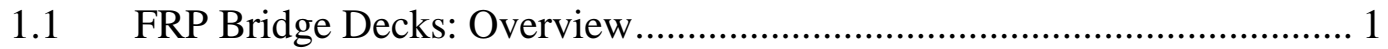

1.2 Types of Available FRP Composite Bridge Decks..................................... 3

1.3 Problem Statement and Objectives ........................................................ 10

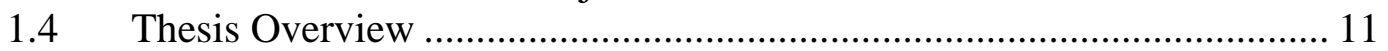

Chapter 2: Mechanics of FRP Honeycomb Core Sandwich Panel....... 14

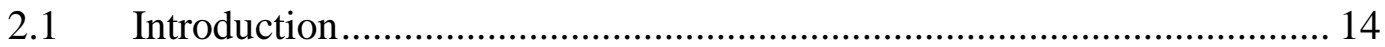

2.2 Modeling of Honeycomb Core ……………….................................. 14

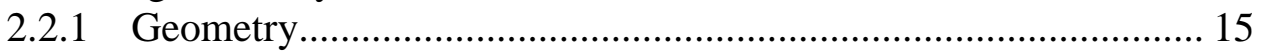

2.2.2 Equivalent Properties .................................................................. 16

Core longitudinal and transverse Young's moduli $\left(\mathrm{E}_{\mathrm{x}}{ }^{\mathrm{e}}\right.$ and $\left.\mathrm{E}_{\mathrm{y}}{ }^{\mathrm{e}}\right) . .20$

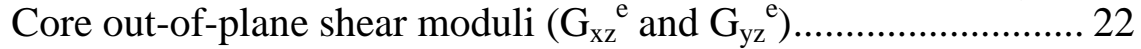

Summary of core equivalent properties ........................................ 24



2.3.1 Microstructure..................................................................... 25

2.3.2 Fiber-Volume Fraction............................................................. 26

2.3.3 Micromechanics...................................................................... 27

2.3.4 Equivalent Elastic Properties .................................................... 27

2.4 Equivalent Properties of FRP Honeycomb Sandwich Panel ................... 29

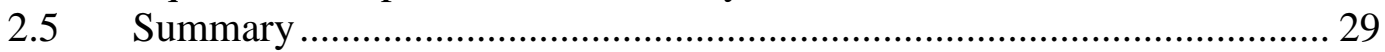

\section{Chapter 3: Experimental Testing and Finite Element Modeling.......... 30}

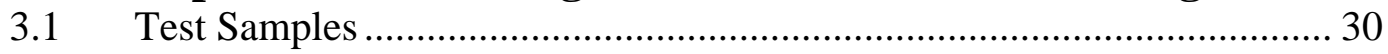

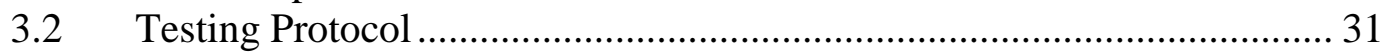

3.2.1 Beam under Bending................................................................ 32

3.2.2 Beam under Torsion............................................................... 32

3.2.3 Panel under Bending ............................................................ 33

3.3 Finite Element Modeling Procedures.......................................................... 33

3.3.1 Formulation of Actual Geometry Model ....................................... 34

3.3.2 Explanation of Results Taken From Actual Geometry Models.... 38

3.3.3 Formulation of Equivalent Plate Model......................................... 41

3.3.4 Explanation of Results Taken From Equivalent Plate Models ..... 43

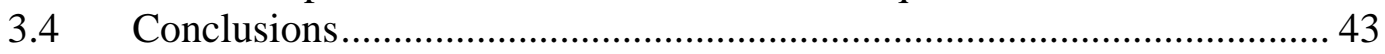




\section{Chapter 4: Evaluation of Sandwich Beams in Bending ......................... 45}



4.2 Experimental Evaluation in Bending ..................................................... 46



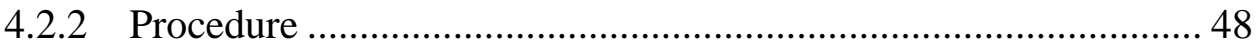

4.2.3 Results........................................................................... 49

4.3 Finite Element Evaluation in Bending ................................................. 55

4.4 Actual Core Geometry Finite Element Model ........................................... 55

4.4.1 Equivalent Plate Finite Element Bending ..................................... 57

4.4.2 Finite Element Bending Predictions …………………………..... 58

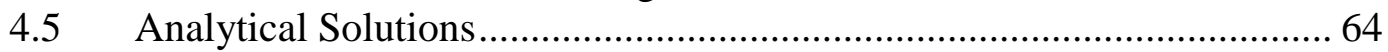

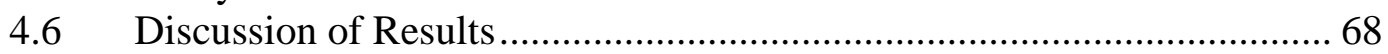

Chapter 5: Evaluation of Sandwich Beams in Torsion........................... 70



5.2 Calibration of the Torsion Testing Machine .............................................. 70

5.2.1 Overview of Experimental Methods ............................................. 71

5.2.2 Analytical Predictions for Aluminum Test Sample ....................... 72

5.2.3 Experimental Results for Aluminum Bar .................................... 73

5.2.4 Finite Element Modeling of Aluminum Bar.................................. 77

5.2.5 Discussion of Calibration Test..................................................... 79

5.3 Experimental Evaluation of FRP

Honeycomb Sandwich Beams in Torsion............................................... 80

5.3.1 Instrumentation and Setup ..................................................... 80

5.3.2 Experimental Procedure............................................................. 84

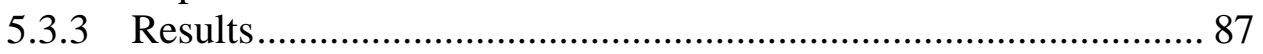

5.4 Finite Element Modeling of FRP Honeycomb

Sandwich Beams in Torsion ................................................................. 91

5.4.1 Actual Geometry Finite Element Model......................................... 91

5.4.2 Equivalent Plate Finite Element Model ......................................... 93

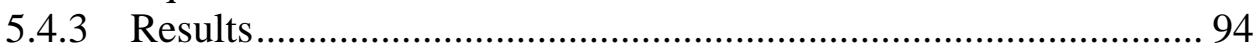

5.5 Comparison of FE and Experimental Results ........................................ 97

Chapter 6: Evaluation of Panel Sample ................................................... 100



6.2 Experimental Evaluation of the Panel................................................... 100

6.2.1 Instrumentation and Testing Setup ........................................... 100

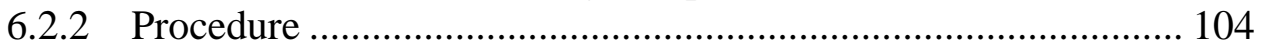

6.2.3 Results for Midspan Loading Conditions ................................... 105

6.2.4 Results for Eccentric Loading Conditions ................................. 108

6.3 Finite Element Evaluation of the Panel ............................................. 112

6.3.1 Formulation of Finite Element Model ........................................ 112

6.3.2 Actual Panel Geometry Finite Element Modeling Results .......... 114

6.3.3 Finite Element Results using the Equivalent Plate Properties .... 114

6.4 Comparison of Results ............................................................................ 120 
Chapter 7: Conclusions and Recommendations ................................... 124

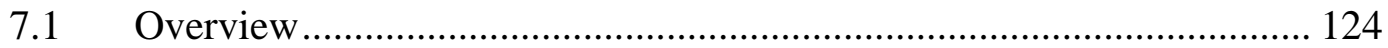

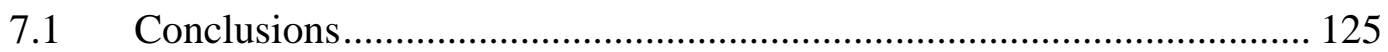

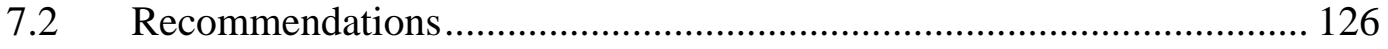

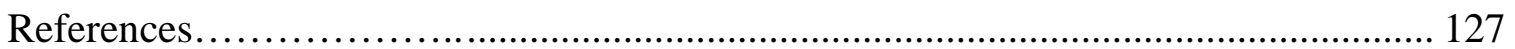




\section{LIST OF TABLES}

Table 1.1

Table 2.1

Table 2.2

Table 2.3

Table 2.4

Table 2.5

Table 2.6

Table 3.1

Table 4.1

Table 4.2

Table 4.3

Table 4.4

Table 4.5

Table 4.6

Table 4.7

Table 4.8

Table 4.9

Table 4.10

Table 4.11

Table 4.12

Table 5.1

Table 5.2

Table 5.3

Table 5.4

Table 5.5

Table 5.6

Table 5.7

Table 5.8

Table 6.1

Table 6.2

Table 6.3

Table 6.4

Table 6.5

Table 6.6

Table 6.7

Table 6.8

Table 6.9

Table 6.10
Summary of Deck Characteristics 10

Elastic equivalent properties for honeycomb core.................................... 25

Properties of Constituent Materials ...................................................... 26

Layer Properties of Face Laminates ..................................................... 26

Layer Stiffness Properties ..................................................................... 27

Equivalent Stiffness Properties of Face Laminates ................................. 28

Equivalent Stiffness Properties of the FRP Honeycomb Panel ................ 29

Range of Longitudinal and Transverse Nodal Strain Values

for an 8" Wide Longitudinal Bending Model with 8' Span....................... 40

Experimental 3-Point Bending Results for Longitudinal Samples ............ 52

Experimental Results for Longitudinal 4-Point Bending........................... 53

Experimental 3-Point Bending Results for Transverse Samples ................ 54

Experimental Results for Transverse 4-Point Bending............................... 54

Strains and Deflection Predictions of Longitudinal Samples

using the Actual Core Geometry Finite Element Model

Strains and Deflection Predictions of Transverse Samples

using the Actual Core Geometry Finite Element Model

Strains and Deflection Predictions of Longitudinal Samples

using the Equivalent Plate Finite Element Model.

Strains and Deflection Predictions of Transverse Samples

using the Equivalent Plate Finite Element Model..

Comparison of Deflections for Longitudinal Beam Samples ..................... 66

Comparison of Deflections for Transverse Beam Samples ......................... 66

Strain Comparisons of Longitudinal Beam Samples ................................... 67

Strain Comparisons of Transverse Beam Samples ................................... 67

Analytical Predictions using St. Venant's Solution................................... 73

Experimental Results for Aluminum Bar ............................................... 76

Finite Element Results for Aluminum Bar ............................................. 78

Summary of Angle of Rotation for the Aluminum Bar ............................ 79

Experimental Results for Torsion Tests................................................. 90

Results for Finite Element Models in Torsion ............................................ 95

Comparison of FE and Experimental Values of Angles of Rotation......... 97

Comparison of FE and Experimental Values of Shear Strains ................. 97

Results for Midspan Loading, LC \#1 through LC \#3 ............................. 106

Displacement Ratios for Symmetric Load Cases.................................... 107

Strain Ratios for Symmetric Load Cases ............................................... 107

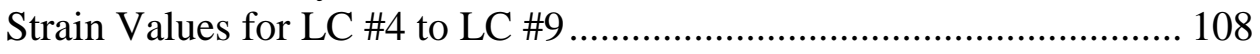

Deflection Values for LC \#4 to LC \#9.................................................. 109

Displacement Ratios for Asymmetric Load Cases .................................. 111

Strain Ratios for Asymmetric Load Cases.............................................. 111

Finite Element Predictions of Concentric Loading using

The Actual Panel Geometry....

Translations Using Equivalent Plate Model .....

Strains Using Equivalent Plate Model

116 
Table 6.11 Displacement Correlation of Experimental Results and FE Models ...... 121

Table 6.12 Strain Correlation of Experimental Results and FE Models.................. 122 


\section{LIST OF FIGURES}

Figure 1.1

Figure 1.2

Figure 1.3

Figure 2.1

Figure 2.2

Figure 2.3.

Figure 2.4.

Figure 2.5

Figure 2.6

Figure 3.1

Figure 3.2

Figure 3.3

Figure 3.4

Figure 3.5

Figure 3.6

Figure 4.1

Figure 4.2

Figure 4.3

Figure 4.4

Figure 4.5

Figure 4.6

Figure 4.7

Figure 5.1

Figure 5.2

Figure 5.3

Figure 5.4

Figure 5.5

Figure 5.6

Figure 5.7

Figure 5.8

Figure 5.9

Figure 5.10

Figure 5.11

Figure 5.12

Figure 5.13

Figure 5.14

Figure 6.1

Figure 6.2
Components of the Superdeck 4

Beam Sections of DuraSpan Bridge Deck ............................................... 5

Core Geometry of Honeycomb Sandwich Panel ...................................... 9

FRP Honeycomb Sandwich Panel ...................................................... 15

Plan View of Honeycomb Core .......................................................... 16

Representative Volume Element (RVE) of Honeycomb Core ................. 17

Computation of Young's Modulus in y-direction $\left(E_{y}{ }^{e}\right)$............................ 19

Computation of out-of-plane shear modulus $\left(G_{x z}{ }^{e}\right)$................................ 23

Lay-up of Face Laminate ................................................................. 28

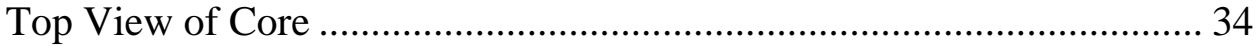

Top and Bottom Plate used in FE Model.............................................. 36

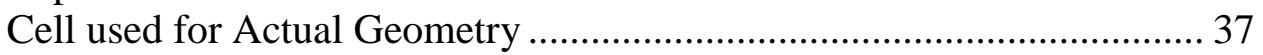

Coincident Node (\#4541) with the Eight Adjacent Elements.................... 39

Equivalent Cell for FE Panel Analysis .................................................... 42

Equivalent Cell for FE Beam Analysis .................................................... 42

Strain Gauge Locations of Beam Samples................................................ 48

Bending Configuration for 3-point ......................................................... 51

Bending Configuration for 4-point ……………………....................... 51

Deformed Shape of Actual Geometry Model of 8" Longitudinal

Sample Under 3-point Bending with 15' Span ...

Strain Distribution of Actual Geometry Model of

8" Longitudinal Sample using 3-point bending with a 15' Span............... 60

Deformed Shape of Equivalent Plate Model of

8" Longitudinal Sample Under 3-point Bending with 15' Span................ 63

Strain Distribution of Equivalent Plate Model of

8" Longitudinal Sample using 3-point bending with a 15' Span................ 63



LVDT Locations of Aluminum Sample ……………………………..... 74

Deformed Shape of Aluminum Sample .................................................... 74

Finite Element Modeling of Aluminum Bar Showing



Location of LVDT's and Strain Gauges ................................................ 81

Transverse Sample Prepared for Experimental Torsion Test .................... 82

Cross-sectional View of FRP Beam Sample in Torsion............................ 83

Clamps Used in Experimental Torsion Testing of Transverse Samples... 85

Mohr's Circle Showing the Maximum Shear Strain.................................. 87

Typical Plot of Torque vs. Angle of Rotation

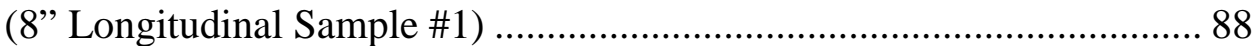

Typical Plot of Torque vs. Shear Strain (8" Longitudinal Sample \#1).... 89

Finite Element Model for 12" Longitudinal Sample ................................. 93

Rotated Cross-section of FRP Beam Sample in Torsion ........................... 96

Total Translation Contour for 8" Transverse Sample in Torsion .............. 96

Location of LVDT's and Strain Gauges .............................................. 102

Load Placements for Panel Tests

103 
Figure 6.3 Basic Setup for Midspan Concentric Load Case .................................. 103

Figure 6.4 Conditions of Finite Element Model for Actual Geometry .................... 113

Figure 6.5 Deflection Contour for Equivalent Panel under Load Condition \#2 ...... 117

Figure 6.6 Deflection Contour for Equivalent Panel under Load Condition \#3 ...... 117

Figure 6.7 Deflection Contour for Equivalent Panel under Load Condition \#5 ...... 118

Figure 6.8 Deflection Contour for Equivalent Panel under Load Condition \#6 ...... 118

Figure 6.9 Longitudinal Strain Contour for Load Case \#2 .................................... 119

Figure 6.10 Transverse Strain Contour for Load Case \#2........................................ 119 


\section{Chapter 1}

\section{Introduction}

\subsection{FRP Bridge Decks: Overview}

There is an increasing demand for a solution to the deterioration of bridge decks. Currently, there are over 600,000 bridges in the United States. One-third of these bridges have been deemed "structurally deficient" or "functionally obsolete"; 132,000 of these deficiencies are attributed to deck decay (Lesko, 2001). Due to the increasing public demand for more and better highway bridges, coupled with the need for increase of load rating, and a tightening budget, several innovative products are being investigated. One such product that holds great future potential is fiber-reinforced plastic (FRP) composite bridge decks.

There are two major types of FRP bridge decks currently in use: deck panels consisting of either sandwich construction or bonded pultruded shapes (Lesko and Davalos, 2001). Decks assembled from pultruded shapes make up a large portion of the structures on the market. However, these systems present limited opportunities for design modifications once machine tooling is produced. Sandwich structure technology has been widely used in the automotive and aerospace industries, but it is just starting to be used in the civil infrastructure. Honeycomb systems with cellular cores are notably the most efficient sandwich construction materials. As recognized in a number of feasibility studies 
(Plunkett, 1997), honeycomb structures are shown to have a high performance with minimal unit weight.

There are many positive aspects to FRP bridge decks. FRP sections have a low unit weight, but high strength and stiffness. This quality could allow for a decrease in the dead load of bridges, thus increasing the live load rating. Also, FRP sections are noncorrosive, which is a good quality, since steel reinforced concrete bridge decks corrode due to deicing salts used during the winter months. Another positive quality is the ease of handling and placement. Mostly all FRP bridge decks on the market today are prefabricated and are shipped directly to the job sites in large sections. Because of this, they can be placed quickly, and normal traffic flow can resume promptly.

There are several issues of concern with FRP bridge decks. Cost, performance and quality control are a few concerns that the manufacturer must deal with. A possible unfavorable structural aspect of composite bridge decks is the lack of composite action between the girders and the deck. This may limit the use of these decks to short-span bridges. However, in glued-laminated timber (Glulam) bridge construction, the noncomposite action between transverse Glulam panels and either timber or steel stringers is not a significant issue. Of greater concern is the difference between the thermal expansions of the steel girder and FRP deck. Other areas which require further investigations include connections, bridge rails and wearing surfaces. 
A major challenge with FRP honeycomb sandwich bridge decks is the development of design procedures. While a high degree of refinement in theoretical modeling of honeycomb structures has been achieved throughout its history (Noor et al., 1996), the characterization of unique shapes of core geometry for sandwich construction still require significant effort. This study is concerned with numerical modeling and experimental evaluation of a FRP honeycomb sandwich panel with sinusoidal core geometry extending in the vertical direction. The goal of this research is to verify the accuracy of explicit solutions for equivalent elastic material properties, which are useful to greatly simplify the design process.

\subsection{Types of Available FRP Composite Bridge Decks}

The FRP Composites industry has been steadily growing for some time now. There are several companies today that have different designs for a composite bridge deck. Many of these designs have been the topics of research publications. The Market Development Alliance (2000) has published a product selection guide, from which the information presented in this section was taken. A summary of different existing FRP bridge deck concepts is given.

Superdeck by Creative Pultrusions: This is a bridge deck system that is produced by pultruding sections to a desired length and then bonding them together to produce a bridge deck. There are two components to form the Superdeck, as shown in Figure 1.1. One is a truss shaped beam, while the other shape is a hexagonal tube, which fits inside 
the truss shape and is attached by adhesive bonding. The hexagonal shape acts as a shear-key, providing a connection device for the truss shapes. The fiber architecture of these two shapes consists of E-glass fibers taking the form of stitch fabrics, continuous strand mats, and continuous roving. The resin is weather-resistant vinyl ester.


Figure 1.1 Components of the Superdeck

Several bridges have been completed using the Superdeck, including the ones located in West Virginia, Ohio and Pennsylvania. These bridges range in length from 20 feet to 168 feet. In all cases, the deck is set on and connected to either steel or FRP girders. The bridges are finished by fitting them with traffic edge barriers and a wearing surface.

Martin Marietta Composites: In late 1992, Lockheed Martin decided to experiment with polymer composites for uses in civil infrastructure. A short-span demonstration 
bridge was unveiled in 1995, but Lockheed decided not to go forward with the new technology. A well-established materials company, itself being a spin-off of Lockheed, Martin Marietta Materials bought the technology and created Martin Marietta Composites. Today, their DuraSpan bridge deck is used in several bridges across the United States.

DuraSpan is made of two different, yet similar diagonally braced box beam shapes, shown in Figure 1.2. They are manufactured from E-glass fibers and isophthalic resin through a pultrusion process and can have a length of up to fifty feet. The beams are bonded together to a width of eight to ten feet, restricted by transportation requirements.

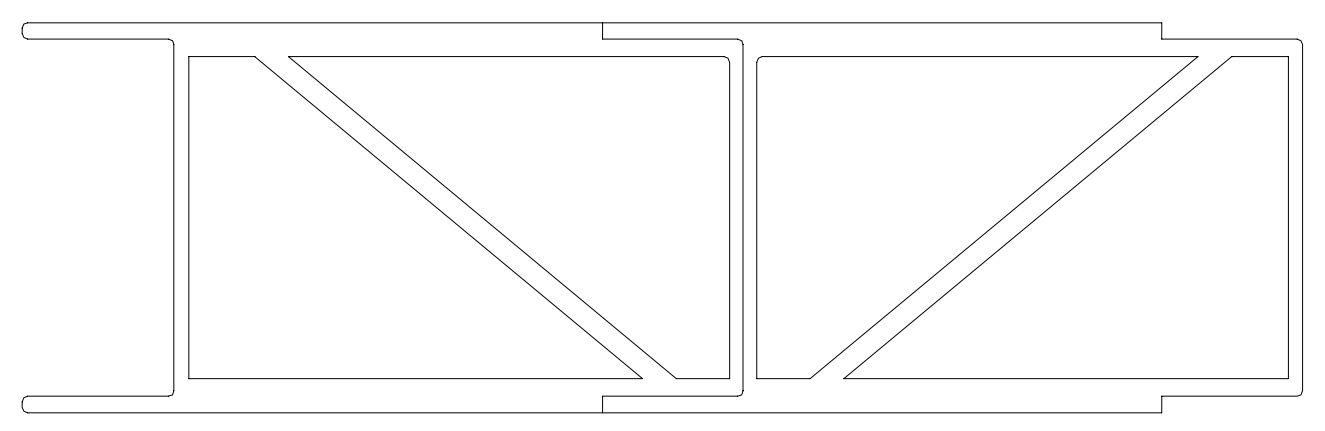

Figure 1.2 Beam Sections of DuraSpan Bridge Deck

The pultruded shapes are produced by Creative Pultrusions, the maker of the Superdeck. The beams can be cut to any length depending on the bridge's dimensions. After the shapes are pultruded and cut, they are bonded together using a polyurethane adhesive. 
The bond was tested at the University of Delaware and exceeded the performance requirements. After a panel is produced by bonding, the finishing work is performed, and the product is shipped to the site.

Hardcore Composites: Hardcore Composites is a fiber reinforced polymer materials company from Delaware. Hardcore manufactures many composite parts for the marine environment, and they recently decided to use their experience to tap into the bridge deck market. Hardcore makes a version of a honeycomb sandwich panel bridge deck. They adopted a manufacturing process called Vacuum Assisted Resin Transfer Molding (VARTM) to manufacture the deck panels.

The deck panels are made of two face skins, concealing a low-density core matrix. The face skins are primarily for resistance of bending forces, while the core maintains shear capacity.

The Hardcore bridge deck has some good qualities. The thickness of the face skins, their fiber architecture, and the core's geometry can be modified for different applications. Also, the depth of the panel section can be modified easily. These are desirable features when replacing existing deck structures. Desired depths can be obtained while still meeting maximum deflection requirements imposed by bridge codes. This is an important consideration, since deflection and not strength generally control composite bridge decks. 
Hardcore Composites use an E-Glass fiber and a vinyl ester resin because of their noncorrosive and workability properties. Because Hardcore uses the VARTM manufacturing process, they can obtain a typical fiber volume fraction of 50\%. They also have the ability to produce complex three-dimensional shapes. This allows important details such as railings, blockouts, crowns, connection hardware, and so on, to be added to the deck during manufacturing.

3TEX, Inc.: 3TEX, Inc. designs and manufactures many different composite material parts for many different industries. Mainly working in the automotive and defense industries, 3TEX has teamed up with several companies to design and manufacture a vehicular and pedestrian bridge deck system.

The deck that 3TEX manufactures and markets is primarily for narrow girder spacing of two to three feet. This is representative of most county bridges across the United States. The deck is targeted at replacing existing corrugated steel with concrete or wood decking.

3TEX calls their bridge deck system TYCOR. It is a fiber-reinforced foam core sandwich panel. The core also has fiberglass roving in the length direction for additional reinforcing. After the face skins and core are molded together, the result is a low-profile deck, approximately 3.3 inches thick. The deck is also cost competitive with conventional corrugated steel decks. 
TYCOR composite panels are made using fiber-reinforced foam (FRF) core and face skins and produced using the VARTM method, as in the Hardcore Composites bridge deck. The face skins use a glass fiber composed of 2-D knitted fabric and 3-D woven fabric. The FRF core is manufactured using a liquid molding process and is co-cured with the face skins to provide the proper bond.

The connection of the deck and stringer is achieved by using coupled steel plates and two bolts. This acts as a clamping system and requires no drilling of the supporting girder. However, an alternate system can be used which is similar, yet with self-tapping screws that screw into the girder. The deck panels are manufactured eight feet wide, and the length of the panel spans the width of the deck.

Kansas Structural Composites, Inc.: KSCI provided the bridge deck panels for this research. It is a honeycomb core sandwich panel, in which a unique system of vertical sinusoidal waves and flats are used as the core of the panel, as shown in Figure 1.3. Basically, KSCI devoted their efforts to structural panels for bridge deck applications. Although the deck panel has undergone laboratory and field investigations by KSCI, no effort has been made to model or optimize the sandwich deck design, until the recent study by the researchers at West Virginia University and the University of Akron (Davalos et al. 2001). 


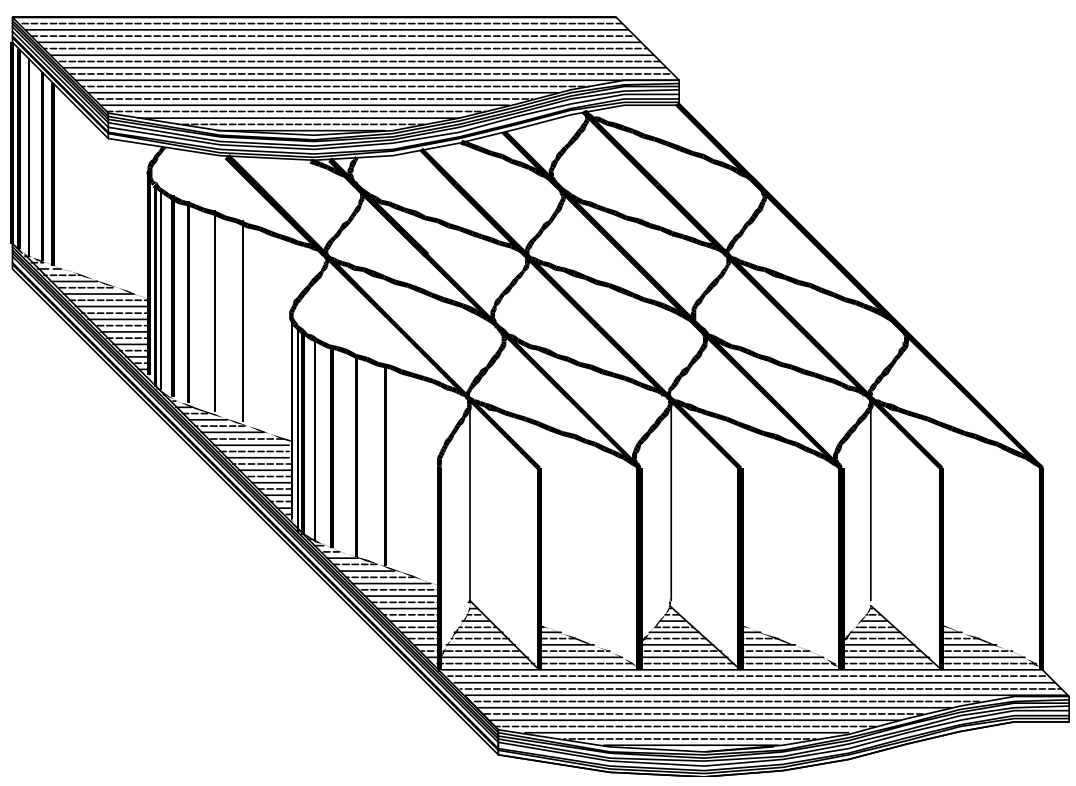

Figure 1.3 Core Geometry of Honeycomb Sandwich Panel

The deck is manufactured using a combined contact molding and hand lay-up procedures. The core geometries are manufactured using molds. The core consists of a combination of a sinusoidal wave called a flute and a flat sheet. The face panels are made of several layers of CSM, $0^{\circ}$ and $90^{\circ}$ E-glass fibers and polyester resins. The thickness of the deck panel can vary from 5" to more than 24". Current research into the core optimization, skin sheet effect, and connector design is taking place at West Virginia University and the University of Akron.

A summary of each of the previously mentioned bridge decks, as well as a few of the other marketed decks, is presented by Lesko and Davalos (2001) and shown in Table 1.1. A comparison of unit weight, cost and normalized deflections show that the KSCI design appears to be more efficient and economical while providing superior stiffness. 
Table 1.1 Summary of Deck Characteristics

\begin{tabular}{|c|c|c|c|c|}
\hline Deck System & Depth & $\mathrm{Lb} . / \mathrm{ft}^{2} \mathrm{a}$ & $\$ / \mathrm{ft}^{2}$ & $\begin{array}{l}\text { Normalized } \\
\text { Deflection }\end{array}$ \\
\hline \multicolumn{5}{|c|}{ Sandwich Construction } \\
\hline Hardcore & $8 "-28 "$ & $20-23$ & $75-95$ & $\mathrm{~L} / 1070$ \\
\hline $\mathrm{KSCl}$ & $5 "-24 "$ & $15.5^{\mathrm{C}}$ & 65 & $\mathrm{~L} / 1300$ \\
\hline \multicolumn{5}{|c|}{ Adhesively Bonded Pultrusions } \\
\hline DuraSpan & 7.63" & 18.5 & $65-75$ & $\mathrm{~L} / 340$ \\
\hline Superdeck & 8" & 22 & 75 & $\mathrm{~L} / 530$ \\
\hline EZSpan & 9" & 20 & $80-100$ & $\mathrm{~L} / 950$ \\
\hline Strongwell & $4.75 "-8 "$ & 23 & $65^{\mathrm{d}}$ & $\mathrm{L} / 325$ \\
\hline
\end{tabular}

\footnotetext{
a - Without wearing surface

b - Normalized to HS20+IM for an 8' center to center between support girders

C - For an 8" deep deck targeted for RC bridge deck replacement

d - For a 6.75" deep deck with wearing surface under experimental fabrication process
}

\subsection{Problem Statement and Objectives}

Due to the complexity of FRP composite materials and the unique structure of the KSCI sinusoidal core sandwich panel (Figure 1.3), an extensive investigation into stiffness responses and equivalent material properties are necessary for design implementation and further optimization. The primary goal of this study is to develop an analytical solution to obtain equivalent material properties of both honeycomb sinusoidal core and sandwich panel and to verify their accuracy using finite element analysis and experimental testing. The equivalent material properties provided in this study can then be used in design of bridge deck systems. More specifically, the three primary goals of this study are: 
1. To present analytical equivalent orthotropic properties, which were developed independently of the study, for the FRP honeycomb bridge deck panel with sinusoidal core configuration.

2. To correlate results for sandwich beam samples obtained by analytical predictions, finite element modeling and experimental testing.

3. To compare finite element modeling results with experimental responses for a simply supported deck panel under centric and eccentric patch loads.

\subsection{Thesis Overview}

The goal of this thesis is to present existing equivalent orthotropic plate properties for the KSCI FRP honeycomb sandwich panel (Figure 1.3), and to verify these properties with experimental and finite element evaluations described in detail herein.

A summary of the analytical investigation of equivalent plate properties for the KSCI sandwich panel with sinusoidal core configuration is presented in Chapter 2. This investigation includes: (1) constituent materials and ply properties, (2) face laminates and core wall engineering properties, (3) equivalent core material properties, and finally (4) apparent stiffness properties for the honeycomb panel and its orthotropic material properties. The face laminate and core wall properties are evaluated using a micro/macromechanics approach; whereas the equivalent core material properties are defined based on a combined energy method and mechanics of materials approach. 
An overview of the experimental program and finite element modeling is presented in Chapter 3, where the experimental samples and testing protocol are described in detail, and some basic principles for the finite element modeling are also introduced and discussed.

Based on the equivalent material properties of the panel obtained from Chapter 2, apparent stiffnesses are used to calculate maximum strains and deflections of beam samples with different widths, core orientations and span lengths under three- and fourpoint bending configurations in Chapter 4. These predicted values are then compared with experimental results. A finite element evaluation with models using the actual core geometry as well as equivalent laminate and core properties is also presented in Chapter 4, to provide further correlation of experimental and analytical analyses.

An analysis of beam samples in torsion is presented in Chapter 5. Since a closed-form analytical solution for the honeycomb sandwich beam samples under torsion is still under investigation by the researchers at West Virginia University and the University of Akron, only finite element predictions for the actual geometry as well as using equivalent panel properties are compared with experimental results in this study.

In Chapter 6, the finite element analyses and experimental results are presented and compared for a sandwich panel tested under midspan and eccentric patch loads. 
Finally, in Chapter 7, the experimental results, finite element analyses and analytical solutions of the sandwich structures with sinusoidal core configuration are summarized to draw significant conclusions and make recommendations for further studies of the FRP honeycomb sandwich panel. 


\section{Chapter 2}

\section{Mechanics of FRP Honeycomb Core Sandwich Panel}

\section{$2.1 \quad$ Introduction}

The analytical evaluation of FRP honeycomb sandwich panels presented in Chapter 2 is mainly extracted from the paper by Davalos et al. (2001) and performed by the researchers at both WVU and the University of Akron (Dr. Pizhong Qiao and coworkers). The procedures to evaluate equivalent properties of the face laminates, the honeycomb core with a sinusoidal configuration, and the sandwich panel as a whole are described. The equivalent properties of the face laminates are obtained using a micro/macromechanics approach, while the properties of the core are evaluated using a combined approach of mechanics of materials and energy method. This chapter outlines the important procedures used to evaluate the equivalent properties for FRP honeycomb sandwich panels.

\subsection{Modeling of Honeycomb Core}

The modeling of the honeycomb core is achieved using the concept of a homogenized Representative Volume Element (RVE). Using a combined energy method and mechanics of materials approach, the equivalent properties of the core are evaluated. 


\subsubsection{Geometry}

The sandwich type structure of concern has two face plates co-cured with a core. The geometry chosen is intended to increase the stiffness and buckling capacity of the panel by continually supporting the core elements with the face laminates. Figure 2.1 is a picture of a 12"x 12" section of the panel.

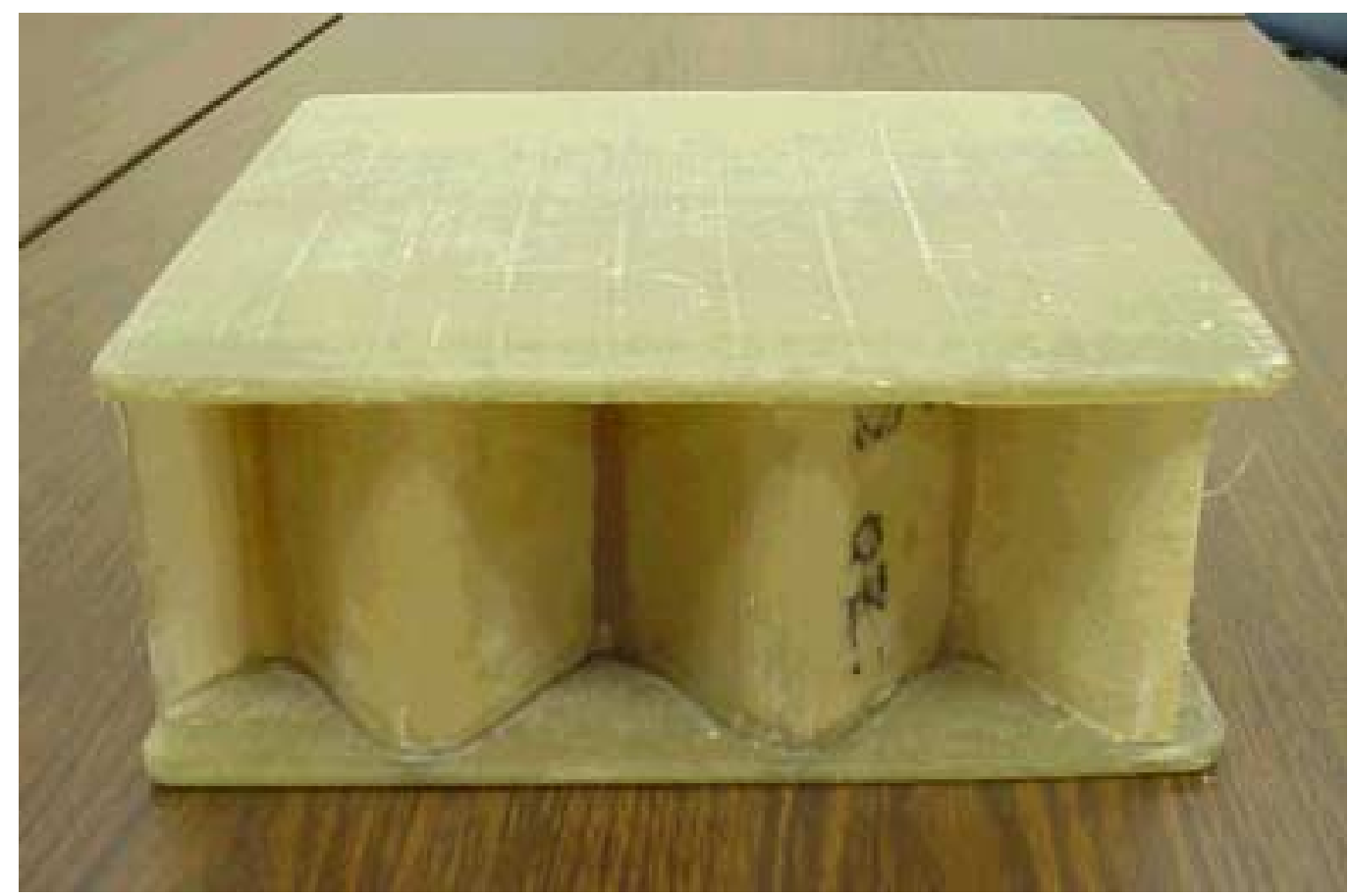

Figure 2.1 FRP Honeycomb Sandwich Panel

The geometry of the core consists of closed honeycomb-type cells. A flat plate combined with a corrugated plate defined a sinusoidal function for the core configuration. The waved section of the core is manufactured by forming the FRP sheet into a corrugated mold. The shape of the wave function of the core can be described by the following equation: 
$y=h\left(1-\cos \frac{2 \pi x}{l}\right)$

where, $2 h$ is the interval distance between two adjoining flat plates and $l$ is the distance of adjoining crests. In this study, the sinusoidal core dimensions are $l=4.0 \mathrm{in}$. and $h=1.0$ in. Figure 2.2 shows a plan view of the core.



Figure 2.2 Plan View of Honeycomb Core

\subsubsection{Equivalent Properties}

The elastic equivalence analysis of sinusoidal-waved honeycomb core structure (see Figure 2.2) is based on a homogenization concept by a combined energy method and mechanics of materials approach (Davalos et al. 2001). The homogenization process of periodic structures requires defining a Representative Volume Element (RVE), for which the global properties can be obtained by periodical conditions and kinematical assumptions. 




Figure 2.3. Representative Volume Element (RVE) of Honeycomb Core

For most sandwich cores, the RVE (as shown in Figure 2.3 in this study) with regular spatial character in double symmetry gives orthotropic properties which can be defined by nine equivalent stiffness constants. The structure of the sandwich core can be separated into a number of substructures. For instance, the sinusoidal core (Figure 2.3) contains the substructures of flat and curve walls, and the walls can be simplified as series of simply supported elements without interaction with the top and bottom face laminates.

The minimum energy theory states that the strain energy calculated from the exact displacement distribution is a minimum. For a given simplified sandwich core, the averaging principle of RVE technique can be generally expressed in parallel and series models according to Voigt and Reuss (see Christensen 1991): 
$\frac{1}{2} \frac{\sigma_{i j}}{C_{i j}} V \leq \sum_{k=1}^{n}\left(U_{b}+U_{s}+U_{a}\right)_{k}$

$\frac{1}{2} C_{i j} \varepsilon_{i j}^{2} V \leq \sum_{k=1}^{n}\left(U_{b}+U_{s}+U_{a}\right)_{k}$

where $k$ accounts for individual substructures in the RVE (Figure 2.3), and $U_{b}, U_{s}$, and $U_{a}$ are, respectively, the strain energies related to bending, shear, and axial responses. Equations (2.2) and (2.3) define, respectively, the conditions of lower and upper bounds for stiffness constants. In this study, only the energy due to bending, shear and axial forces is included in the computation, which satisfies most periodic structures.

To obtain the elastic constants in Eqs. (2.2) and (2.3), several types of loading arrangements for lower or upper bound condition are applied to the RVE and produce a system of linear equations. The most obvious and simple loading arrangement is the application of each single principal stress or strain to obtain the corresponding stiffness without other types of strain energy involved.

When a principal load/strain is applied, the strain energy in Eqs. (2) and (3) can be written as:

$U=\sum_{k=1}^{n}\left\{\int_{0}^{s}\left(\frac{\delta_{11} M_{11}^{2}}{2}+\frac{\alpha_{11} N_{11}^{2}}{2}+\frac{h_{44} V_{12}^{2}}{2}\right) d s\right\}_{k}$

where $M_{11}, N_{11}, V_{12}$ are the bending moment, axial force, and transverse shear force acting on the core wall (Figure 2.4), and $\delta_{11}, \alpha_{11}$ and $h_{44}$ are the corresponding compliance coefficients. The subscripts 1,2 and 3 denote local Cartesian coordinates, with the 1-axis tangent and the 2-axis normal to the wave curve (see Figure 2.4). 

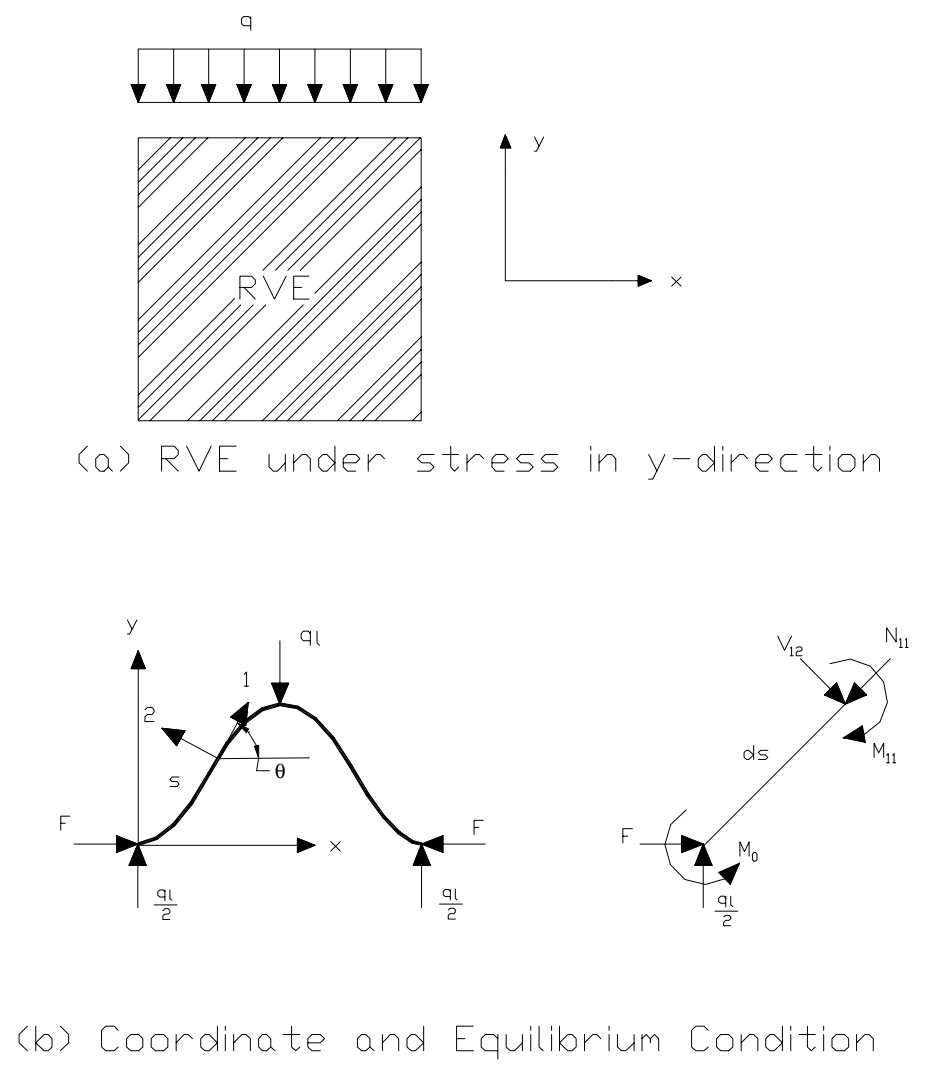

Figure 2.4. Computation of Young's Modulus in y-direction $\left(E_{y}{ }^{e}\right)$

For simplicity, there are several assumptions made in equivalence analysis of a sandwich core: the material behaves linear-elastically; perfect bonding exists at face-to-core and core wall-to-wall contacts; and the ratio of thickness of core wall to radius of core wall is small, and beam bending theory can be applied. In the following section, core equivalent properties are derived. 
Core longitudinal and transverse Young's moduli $\left(E_{x}^{e}\right.$ and $\left.E_{y}{ }^{e}\right)$

In this study, a basic element of honeycomb (RVE) is taken (Figure 2.3), and the wave function is defined by Eq. (2.1). The properties of ContSM core wall can be obtained from micromechanics (see Section 2.3.1).

By applying a uniform stress $q$ in the $y$-direction (Figure 2.4), the internal energy $U$ of the RVE in Eq. (2.4) becomes

$$
\mathrm{U}=4 \mathrm{t} 2 \int_{0}^{\mathrm{s}}\left(\frac{\delta_{11} \mathrm{M}_{11}{ }^{2}}{2}+\frac{\alpha_{11} \mathrm{~N}_{11}{ }^{2}}{2}+\frac{\mathrm{h}_{44} \mathrm{~V}_{12}{ }^{2}}{2}\right) \mathrm{ds}+\frac{\alpha_{11} \mathrm{~F}^{2} 1}{2}
$$

where the bending moment, axial force, and shear force can be simply obtained by the equilibrium condition and geometric property as (see Figure 2.3):

$$
\begin{aligned}
& M_{11}=\frac{l x}{2} q-h\left[1-\cos \left(\frac{2 \pi}{l} x\right)\right] F-M_{0} ; \quad M_{o}=l q-h F \\
& N_{11}=\frac{h \pi \sin \left(\frac{2 \pi}{l} x\right) q+F}{\sqrt{1+\frac{\pi^{2} h^{2}}{l^{2}} \sin ^{2}\left(\frac{2 \pi}{l} x\right)}} ; \quad V_{12}=\frac{\frac{q l}{2}-\frac{2 \pi h}{l} \sin \left(\frac{2 \pi}{l} x\right) F}{\sqrt{1+\frac{\pi^{2} h^{2}}{l^{2}} \sin ^{2}\left(\frac{2 \pi}{l} x\right)}}
\end{aligned}
$$

and for ContSM core wall, the compliance coefficients are:

$$
\delta_{11}=\frac{12}{E_{1} t_{2}{ }^{3}} ; \quad \alpha_{11}=\frac{1}{E_{1} t_{2}} ; \quad h_{44}=\frac{1}{\kappa G_{13} t_{2}}
$$

where, $H=4 h+2 t_{1}+2 t_{2}$ (Figure 2.3); $s=$ one half curve length of a sinusoidal period starting from the origin of Cartesian coordinates; $t_{1}=$ thickness of flat core wall; $t_{2}=$ thickness of corrugated core wall; $F=$ internal force; $q=$ applied uniform stress parallel to the $y$-axis; $\kappa=$ shear correction factor, $5 / 6$ for a rectangular cross-section. 
The apparent strain value of RVE, $\varepsilon_{y}$, can be calculated through Castigliano's second theorem. The theorem states that under the principal of superposition, a partial derivative of the strain energy with respect to an external force gives the displacement corresponding to that force. In this case, the displacement $\left(\Delta_{y}\right)$ in $y$-direction can be obtained as:

$\Delta_{y}=H \varepsilon_{y}=\frac{\partial U}{\partial(q l)}$

Before Eq. (2.8) is applied, the unknown internal force $F$ can be found by imposing the compatibility condition:

$$
\begin{aligned}
& \Delta_{\mathrm{x}}=l \varepsilon_{x}=\frac{\partial U^{\prime}}{\partial F}=\frac{F l}{E_{1} t_{1}} \\
& U^{\prime}=2 t_{2} \int_{0}^{s}\left(\frac{\delta_{11} M_{11}{ }^{2}}{2}+\frac{\alpha_{11} N_{11}{ }^{2}}{2}+\frac{h_{44} V_{12}{ }^{2}}{2}\right) d s
\end{aligned}
$$

where $U^{\prime}$ is the strain energy stored in one period of sinusoidal wave.

Once the strains are defined, the equivalent stiffness $\left(E_{y}{ }^{e}\right)$ in the $y$-direction and the Poisson's ratio $\left(v_{y x}{ }^{e}\right)$ can be obtained as:

$$
E_{y}^{e}=\frac{q}{\varepsilon_{y}} ; v_{y x}^{e}=-\frac{\varepsilon e_{x}}{\varepsilon_{y}}=\frac{\Delta_{x} H}{\Delta_{y} l}
$$

The above results based on mechanics of materials approach lead to an exact solution, and the upper and lower bounds given in Eqs. (2.2) and (2.3) result in the same solutions. 
Similarly, the equivalent stiffness in the $x$-direction can be obtained by applying a uniform stress in that direction. Based on the above formulation, the analysis indicates that the stiffness contribution of the curve beams is negligible in the $x$-direction, and the equivalent stiffness, $E_{x}{ }^{\mathrm{e}}$, can be approximated as

$$
E_{x}^{e}=\frac{2 t_{1}}{H} E_{1}
$$

Core out-of-plane shear moduli $\left(G_{x z}{ }^{e}\right.$ and $\left.G_{y z}{ }^{e}\right)$

When a shear force is applied, the induced deformation at each core wall is due to the spatial non-uniformity of honeycomb structure. Unlike the cases of Young's moduli, the shear stiffness usually involves a complicated state of deformation, and it is relatively difficult to get an exact analytical solution. However, using the energy method, the lower and upper bound solutions can be obtained, and the lower bound usually provides a conservative solution in practical design.

When a shear stress $\tau_{x z}$ is applied in the $x$-direction, the resulting apparent distributed shear flow is as shown in Figure 2.5. The equilibrium equation and compatibility condition are written as

$$
\begin{aligned}
& 4 t_{2} \int_{0}^{s} \tau_{2} \cos \theta d s+2 t_{1} l \tau_{1}=H l \tau_{x z} \\
& 2 \int_{0}^{s} \frac{\tau_{2}}{G_{12}{ }^{s}} d s=\frac{\tau_{1}}{G_{12}{ }^{s}} l
\end{aligned}
$$

where $2 \int_{0}^{s} \cos \theta d s=l$. Eqs. (2.13) and (2.14) lead to 


$$
\begin{gathered}
\tau_{1}=\frac{H \int_{0}^{s} d s}{l t_{2}+2 t_{1} \int_{0}^{s} d s} \tau_{x z} \\
\tau_{2}=\frac{H}{2 t_{2}+4 t_{1} \int_{0}^{s} d s / l} \tau_{x z}
\end{gathered}
$$

By applying Eq. (2.2), we can obtain:

$$
\frac{G_{x z}^{e}}{G_{12}^{s}} \geq \frac{2 t_{1}}{H}+\frac{t_{2} l}{H \int_{0}^{s} d s}
$$

where $G_{12}{ }^{s}$ is the in-plane shear modulus of core wall (see Section 2.3.1).
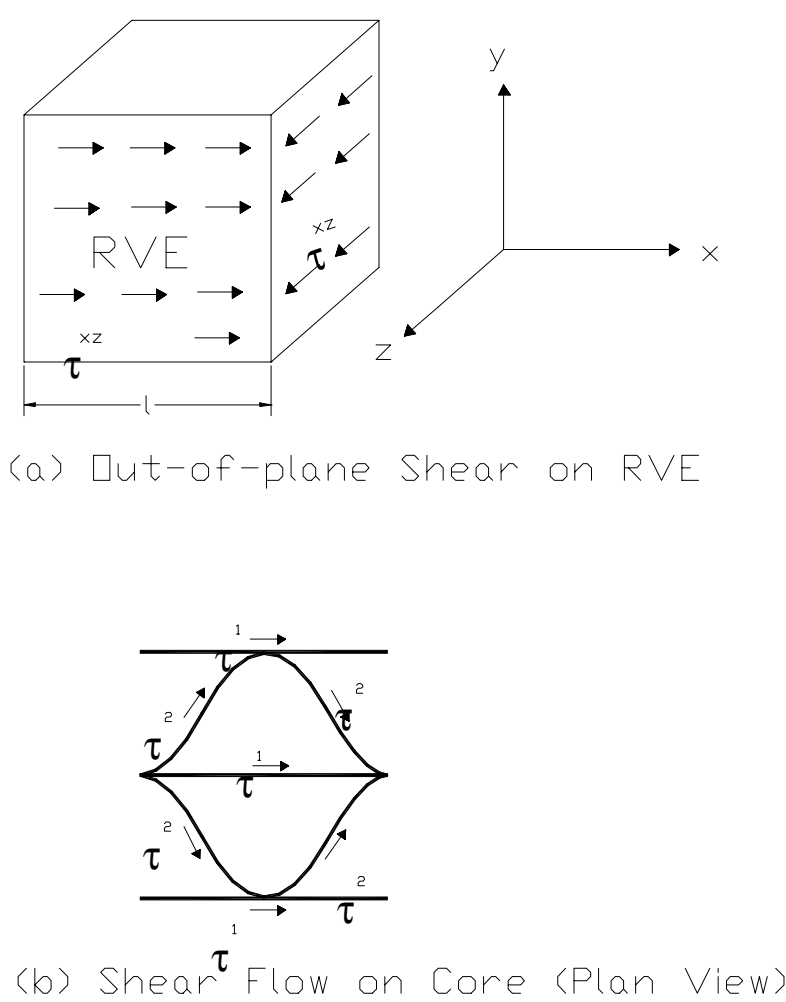

Figure 2.5 Computation of out-of-plane shear modulus $\left(G_{x z}{ }^{e}\right)$ 
Similarly, applying a shear strain $\varepsilon_{x z}$ and combining with corresponding compatibility conditions, we can express Eq. (2.3) as

$2 t_{1} l \frac{1}{2} \gamma_{x z}^{2} G_{12}^{s}+4 \int_{0}^{s} \frac{1}{2} G_{12}^{s}\left(\gamma_{x z} \cos \theta\right)^{2} t_{2} d s \geq \frac{H l}{2} G_{x z}{ }^{e} \gamma_{x z}^{2}$

Simplifying Eq. (2.18) gives:

$\frac{G_{x z}^{e}}{G_{12}^{s}} \leq \frac{2 t_{1}}{H}+\frac{4 t_{2}}{H l} \int_{0}^{s} \cos ^{2} \theta d s$

Following a similar analysis process, the out-of-plane shear modulus, $G_{y z}{ }^{e}$, can be obtained as

$\frac{4 t_{2} \int_{0}^{s} \sin ^{2} \theta d s}{l H} G_{12}^{s} \geq G_{y z}{ }^{e} \geq \frac{16 t_{2} h^{2}}{l H \int_{0}^{s} d s} G_{12}^{s}$

\section{Summary of core equivalent properties}

Based on the above formulations, the equivalent properties of FRP honeycomb core are computed and given in Table 2.1. In a similar fashion and based on a mechanics of materials approach, the Young's modulus $\left(E_{z}{ }^{e}\right)$ in $z$-direction and in-plane shear modulus $\left(G_{x y}{ }^{e}\right)$ are derived. As shown in Table 2.1, the lower and upper bounds for the out-ofplane shear moduli are within a relatively narrow range. 
Table 2.1 Equivalent elastic properties for honeycomb core

\begin{tabular}{|c|c|c|c|}
\hline \multicolumn{4}{|c|}{$\begin{array}{c}\text { Geometric data: } h=1 \mathrm{in} ; l=4 \mathrm{in} ; t_{l}=t_{2}=0.0898 \mathrm{in} \\
\quad \text { Solid core wall properties: } \\
E_{l}{ }^{s}=E_{2}{ }^{s}=1.71 \times 10^{6} \mathrm{psi} ; G_{12}{ }^{s}=0.611 \times 10^{6} \mathrm{psi}\end{array}$} \\
\hline \multirow[t]{2}{*}{$\begin{array}{l}\text { Young's } \\
\text { Moduli }\end{array}$} & $E_{x}^{e}$ & $E_{y}^{e}$ & $\overline{E_{z}^{e}}$ \\
\hline & $0.0449 E_{l}^{s}$ & $8.36 \times 10^{-5} E_{l}^{s}$ & $0.107 E_{2}^{s}$ \\
\hline Shear Moduli & $\overline{G_{x y}{ }^{e}}$ & $\overline{G_{x z}{ }^{e}}$ & $\overline{G_{y z}}$ \\
\hline Upper bound & $5.98 \times 10^{-5} E_{1}^{s}$ & $0.078 G_{12}{ }^{s}$ & $0.033 G_{12}^{s}$ \\
\hline Lower bound & $5.98 \times 10^{-5} E_{I}^{s}$ & $0.075 G_{12}{ }^{s}$ & $0.027 G_{12}^{s}$ \\
\hline \multirow[t]{2}{*}{ Poisson's Ratios } & $v_{x y}^{e}$ & $v_{x z}^{e}$ & $v_{y z}^{e}$ \\
\hline & 0.431 & 0.169 & $0.273 \times 10^{-4}$ \\
\hline
\end{tabular}

\subsection{Modeling of Face Laminates}

Engineering properties for the face laminates can be obtained from a micro/macromechanics approach. Using micromechanics, the stiffness properties of each layer, or ply, of the laminates can be predicted. Based on the ply properties and lay-up, the apparent stiffness of the laminate can be found using classical lamination theory.

\subsubsection{Microstructure}

The fiber architecture of the top and bottom face laminates is symmetric about the neutral plane of the sandwich panel. Thus the equivalent stiffnesses of the two face laminates are the same. Each laminate (Figure 2.6) consists of two layers of CM-3205, six layers of UM-1810, and a bonding layer, which is a chopped strand mat, or ChopSM. The CM3205 is comprised of a $0 / 90$ bi-directional stitched fabric and a continuous strand mat, 
or ContSM. The UM-1810 is comprised of a unidirectional layer and a ContSM layer. The constituent materials of the FRP honeycomb panel are E-glass fibers and polyester resin, for which their material properties can be found in Table 2.2. The details for each of the face sheet layers are given in Table 2.3.

Table 2.2 Properties of Constituent Materials

\begin{tabular}{|c|c|c|c|c|}
\hline Material & $E, \times 10^{6} \mathrm{psi}$ & $G, \times 10^{6} \mathrm{psi}$ & & ${\text {, lb. } / \mathrm{in}^{3}}^{3}$ \\
\hline E-Glass Fiber & 10.5 & 4.18 & 0.255 & 0.092 \\
\hline Polyester Resin & 0.734 & 0.237 & 0.30 & 0.041 \\
\hline
\end{tabular}

Table 2.3 Layer Properties of Face Laminates

\begin{tabular}{|c|c|c|c|c|}
\hline Ply name & Ply type & $\begin{array}{c}\text { Nominal Weight } \\
w, \text { oz/ } / \mathrm{ft}^{2}\end{array}$ & $\begin{array}{c}\text { Thickness } \\
t, \text { in }\end{array}$ & $V_{f}$ \\
\hline Bonding Layer & ChopSM & 3.0 & 0.082 & 0.1726 \\
\hline CM-3205 & 0 & 1.667 & 0.0245 & 0.3428 \\
\hline & 90 & 1.667 & 0.0245 & 0.3428 \\
\hline & ContSM & 0.5 & 0.01 & 0.2359 \\
\hline UM-1810 & 0 & 2.0 & 0.025 & 0.3774 \\
\hline & ContSM & 1.0 & 0.0132 & 0.3582 \\
\hline
\end{tabular}

\subsubsection{Fiber-Volume Fraction}

The fiber-volume fraction, $V_{f}$, found for each layer, is listed in Table 2.3. The stiffness properties of each ply depend on this value. The fiber-volume fraction can be expressed using the following equation:

$V_{f}=\frac{\omega}{\rho \cdot t}$ 
where is the nominal weight of the fabric, $t$ is the thickness of the layer and is the density of the fibers. The fiber-volume fraction is then used in micromechanics to obtain stiffnesses of each layer.

\subsubsection{Micromechanics}

A micromechanics model for composites with periodic microstructure (Luciano and Barbero 1994) is used to obtain the elastic constants for each individual layer. The stiffness properties of the ChopSM and the ContSM is found using an averaging technique, based on the assumption that the material is isotropic in the ply plane. The values of the layer stiffnesses are summarized in Table 2.4.

Table 2.4 Layer Stiffness Properties

\begin{tabular}{|c|c|c|c|c|c|c|c|}
\hline Ply name & Orientation & $\mathrm{E}_{1}, \times 10^{6} \mathrm{psi}$ & $\mathrm{E} 2, \times 10^{6} \mathrm{psi}$ & $\mathrm{G}_{12}, \times 10^{6} \mathrm{psi}$ & $\mathrm{G}_{23}, \times 10^{6} \mathrm{psi}$ & 12 & 23 \\
\hline Bond Layer & Random & 1.41 & 1.41 & 0.507 & 0.308 & 0.394 & 0.401 \\
\hline CM-3205 & 0 or 90 & 4.02 & 1.16 & 0.447 & 0.417 & 0.295 & 0.39 \\
\hline & Random & 1.71 & 1.71 & 0.61 & 0.343 & 0.402 & 0.4 \\
\hline Um-1810 & 0 & 4.36 & 1.24 & 0.479 & 0.447 & 0.293 & 0.386 \\
\hline & Random & 2.31 & 2.31 & 0.82 & 0.43 & 0.409 & 0.388 \\
\hline Core Mat & Random & 1.71 & 1.71 & 0.611 & 0.431 & 0.402 & 0.388 \\
\hline
\end{tabular}

\subsubsection{Equivalent Elastic Properties}

The equivalent elastic properties of the face laminates are computed using the classical lamination theory. Using the ply properties found by micromechanics, a set of equivalent laminate properties $\left(E_{x}, E_{y}, G_{x y}, \quad x y\right)$ can be defined. These constants represent a 
fictitious, equivalent, orthotropic plate that behaves in the manner of the actual laminate under in-plane loading.

The elastic properties are based on the lay-up of the laminate, as well as the individual ply properties. Figure 2.6 shows the lay-up of the face laminates, and Table 2.5 gives the equivalent elastic properties of the face laminate.



Figure 2.6 Lay-up of Face Laminate

Table 2.5 Equivalent Stiffness Properties of Face Laminates

\begin{tabular}{|c|c|c|c|}
\hline$E_{x}, \mathrm{x} 10^{6} \mathrm{psi}$ & $E_{y}, \mathrm{x} 10^{6} \mathrm{psi}$ & ${ }_{x y}$ & $G_{x y}, \mathrm{x} 10^{6} \mathrm{psi}$ \\
\hline 2.846 & 1.850 & 0.302 & 0.546 \\
\hline
\end{tabular}




\subsection{Equivalent Properties of FRP Honeycomb Sandwich Panel}

Once the equivalent properties of the core and face laminates are found, classical lamination theory is again used to find equivalent sandwich panel properties. The values are given in Table 2.6. The layer properties for the face laminates are given in Table 2.5, and the properties for the core are taken from the average of the lower and upper bounds in Table 2.1.

Table 2.6 Equivalent Stiffness Properties of the FRP Honeycomb Panel

\begin{tabular}{|c|c|c|c|c|}
\hline & $E_{x}, \mathrm{x} 10^{6} \mathrm{psi}$ & $E_{y}, \mathrm{x} 10^{6} \mathrm{psi}$ & $G_{x y}, \mathrm{x} 10^{6} \mathrm{psi}$ & $x y$ \\
\hline In-plane & 0.553 & 0.320 & 0.094 & 0.303 \\
\hline Bending & 1.273 & 0.803 & 0.236 & 0.301 \\
\hline
\end{tabular}

\subsection{Summary}

In this chapter, the equivalent properties for the FRP honeycomb sandwich panel are summarized and are later used in design analysis and finite element modeling. Based on mechanics of materials and energy method (Davalos et al. 2001), the procedures and equations for homogenization of honeycomb core with a sinusoidal core configuration are presented. The equivalent properties of face sheet laminates and sandwich panels are evaluated from a combined micro/macromechanics approach. The equivalent properties obtained in this chapter are used to predict strains and deflections of sandwich beams under bending (Chapter 4). The equivalent properties defined in this chapter can be efficiently used in design and applications of the honeycomb sandwich structure. 


\section{Chapter 3}

\section{Experimental Testing and Finite Element Modeling}

An overview of the experimental testing protocol and finite element modeling is presented. The description of the test samples includes lengths, core orientations and widths. An explanation of the actual geometry and equivalent plate finite element models is presented, as well as the methods used to collect and report the pertinent dat from these separate analyses.

\subsection{Test Samples}

The experimental testing is performed to indirectly verify the accuracy of the analytical predictions of the equivalent orthotropic properties of the FRP sandwich panel (as derived and shown in Chapter 2). Because of the manufacturing-induced imperfections and variability present in the FRP sandwich panels, a number of samples must be tested under several different loading conditions to achieve a confident comparison with analytical solutions. The main purpose of the several tests preformed is to describe the responses for various loading conditions, thus comparing theoretical predictions to experimental results.

As presented in Chapter 2, the honeycomb sandwich panel is modeled as an equivalent orthographic plate with three-layer laminate configuration, which includes top and 
bottom skin sheets and homogenized core. The equivalent elastic properties of skin sheets and core are obtained using a micro/macromechanics approach and a homogenization method (a combined energy method and Mechanics of Materials approach), respectively. The panel with orthotropic properties has three orthogonal planes of symmetry described by nine material constants as established in Chapter 2 . Thus, the panel responses under various loading conditions can be predicted using these equivalent material properties. Both, a rectangular panel and beam samples with longitudinal and transverse core geometries are experimentally tested, so that analytical solutions and finite element modeling results obtained with input of these equivalent material constants can be verified and compared.

\subsection{Testing Protocol}

The FRP honeycomb sandwich panel and beam samples used in the experimental testing were manufactured by Kansas Structural Composites, Inc. The same beam samples are used for the experimental evaluations in bending and torsion, although the lengths of certain samples were not identical for each type of test. The deck panel is also tested under symmetric and asymmetric patch loadings. This section provides a background for the testing arrangements of the samples. 


\subsubsection{Beam under bending}

There are a total of eight longitudinal and transverse beam samples, four eight inches wide and the other four twelve inches wide. Four samples of 16 feet long have longitudinal sinusoidal core geometries (hereby defined as longitudinal samples), of which two samples are eight inches wide and the other two are twelve inches. Four samples of nine feet long have transverse sinusoidal core geometries (defined as transverse samples), of which two of these samples are eight inches wide and the other two are twelve inches wide.

The beam samples are provided by KSCI with the dimensions listed above. Thus, the bending tests are conducted without any physical alterations to the specimens. The longitudinal samples, which are sixteen feet in length, are tested with span lengths of 15', $11^{1 / 2} 2^{\prime}, 8^{\prime}$, and $5^{1 / 2}$ feet. The transverse samples are nine feet in length and are tested with spans of $8^{\prime}$ and $5 \frac{1}{2}{ }^{\prime}$. The procedure and results for the bending tests are later discussed in Chapter 4.

\subsubsection{Beam under torsion}

The torsion test is conducted using a torsion machine (see Figure 5.1 in Chapter 5) and the same beam samples described in Section 3.2.1. The fixed spacing of the torsion machine grips is ten feet end-to-end, and due to the span-length limitation of the torsion machine, the longitudinal samples, originally 16 feet long, must be cut to 10 feet in 
length. The original length of the transverse samples is nine feet thus, a special clamp (as shown in Figure 5.8, Chapter 5) is manufactured to compensate for the additional onefoot to grip the sample. All eight beam samples are tested in torsion, and the experimental procedures and results for both the longitudinal and transverse core orientations are give in Chapter 5.

\subsubsection{Panel under bending}

A sandwich panel with dimension of $16^{\prime} \times 8^{\prime}$ is used for bending tests under symmetric and asymmetric loading conditions. The longitudinal core orientation extends in the 16' length direction of the panel. Consequently, the core is oriented transversely through the 8' width of the panel. The span-length used for the loading conditions is $15^{\prime}$, and a pinroller support condition is provided along the 8 ' direction of the panel. The experimental testing procedures and results are presented in Chapter 6.

\subsection{Finite Element Modeling Procedures}

The finite element method is a very useful tool in providing verification for analytical predictions or experimental responses. A background is presented on the formulation of each model used in this study, in order to provide confidence on the data collected and reported for comparative studies. The following sections describe two different models used in the finite element evaluations: the actual geometry model, and the equivalent orthotropic plate model. The commercial Finite Element (FE) program ABAQUS 
version 5.8 (1998) is used in this study, and FEMAP version 7.10 (1999) is used for the pre- and post-processing operations. Both, the formulation and post-processing of results for each of the models used are discussed.

\subsubsection{Formulation of Actual Geometry Model}

The geometry of the sandwich panel consists of top and bottom face sheets and a core with vertical sinusoidal waves and flats. This geometry is described in Chapter 2 (see Figures 2.1 and 2.3). The purpose of generating the actual geometry finite element model is to reproduce and simulate the samples as identically and accurately as possible.

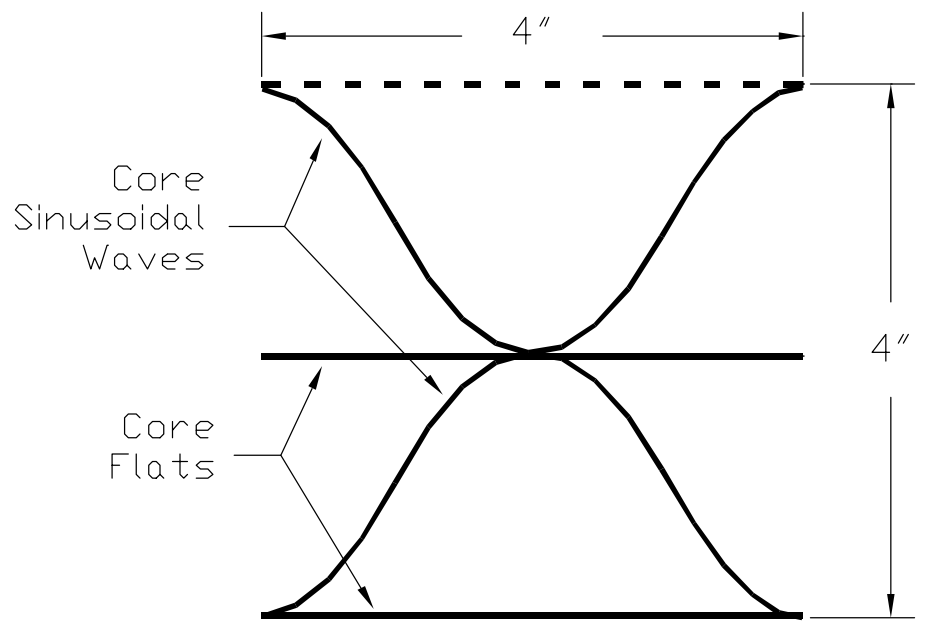

Figure 3.1 Top View of Core

The first portion of the actual geometry model is the simulation of the unique sinusoidal core (Figure 3.1). The core possesses a very unique shape and presents a challenge in modeling. Figure 3.1 shows a top view of the core used in the finite element model of the 
actual geometry. Since the shape function of the core is sinusoidal, shell elements defined by parabolic curves must be used in creating the sinusoidal portion of the core. Thus, the core consists of 8-node shell elements using reduced integration. Eight elements were used in each four-inch span of wave, attempting to match the actual panel geometry as best as possible. For the flats we used four elements in a four-inch span. The core consists of a chopped strand mat, with material properties and thickness as described in Table 2.3 of Chapter 2. In the FE modeling, the core extends vertically from the mid-plane of the top plate to the mid-plane of the bottom plate, with a distance of 4.554 inches.

The top and bottom face sheets are modeled using 6-node triangular layered shell elements with orthotropic $2 \mathrm{D}$ material properties. The lay-up of the bottom plate is shown in Figure 2.6, Chapter 2, and the material properties and thicknesses used in the formulation are given in Tables 2.3 and 2.4. The top and bottom plates are symmetric about the midplane of the panel; thus the material lay-up for the top face laminate is in the reverse order of that for the bottom laminate. 
Since the top and bottom panels must be connected to the core, the panel and the core must have coincidental nodes. Basically, the geometry of the core controls the shape of each face element, presenting a challenge when defining the geometry of the triangular elements. However, once the core elements are produced, the elements of the face laminates can be carefully added. Figure 3.2 shows a plan view of a 4"x 4" laminate.

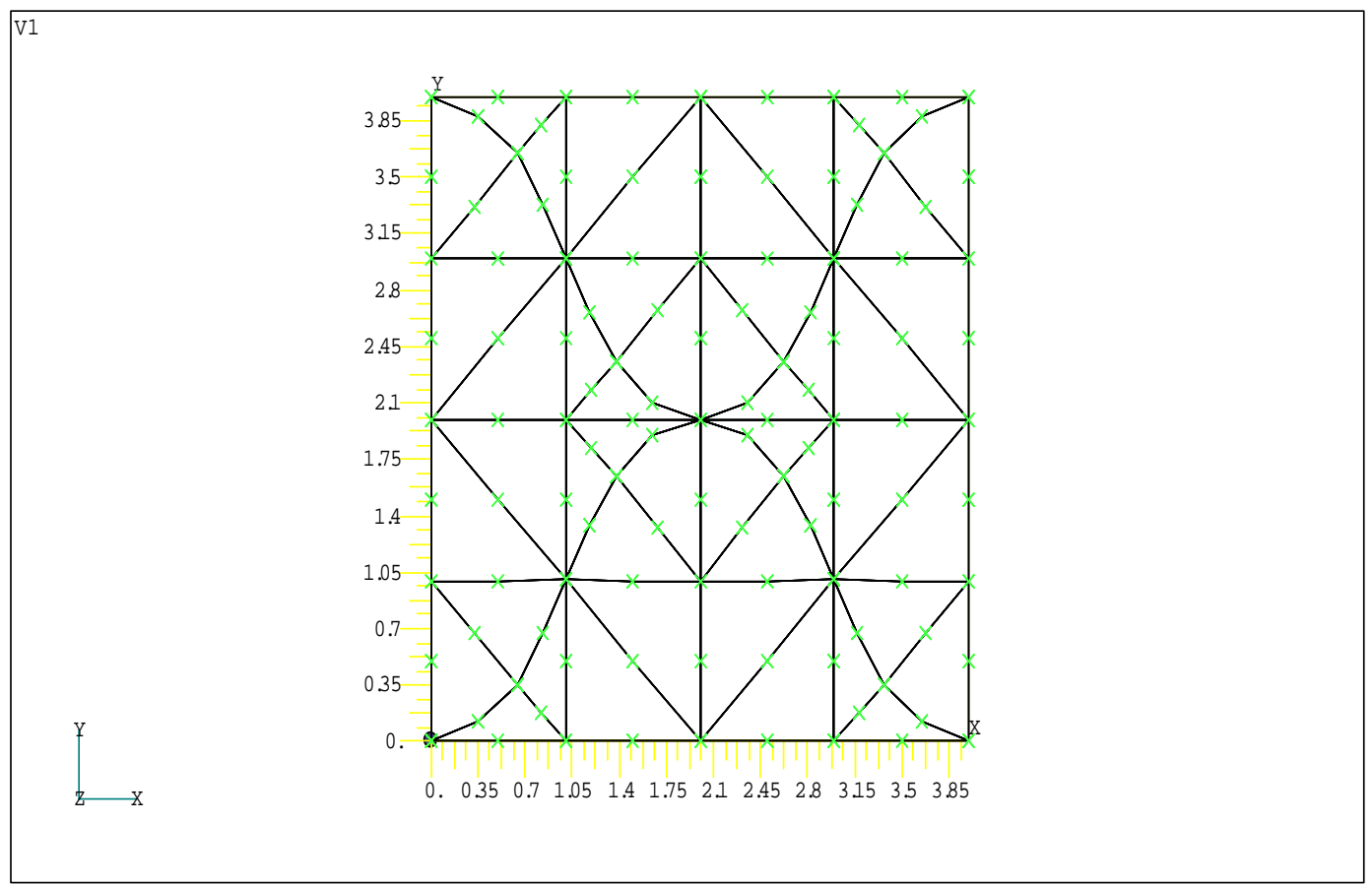

Figure 3.2 Top and Bottom Plate used in FE Model

The 6-node triangular layered shell element used for modeling the face sheets has three integration points for reduced integration. The advantage of reduced integration is computational economy, taking less time to analyze larger models. Because the size of the actual samples used in the finite element analysis in Chapters 4, 5 and 6 are relatively large, and the files generated by ABAQUS are of substantial size, it is advantageous to use reduced integration. Furthermore, reduced integration sometimes "softens" the model, making up for the overestimation in stiffness from a finite element analysis. The 
disadvantages to reduced integration are the decrease in accuracy of the model (Bathe, 1982) and the nodal discontinuities of strains between elements (Cook et al., 1989). For example, two elements sharing a common node could display significantly different strain values. This phenomenon is further discussed in Section 3.3.2.

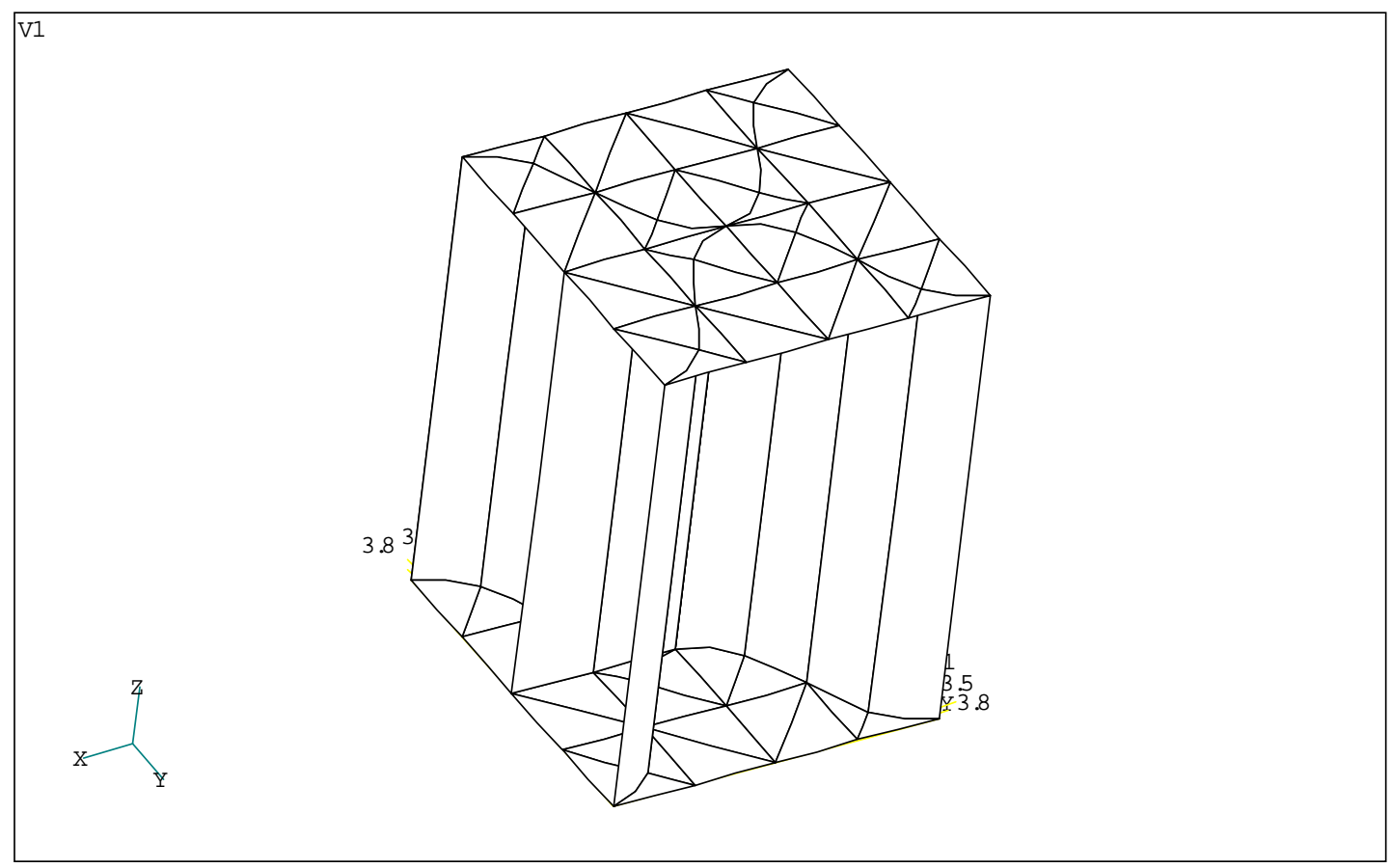

Figure 3.3 Cell used for Actual Geometry

A three-dimensional view of a 4"x 4" unit cell used in the actual geometry models is shown in Figure 3.3. This unit cell is used to create all actual geometry models used in the finite element analyses, despite the size, length or core orientation characteristics. Once the unit cell is produced, it can be duplicated as many times as necessary in order to create the desired model. 


\subsubsection{Explanation of Results from Actual Geometry Model}

The values from the finite element models are analyzed and compared with analytical and experimental values. The data consist of deflections and extensional longitudinal and transverse strains, as well as shear strains. In order to provide reasonable certainty about the methods used for extracting the required data, a proper and consistent method must be used. The deflection values are calculated directly at the nodes by the finite element program, and thus can be reported for the location of interest with relative certainty. However, the strain data cannot be easily extracted and usually require additional explanation.

Based on reduced integration, the output for strain is given at the three integration points for the six-node triangular elements used for the face laminates. The strain values at the corner nodes and the centroid of each element are then calculated in ABAQUS through interpolation functions.

The desired strain data are collected at the locations where strain gauges are placed for the experimental evaluations. Using the actual geometry models in the finite element analyses, these locations always coincide with a node either on the top or bottom face elements. 


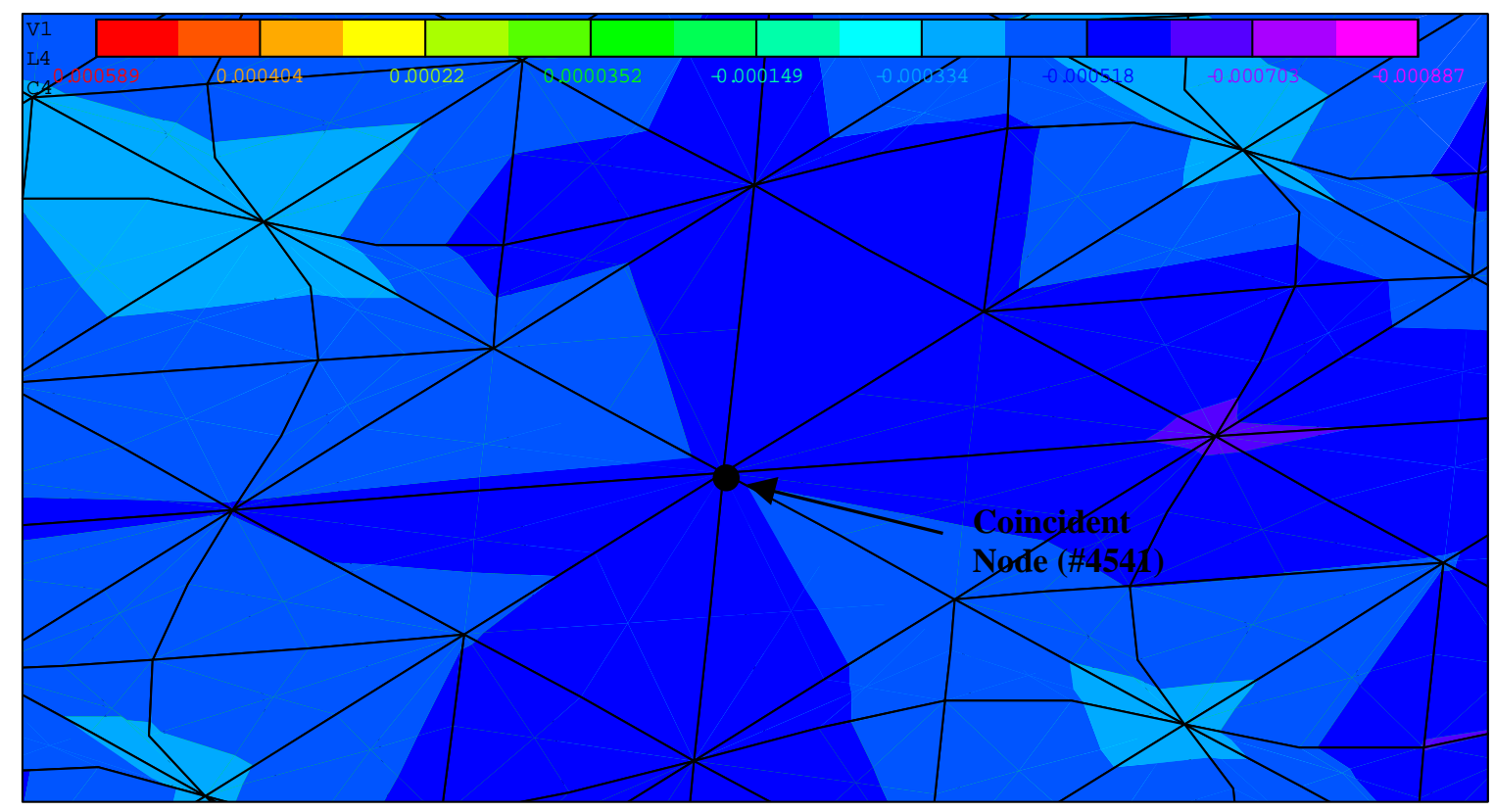

Figure 3.4 Coincident Node (\#4541) for the Eight Adjacent Elements

However, in this model, one node is common to eight different triangular elements, as can be seen in Figure 3.4. Thus, eight separate strain values are found at this node.

Because of the coarseness of the FE mesh, the strain values found at this node are not all identical. To complicate things further, each triangular element consists of 19 layers, and for each layer, ABAQUS can report the strain at top and bottom of the layer at each integration point. 
Table 3.1 Range of Longitudinal and Transverse Nodal Strain Values for an 8” Wide Longitudinal Bending Model with 8' Span

\begin{tabular}{|c|c|c|c|c|}
\hline Element & E11, microstrain & \% from Average & E22, microstrain & \% from Average \\
\hline 2515 & -555 & 5.6 & 129 & 31.7 \\
\hline 2516 & -531 & 1.1 & 259 & 37.2 \\
\hline 2517 & -455 & 13.4 & 246 & 30.3 \\
\hline 2518 & -561 & 6.8 & 129 & 31.7 \\
\hline 2587 & -649 & 23.5 & 172 & 8.9 \\
\hline 2588 & -371 & 29.4 & 203 & 7.5 \\
\hline 2589 & -449 & 14.5 & 200 & 6.0 \\
\hline 2590 & -632 & 20.3 & 172 & 8.9 \\
\hline Average & -525.4 & 0.0 & 188.8 & 0.0 \\
\hline
\end{tabular}

A consistent procedure to obtain reasonable strain values should be devised to smooth out the inconsistencies in the values of strain at a given node. At a nodal point, there are eight nodal strain values found from each of the eight connecting elements. Thus, the average of each of the eight strain readings is taken and reported as the final strain reading. Table 3.1 shows an example of this procedure. The data in Table 3.1 is for an 8-inch wide section (see Figure 3.4) of an 8-foot long longitudinal sample under bending. The strain values are taken 6 inches away from the midspan of the top layer of the top face sheet, at the center of the width of the beam. This average value of eight strain readings is later correlated with experimental data at location of SG\#2 (see Figure 4.1 and Table 4.1, Chapter 4). As indicated in Table 3.1, a range of as much as $\pm 30 \%$ for strain reading compared to the average value is typical for every node in the model. The described procedure is used to obtain the required strain values for each of the actual 
geometry models. These values are later compared with analytical predictions and experimental results.

\subsubsection{Formulation of Equivalent Plate Model}

Finite element models using equivalent orthotropic properties of face sheets and core, described as in Chapter 2, are also produced for bending, torsion and panel analysis. These models are much simpler to analyze and smaller in size compared to their counterparts that simulate the actual panel geometry.

A similar process is used for the equivalent models as for the actual geometry models. A unit 4"x 4" cell is created. For the finite element modeling of the deck panel, the cell consists of one eight-node layered shell element (Figure 3.5); whereas for beam samples under bending and torsion, the models use four eight-node layered shell elements within a unit 4"x4" cell (Figure 3.6).

The equivalent plate models consist of three layers: a top plate, a core and a bottom plate. Equivalent properties for each equivalent layer are given in Tables 2.1 and 2.5 of Chapter 2. The simulation using an equivalent plate for a honeycomb sandwich panel is much simpler than that of the actual geometry, thus there are far fewer nodes and elements. 


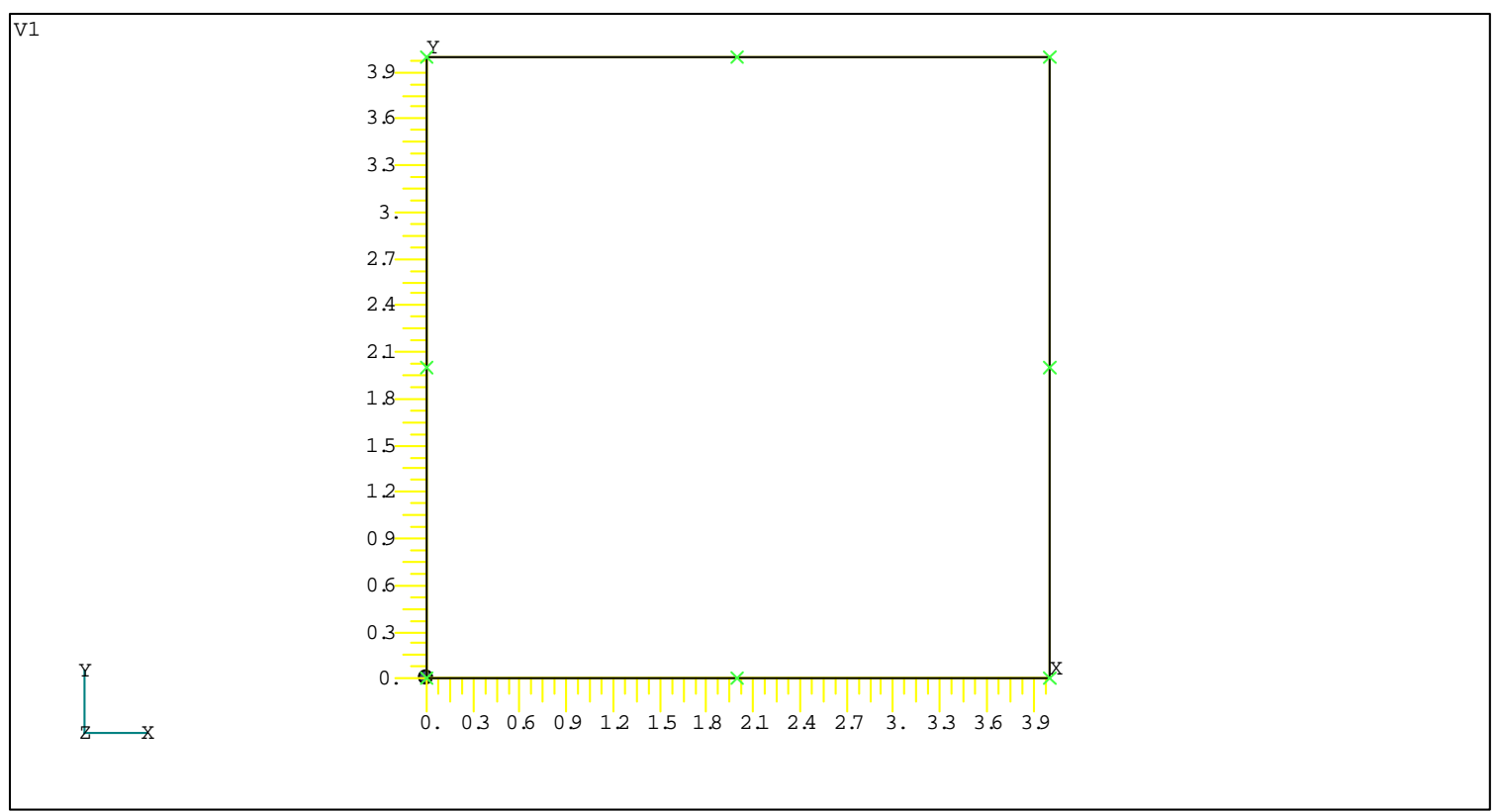

Figure 3.5 Equivalent Cell for FE Panel Analysis



Figure 3.6 Equivalent Cell for FE Beam Analysis 


\subsubsection{Explanation of Results Taken From Equivalent Plate Models}

Results are obtained through the same process that is used for the actual geometry models. The desired outputs from the equivalent plate models are the strain and deflection values. The data from the equivalent plate model are needed for comparison with actual geometry FE models, analytical predictions and experimental results; thus, the accuracy of the equivalent plate model can be verified, and it also indirectly validates the equivalent orthotropic properties of face laminates and core as given in Chapter 2.

The deflection data are taken from the nodes directly. The value of deflection at a given location is provided by a nodal output, which shows deflections and rotations along three principal axes. The strain data required could be in one of two locations. The strain readings could either fall on a node, or at the centroid of an element. If the strain reading location falls at the centroid, the interpolated value of strain is taken. If the strain reading location is at a node, then the average value of the contributing elements adjacent to the node is taken. The equivalent plate model is defined by regular rectangular elements, resulting in more continuous strain data than for the actual geometry models.

\subsection{Conclusions}

This chapter provides a background for the experimental testing and finite element modeling work reported in the following chapters. The descriptions of the experimental samples and testing protocol are useful in understanding sample types, testing 
arrangements, and procedures. The formulation of the finite element models is important in understanding some basic principles behind each different model; for instance, the size and type of elements and material properties. The method of data collection from each of the two types of models is instrumental in understanding the accuracy of the FE predictions and comparisons in the following chapters. 


\section{Chapter 4}

\section{Evaluation of Sandwich Beams in Bending}

\subsection{Introduction}

Characterizing the behaviors of FRP honeycomb sandwich panels in bending is important for developing sound design guidelines that can be confidently applied. In this study, beam samples with core orientations in the longitudinal and transverse directions are tested in bending, and the experimental results are used to verify analytical predictions, either in explicit form or by the finite element method.

In this chapter, a comprehensive characterization of FRP honeycomb sandwich beams under bending is presented, base on experimental tests, numerical modeling (FE), and explicit solutions. First, the experimental setup, procedures and results for three- and four-point bending tests are presented in detail. Then, the simulations and results using actual geometry and equivalent plate finite element models are discussed. Finally, the analytical solution using Timoshenko beam theory is formulated, and comparisons of the results among experimental, numerical and analytical evaluations are given. 


\subsection{Experimental Evaluation}

Experimental bending tests were performed using the longitudinal and transverse samples described in Chapter 3. The bending tests were conducted using 3-point and 4-point loading conditions with various span lengths. The testing setup and instrumentation of beam samples are described in Section 4.2.1. The procedure used in the experimental testing is presented in Section 4.2.2, and the results are given in Section 4.2.3. Later in this chapter (Section 4.5), the experimental results are correlated with theoretical predictions and numerical simulations.

\subsubsection{Instrumentation and Testing Setup}

The testing samples used are those outlined in Chapter 3 of this thesis. All four longitudinal samples as well as all four transverse samples were instrumented with strain gauges and LVDT's. These devices were placed at selected locations to provide us with useful and reliable data.

The strain gauges used are 350-Ohm linear quarter bridge gauges. There are four gauges placed on each sample. Each gauge is oriented along the length of the sample, as to measure strain longitudinally with respect to the span length. There are three gauges bonded on the top face and one on the bottom face of each sample. To provide adequate space for the loading plate during the 3-point bending test, the gauges on the top face are placed six inches away from the midspan of the beams, and they are spaced at $w / 4, w / 2$, 
and $3 w / 4$ along the width $w$ of the sample. The purpose of this setup is to gain an understanding of the strain distribution through the width of the sample. The strain gauge placement on the top plate of a beam sample is shown in Figure 4.1. On the bottom face of the sample, one gauge is bonded and used to measure strain along the length. This gauge is bonded at the center of the beam, with respect to the length and width (Figure 4.1). This is to provide us with the maximum tensile strain that the bottom face will undergo during the testing. It is felt that one gauge is sufficient to provide the maximum strain on the bottom of the sample, since the normal strain distribution in tension is expected to be approximately constant through the width; i.e., no shear lag effect. All strain gauges were bonded using the recommended materials and procedures from the manufacturer (Micro-Measurements Group, Inc.). A bondable terminal was used as not to apply any stress on the lead wires during loading of the samples.

Linear Voltage Differential Transducers, or LVDT's, are used to measure the displacements during the experiments. The placement of the LVDT's is based on the span length. They are placed at $L / 3, L / 2$ and $2 L / 3$, where $L$ is the span length. At these locations and along the width of the sample, a wire is strung from one edge of the bottom plate to the other edge of the bottom plate, and the core of the LVDT is then hung from the center of the wire, in order to decrease localized effects and improve accuracy.

A two-kip load cell is used to measure the amount of load being placed on the samples, and the load is applied with a manually operated hydraulic jack supported by a testing frame. 

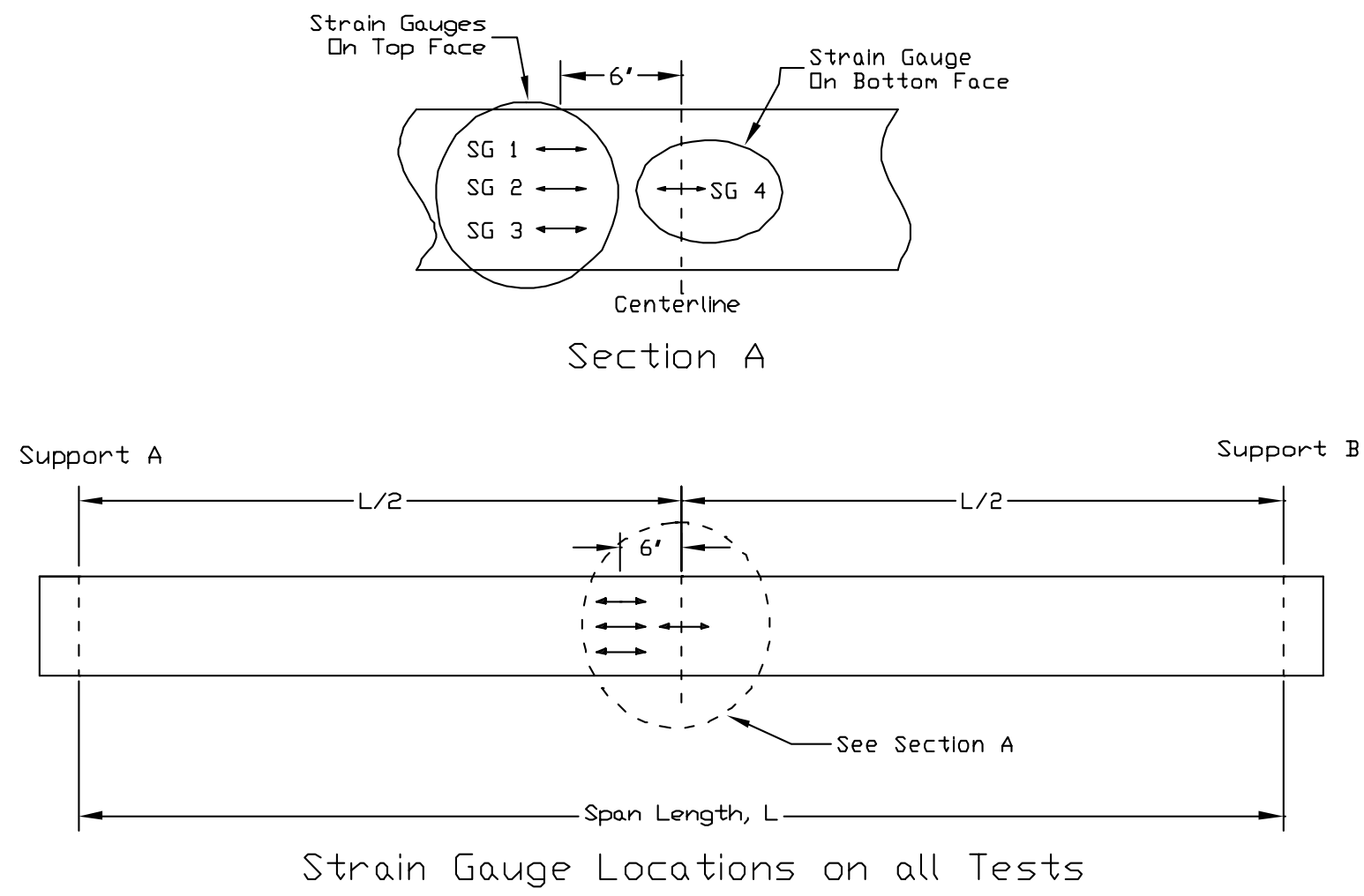

Figure 4.1 Strain Gauge Locations of Beam Samples

\subsubsection{Procedure}

The experimental testing was conducted strictly within the linear elastic response of the material. A constant load rate was applied to each sample, and as a consequence of the loading apparatus used, the load rate was controlled by deflection, and thus determined by the specific loading configuration and stiffness of the sample.

Each sample was tested under 3-point and 4-point loading conditions. For the 3-point test, the load was applied through a swivel mechanism onto the loading plate located at the midspan of the beam. The 3-point bending configuration is shown in Figure 4.2. For 
the 4-point bending condition, the load was applied through a swivel and onto a spreader beam, which transferred the applied load equally onto the test sample at $\mathrm{L} / 3$ and $2 \mathrm{~L} / 3$. The 4-piont bending configuration is illustrated in Figure 4.3.

The testing started with the longitudinal samples with a 15' span. First a sample is tested under three-point bending, and next under four-point bending. After the four longitudinal samples are tested in three- and four-point bending conditions, the supports are moved inward and the span is reduced to 11.5 '. Each sample is then tested in three- and fourpoint bending configurations. Similarly, the beams were further tested for spans of 8 ' and 5.5'.

Since the transverse samples are only 9' in length, they are tested at the spans of 8 ' and 5.5'. At 8' spans, the longitudinal and transverse samples are tested in both three- and four-point bending configurations. At the 5.5' span, the samples are only tested in threepoint bending, due to the short span length.

\subsubsection{Results}

Results for the experimental bending tests are shown in Tables 4.1 through 4.4. The results of the longitudinal samples in three-point bending are shown in Table 4.1, while the four-point bending results are given in Table 4.2. The results of transverse samples under three-point bending and four-point bending are provided in Tables 4.3 and 4.4, respectively. All strain data is given in microstrain per kilo-pound (kip) of loading, and 
the displacement data is given in inches per kip of loading. Each sample is tested twice and the average value is presented

After the two samples with the same core orientation and width are tested, the corresponding values are averaged and shown in the tables. There are some occasional discrepancies in correlating values (e.g., the deflections in Table 4.1 for 5.5' span), but in general, the bending responses for similar samples seems to be easily duplicated, and the amount of experimental error is generally small. 




Figure 4.2 Bending Configuration for 3-point Loading



Figure 4.3 Bending Configuration for 4-point Loading 
Table 4.1 Experimental 3-Point Bending Results for Longitudinal Samples

\begin{tabular}{|c|c|c|c|c|c|c|c|c|c|}
\hline \multirow{3}{*}{ Span } & \multirow{3}{*}{ Width } & \multirow{3}{*}{ Sample } & \multicolumn{4}{|c|}{ Strains, microstrain/kip } & \multirow{2}{*}{\multicolumn{3}{|c|}{ Deflection, inches/kip }} \\
\hline & & & \multicolumn{3}{|c|}{ Top } & \multirow{2}{*}{$\frac{\text { Bottom }}{1}$} & & & \\
\hline & & & 1 & 2 & 3 & & $\mathrm{~L} / 3$ & $\mathrm{~L} / 2$ & $2 \mathrm{~L} / 3$ \\
\hline \multirow[t]{6}{*}{$15 \mathrm{ft}$} & \multirow[t]{3}{*}{12 inch } & $\# 1$ & -557 & -530 & -539 & 547 & 0.5675 & 0.6912 & 0.5592 \\
\hline & & $\# 2$ & -509 & -475 & -519 & 593 & 0.554 & 0.6774 & 0.5473 \\
\hline & & Average & -533 & -502.5 & -529 & 570 & 0.56075 & 0.6843 & 0.55325 \\
\hline & \multirow[t]{3}{*}{8 inch } & $\# 1$ & -849 & -835 & -858 & 814 & 0.8348 & 1.0055 & 0.8103 \\
\hline & & $\# 2$ & -781 & -790 & -851 & 857 & 0.8312 & 0.9989 & 0.817 \\
\hline & & Average & -815 & -812.5 & -854.5 & 835.5 & 0.833 & 1.0022 & 0.81365 \\
\hline \multirow[t]{6}{*}{$11.5 \mathrm{ft}$} & \multirow[t]{3}{*}{12 inch } & \#1 & -417 & -396 & -403 & 418 & 0.2586 & 0.3181 & 0.2624 \\
\hline & & $\# 2$ & -376 & -349 & -386 & 458 & 0.2575 & 0.3236 & 0.2702 \\
\hline & & Average & -396.5 & -372.5 & -394.5 & 438 & 0.25805 & 0.32085 & 0.2663 \\
\hline & \multirow[t]{3}{*}{8 inch } & $\# 1$ & -613 & -608 & -637 & 616 & 0.3827 & 0.4663 & 0.3855 \\
\hline & & $\# 2$ & -593 & -592 & -643 & 650 & 0.3795 & 0.4662 & 0.3967 \\
\hline & & Average & -603 & -600 & -640 & 633 & 0.3811 & 0.46625 & 0.3911 \\
\hline \multirow[t]{6}{*}{$8 \mathrm{ft}$} & \multirow[t]{3}{*}{12 inch } & $\# 1$ & -278 & -260 & -267 & 284 & 0.0813 & 0.1050 & 0.0872 \\
\hline & & $\# 2$ & -230 & -216 & -262 & 321 & 0.0942 & 0.1258 & 0.1048 \\
\hline & & Average & -254 & -238 & -265 & 303 & 0.0878 & 0.1154 & 0.0960 \\
\hline & \multirow[t]{3}{*}{8 inch } & $\# 1$ & -415 & -404 & -412 & 420 & 0.1324 & 0.1598 & 0.1351 \\
\hline & & $\# 2$ & -383 & -383 & -407 & 457 & 0.1287 & 0.1613 & 0.1383 \\
\hline & & Average & -399 & -394 & -410 & 439 & 0.1306 & 0.1606 & 0.1367 \\
\hline \multirow[t]{6}{*}{$5.5 \mathrm{ft}$} & \multirow[t]{3}{*}{12 inch } & $\# 1$ & -168 & -168 & -178 & 194 & 0.0340 & 0.0420 & 0.0345 \\
\hline & & $\# 2$ & -172 & -132 & -135 & 224 & 0.0493 & 0.0597 & 0.0430 \\
\hline & & Average & -170 & -150 & -157 & 209 & 0.0417 & 0.0509 & 0.0388 \\
\hline & \multirow[t]{3}{*}{8 inch } & $\# 1$ & -258 & -263 & -276 & 290 & 0.0497 & 0.0584 & 0.0513 \\
\hline & & $\# 2$ & -251 & -246 & -260 & 306 & 0.0514 & 0.0631 & 0.0565 \\
\hline & & Average & -255 & -255 & -268 & 298 & 0.0506 & 0.0608 & 0.0539 \\
\hline
\end{tabular}


Table 4.2 Experimental Results for Longitudinal 4-Point Bending

\begin{tabular}{|c|c|c|c|c|c|c|c|c|c|}
\hline \multirow[t]{3}{*}{ Span } & \multirow[t]{3}{*}{ Width } & \multirow[t]{3}{*}{ Sample } & \multicolumn{4}{|c|}{ Strains, microstrain/kip } & \multirow{2}{*}{\multicolumn{3}{|c|}{ Deflection, inches/kip }} \\
\hline & & & \multicolumn{3}{|c|}{ Top } & \multirow{2}{*}{$\frac{\text { Bottom }}{1}$} & & & \\
\hline & & & 1 & 2 & 3 & & $\mathrm{~L} / 3$ & $\mathrm{~L} / 2$ & $2 \mathrm{~L} / 3$ \\
\hline \multirow[t]{6}{*}{$15 \mathrm{ft}$} & \multirow[t]{3}{*}{12 inch } & \#1 & -390 & -378 & -387 & 369 & 0.487 & 0.5925 & 0.4786 \\
\hline & & $\# 2$ & -390 & -354 & -371 & 378 & 0.482 & 0.551 & 0.4677 \\
\hline & & Average & -390 & -366 & -379 & 373.5 & 0.4845 & 0.57175 & 0.47315 \\
\hline & \multirow[t]{3}{*}{8 inch } & $\# 1$ & -610 & -578 & -581 & 539 & 0.7171 & 0.8304 & 0.6963 \\
\hline & & $\# 2$ & -561 & -564 & -608 & 577 & 0.7211 & 0.8415 & 0.7076 \\
\hline & & Average & -585.5 & -571 & -594.5 & 558 & 0.7191 & 0.83595 & 0.70195 \\
\hline \multirow[t]{6}{*}{$11.5 \mathrm{ft}$} & \multirow[t]{3}{*}{12 inch } & $\# 1$ & -296 & -289 & -297 & 282 & 0.2131 & 0.2627 & 0.2232 \\
\hline & & $\# 2$ & -317 & -274 & -270 & 293 & 0.2272 & 0.2633 & 0.2308 \\
\hline & & Average & -306.5 & -281.5 & -283.5 & 287.5 & 0.22015 & 0.263 & 0.227 \\
\hline & \multirow[t]{3}{*}{8 inch } & $\# 1$ & -432 & -444 & -480 & 410 & 0.3281 & 0.3837 & 0.3273 \\
\hline & & \#2 & -427 & -432 & -474 & 440 & 0.3294 & 0.3861 & 0.34 \\
\hline & & Average & -430 & -438 & -477 & 425 & 0.3288 & 0.3849 & 0.3337 \\
\hline \multirow[t]{6}{*}{$8 \mathrm{ft}$} & \multirow[t]{3}{*}{12 inch } & $\# 1$ & -211 & -202 & -203 & 197 & 0.0733 & 0.0897 & 0.0788 \\
\hline & & $\# 2$ & -223 & -195 & -191 & 202 & 0.0854 & 0.1048 & 0.0902 \\
\hline & & Average & -217 & -199 & -197 & 200 & 0.0794 & 0.0973 & 0.0845 \\
\hline & \multirow[t]{3}{*}{8 inch } & $\# 1$ & -322 & -308 & -311 & 285 & 0.1175 & 0.1360 & 0.1182 \\
\hline & & $\# 2$ & -303 & -300 & -318 & 304 & 0.1133 & 0.1365 & 0.1214 \\
\hline & & Average & -313 & -304 & -315 & 295 & 0.1154 & 0.1363 & 0.1198 \\
\hline
\end{tabular}


Table 4.3 Experimental 3-Point Bending Results for Transverse Samples

\begin{tabular}{|c|c|c|c|c|c|c|c|c|c|}
\hline \multirow[t]{3}{*}{ Span } & \multirow[t]{3}{*}{ Width } & \multirow[t]{3}{*}{ Sample } & \multicolumn{4}{|c|}{ Strains, microstrain/kip } & \multirow{2}{*}{\multicolumn{3}{|c|}{ Deflection, inches/kip }} \\
\hline & & & \multicolumn{3}{|c|}{ Top } & \multirow{2}{*}{$\frac{\text { Bottom }}{1}$} & & & \\
\hline & & & 1 & 2 & 3 & & $\mathrm{~L} / 3$ & $\mathrm{~L} / 2$ & $2 \mathrm{~L} / 3$ \\
\hline \multirow[t]{6}{*}{$8 \mathrm{ft}$} & \multirow[t]{3}{*}{12 inch } & $\# 1$ & -519 & -518 & -463 & 560 & 0.1655 & 0.2066 & 0.1766 \\
\hline & & $\# 2$ & -496 & -520 & -482 & 567 & 0.1666 & 0.2078 & 0.1701 \\
\hline & & Average & -507.5 & -519 & -472.5 & 563.5 & 0.16605 & 0.2072 & 0.17335 \\
\hline & \multirow[t]{3}{*}{8 inch } & $\# 1$ & -670 & -703 & -686 & 851 & 0.2825 & 0.3429 & 0.2868 \\
\hline & & $\# 2$ & -718 & -705 & -773 & 910 & 0.2582 & 0.3274 & 0.2616 \\
\hline & & Average & -694 & -704 & -729.5 & 880.5 & 0.27035 & 0.33515 & 0.2742 \\
\hline \multirow[t]{6}{*}{$5.5 \mathrm{ft}$} & \multirow[t]{3}{*}{12 inch } & $\# 1$ & -330 & -332 & -301 & 388 & 0.0638 & 0.0791 & 0.0660 \\
\hline & & $\# 2$ & -289 & -320 & -264 & 384 & 0.0673 & 0.0813 & 0.0660 \\
\hline & & Average & -310 & -326 & -283 & 386 & 0.0656 & 0.0802 & 0.0660 \\
\hline & \multirow[t]{3}{*}{8 inch } & $\# 1$ & -443 & -435 & error & 648 & 0.0991 & 0.1250 & 0.1063 \\
\hline & & $\# 2$ & -431 & -460 & -441 & 531 & 0.0996 & 0.1163 & 0.0960 \\
\hline & & Average & -437 & -448 & -441 & 590 & 0.0994 & 0.1207 & 0.1012 \\
\hline
\end{tabular}

Table 4.4 Experimental Results for Transverse 4-Point Bending

\begin{tabular}{|c|c|c|c|c|c|c|c|c|c|}
\hline \multirow[t]{3}{*}{ Span } & \multirow[t]{3}{*}{ Width } & \multirow[t]{3}{*}{ Sample } & \multicolumn{4}{|c|}{ Strains, microstrain/kip } & \multirow{2}{*}{\multicolumn{3}{|c|}{ Deflection, inches/kip }} \\
\hline & & & \multicolumn{3}{|c|}{ Top } & \multirow{2}{*}{$\frac{\text { Bottom }}{1}$} & & & \\
\hline & & & 1 & 2 & 3 & & $\mathrm{~L} / 3$ & $\mathrm{~L} / 2$ & $2 \mathrm{~L} / 3$ \\
\hline \multirow[t]{6}{*}{$8 \mathrm{ft}$} & \multirow[t]{3}{*}{12 inch } & \#1 & -406 & -404 & -370 & 386 & 0.1475 & 0.1726 & 0.157 \\
\hline & & $\# 2$ & -399 & -403 & -389 & 377 & 0.1455 & 0.1795 & 0.15 \\
\hline & & Average & -402.5 & -403.5 & -379.5 & 381.5 & 0.1465 & 0.17605 & 0.1535 \\
\hline & \multirow[t]{3}{*}{8 inch } & \#1 & -547 & -565 & -554 & 561 & 0.2422 & 0.2742 & 0.2437 \\
\hline & & $\# 2$ & -554 & -544 & -589 & 578 & 0.2308 & 0.2751 & 0.2325 \\
\hline & & Average & -550.5 & -554.5 & -571.5 & 569.5 & 0.2365 & 0.27465 & 0.2381 \\
\hline
\end{tabular}




\subsection{Finite Element Evaluation in Bending}

To further correlate results from analytical solutions and experimental testing, a finite element analysis of each individual sample is performed, and each model is constrained and loaded following the experimental conditions.

\subsubsection{Actual Core Geometry Finite Element Model}

There are two different models developed for the finite element evaluation of beam samples. First, a model using the actual core geometry is produced and analyzed. This model uses the 4" $\mathrm{x}$ 4" cell described in Section 3.3.1. Once this cell is produced, it can be copied any number of times, and in any direction. Thus all longitudinal and transverse beam models are defined using this cell.

For each beam model, the appropriate loading and constraints are applied. A simplysupported boundary condition is specified to eliminate axial strain effects and to simulate actual experimental conditions. Because of the significant number of nodes and elements in the model, the concept of symmetry is exploited to decrease processing time and reduce the size of the model. By applying a shear release on all the nodes at the midspan of the beam, the length of the model can be cut in half. For the symmetric half, the boundary conditions allow for transverse and lateral translations, but constrain the longitudinal translations and in-plane rotations. To prevent instability of the model, one node must be constrained against lateral displacement. 
Because of the numerous span lengths for the experimental testing, it is impractical to make a different model for each test. Thus, the end roller supports are moved to the proper location for a given span. Although this will cause one end of the model to have a cantilevered portion, it is of no consequence since the beam model has no self-weight. For the roller supports, translation is restrained in the transverse direction, but not in the axial direction. No rotation is constrained at the roller-support location, and the only other constraint is the lateral translation on one node to prevent instability.

The loading of the model consisted of a line load. To simulate the experimental load, a number of nodes spanning the width of the sample are defined by a line. The load per unit width is then placed on this line and automatically discretized to the nodes. Because we are dealing with different width samples, this value differs. However, for all samples, there is 500 pounds of applied load for both 3-point and 4-point bending and due to the use of symmetry, this results in a total of one kip applied to a full model.

For the 3-point bending case, the load is applied on the top face sheet at the edge of the beam where the shear release exists. For the 4-point bending case, the load is applied at a distance of $L / 6$ from the shear release, where $L$ is the total span length. 


\subsubsection{Equivalent Plate Finite Element Model}

The models using the equivalent plate properties in the finite element investigation are formulated using the procedures outlined in Section 3.3.3 of Chapter 3. The eight-node shell elements in ABAQUS with dimensions of 2" $\mathrm{x}$ 2"are used to simulate the beam models, and the shell element consists of three layers: top and bottom face sheets and a homogenized core. The equivalent properties for all three layers are given in Chapter 2. Unlike the actual geometry models in which only half of the beam is created and the symmetry of the samples is exploited, the equivalent plate model uses the entire length of each beam.

The boundary conditions are simply supported, as explained before for the actual geometry model. One beam model is produced for each width and used for all span lengths, and the constraints are adjusted accordingly.

The load is applied using line loadings for both the three- and four-point bending conditions. The full load of 1000 pounds is placed at the midspan of the beam for the three-point bending and discretized accordingly. The four-point bending conditions consist of the load being placed at two locations, a distance of L/6 from the midspan toward both supports. A load of 500 pounds is applied to each line to simulate the fourpoint bending conditions. 


\subsubsection{Finite Element Bending Predictions}

The finite element predictions are given for the actual core geometry and the equivalent plate models. For each of these models, the strains and deflections are taken at the same locations as for the experimental testing. The FE results are compared with the analytical predictions and the experimental data in the following sections.

The predictions of the finite element analysis using the actual geometry models are given in Tables 4.5 and 4.6. The values for deflection and strain of the actual core geometry model are found using the procedures outlined in Section 3.3.2 of Chapter 3. The results of interest are the normal strain and transverse deflection values. The results for the longitudinal samples are listed in Table 4.5, and for the transverse samples are listed in Table 4.6. Each value is given in units per one kip of loading. As an illustration, the displacement and strain contour for one sample is given in Figures 4.4 and 4.5, respectively.

It should be noted that the strain values presented for the actual geometry finite element models can fluctuate widely within the distance of a couple of inches. This is partially due to the unusual shape of the elements on the face laminates as discussed in Section 3.3.2 of Chapter 3. While the experimental strain readings are taken at $w / 4, w / 2$ and $3 w / 4$, where $w$ is the width of the beam sample, the actual geometry FE strain values are shown only at $w / 4$ and $w / 2$. This is due to the symmetry that exists about the mid-width of the beam samples. Although the strain values at $w / 4$ and $3 w / 4$ obtained from model 
Table 4.5 Strains and Deflection Predictions of Longitudinal Samples using the Actual Core Geometry Finite Element Model

\begin{tabular}{|c|c|c|c|c|c|c|c|}
\hline \multirow[t]{2}{*}{ Span } & \multirow[t]{2}{*}{ Width } & \multirow[t]{2}{*}{$\begin{array}{l}\text { Bending } \\
\text { Type }\end{array}$} & \multicolumn{3}{|c|}{$\begin{array}{c}\text { Strains, } \\
\text { microstrain/kip }\end{array}$} & \multicolumn{2}{|c|}{$\begin{array}{l}\text { Deflection, } \\
\text { in/kip }\end{array}$} \\
\hline & & & Top-w/4 & Top-w/2 & Bottom & $L / 3$ of Span & $\mathrm{L} / 2$ of $\mathrm{Span}$ \\
\hline \multirow[t]{4}{*}{ 15-foot } & \multirow[t]{2}{*}{ 12-inch } & 3-point & -731 & -537 & 659 & 0.645 & 0.701 \\
\hline & & 4-point & -524 & -383 & 435 & 0.562 & 0.645 \\
\hline & \multirow[t]{2}{*}{ 8-inch } & 3-point & -678 & -835 & 964 & 0.921 & 1.087 \\
\hline & & 4-point & -482 & -596 & 646 & 0.803 & 0.921 \\
\hline \multirow[t]{4}{*}{ 11.5-foot } & \multirow[t]{2}{*}{ 12-inch } & 3-point & -548 & -403 & 507 & 0.294 & 0.348 \\
\hline & & 4-point & -402 & -293 & 334 & 0.257 & 0.294 \\
\hline & \multirow[t]{2}{*}{ 8-inch } & 3-point & -510 & -626 & 738 & 0.421 & 0.498 \\
\hline & & 4-point & -370 & -457 & 495 & 0.368 & 0.421 \\
\hline \multirow[t]{4}{*}{ 8-foot } & \multirow[t]{2}{*}{ 12-inch } & 3-point & -342 & -268 & 354 & 0.103 & 0.122 \\
\hline & & 4-point & -258 & -204 & 233 & 0.09 & 0.103 \\
\hline & \multirow[t]{2}{*}{ 8-inch } & 3-point & -407 & -525 & 513 & 0.155 & 0.184 \\
\hline & & 4-point & -308 & -400 & 345 & 0.136 & 0.155 \\
\hline \multirow[t]{2}{*}{ 5.5-foot } & 12-inch & 3-point & -221 & -173 & 245 & 0.036 & 0.043 \\
\hline & 8-inch & 3-point & -264 & -338 & 352 & 0.054 & 0.065 \\
\hline
\end{tabular}

Table 4.6 Strains and Deflection Predictions of Transverse Samples using the Actual Core Geometry Finite Element Model

\begin{tabular}{|c|c|c|c|c|c|c|c|}
\hline Span & \multirow{2}{*}{ Width } & $\begin{array}{c}\text { Bending } \\
\text { Type }\end{array}$ & \multicolumn{3}{|c|}{$\begin{array}{c}\text { Strains, } \\
\text { microstrain/kip }\end{array}$} & \multicolumn{2}{c|}{$\begin{array}{c}\text { Deflection, } \\
\text { in/kip }\end{array}$} \\
\cline { 4 - 8 } & & & Top-w/4 & Top-w/2 & Bottom & L/3 of Span & L/2 of Span \\
\hline \multirow{3}{*}{ 8-foot } & \multirow{2}{*}{ 12-inch } & 3-point & -490 & -510 & 481 & 0.167 & 0.2 \\
\cline { 3 - 8 } & & 4-point & -370 & -381 & 348 & 0.147 & 0.167 \\
\cline { 3 - 8 } & \multirow{2}{*}{ 8-inch } & 3-point & -758 & -741 & 833 & 0.251 & 0.301 \\
\cline { 3 - 8 } & & 4-point & -567 & -551 & 567 & 0.221 & 0.251 \\
\hline 5.5-foot & 12-inch & 3-point & -317 & -331 & 318 & 0.06 & 0.073 \\
\cline { 2 - 8 } & 8-inch & 3-point & -491 & -483 & 567 & 0.09 & 0.109 \\
\hline
\end{tabular}




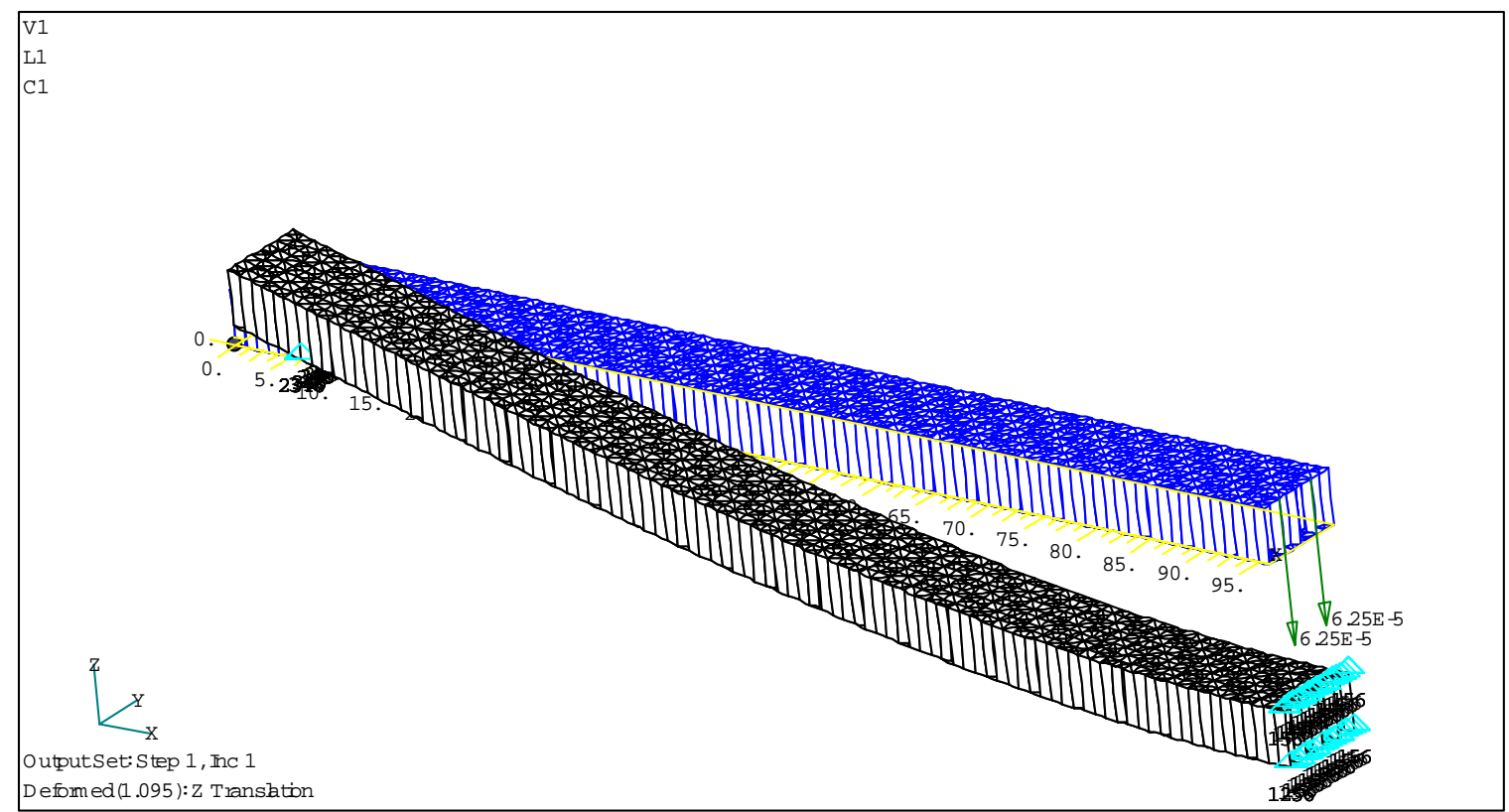

Figure 4.4 Deformed Shape of Actual Geometry Model of 8" Longitudinal Sample Under 3-point Bending with 15' Span

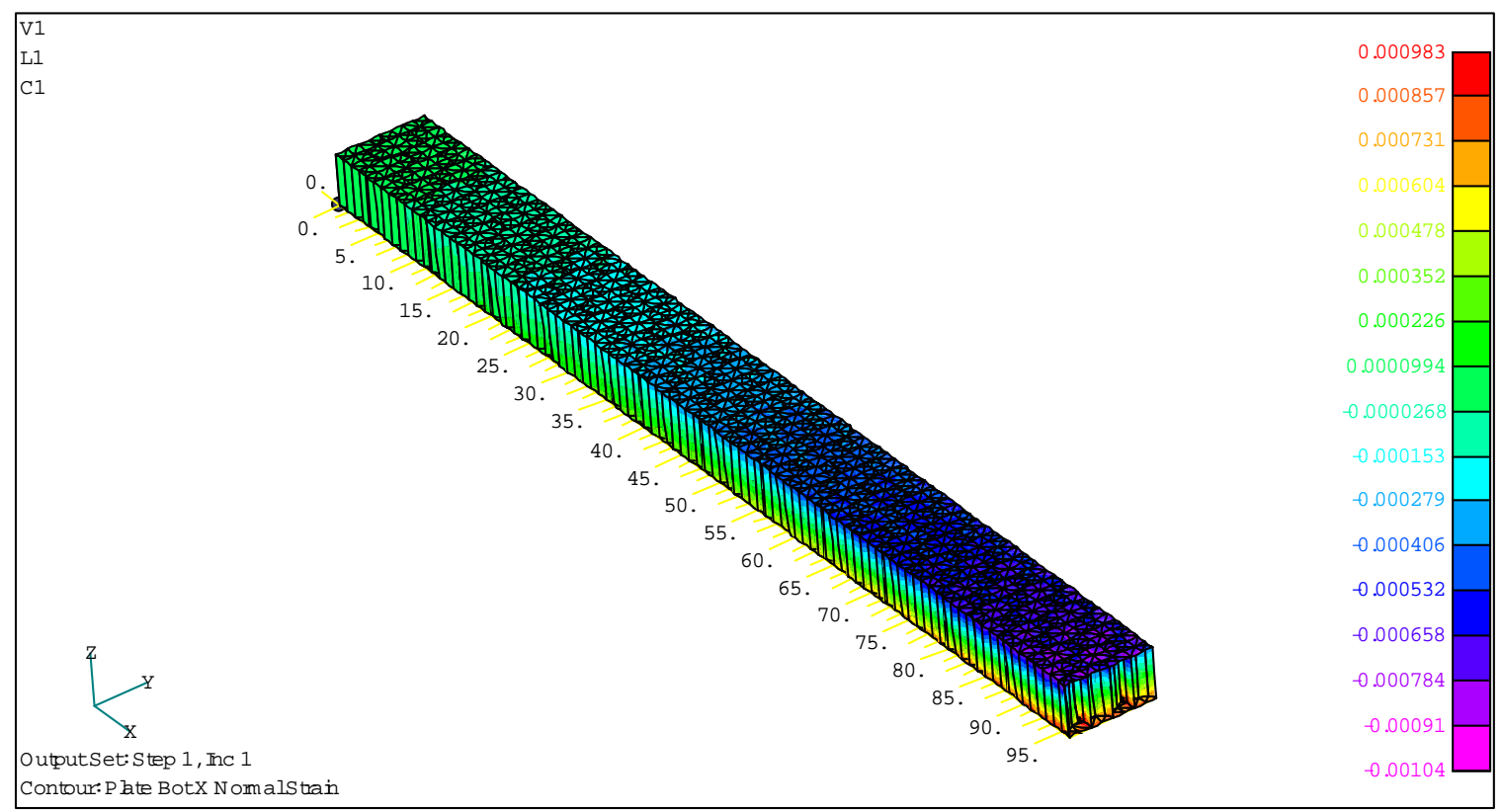

Figure 4.5 Strain Distribution of Actual Geometry Model 8' Longitudinal Sample using 3-point bending with a 15' Span 
are sometimes not identical due to the complexity and uniqueness of the elements, the variation is relatively small. Thus, the two compressive strain values along the width can serve to interpolate an average strain for the top face sheet.

There is one strain reading taken on the bottom face of the sample, as in the experiment. This FE strain reading is taken at one inch from the symmetric boundary condition, directly at the mid-width of the sample. This is to avoid any localized effects associated with the constraint. The deflection values are taken at nodes located at the mid-width of the sample and at the same locations as in the experiment. The deflection values remained relatively constant through the cross-section at any location.

The values of the finite element analysis using the equivalent plate models are shown in Tables 4.7 and 4.8, respectively, for the longitudinal and transverse samples. Unlike the actual geometry FE models, the strain distribution throughout the width is uniform. Since the models have elements with rectangular shapes, the strain values are constant and thus easily extracted. A graphical output for one sample is shown in Figures 4.7 and 4.8 . 
Table 4.7 Strains and Deflection Predictions of Longitudinal Samples using the Equivalent Plate Finite Element Model

\begin{tabular}{|c|c|c|c|c|c|c|c|}
\hline \multirow[t]{2}{*}{ Span } & \multirow[t]{2}{*}{ Width } & \multirow[t]{2}{*}{$\begin{array}{l}\text { Bending } \\
\text { Type }\end{array}$} & \multicolumn{3}{|c|}{$\begin{array}{c}\text { Strains, } \\
\text { microstrain/kip }\end{array}$} & \multicolumn{2}{|c|}{$\begin{array}{l}\text { Deflection, } \\
\text { in/kip }\end{array}$} \\
\hline & & & Top-w/4 & Top-w/2 & Bottom & $L / 3$ of Span & $L / 2$ of Span \\
\hline \multirow[t]{4}{*}{ 15-foot } & \multirow[t]{2}{*}{ 12-inch } & 3-point & -665 & -665 & 713 & 0.668 & 0.788 \\
\hline & & 4-point & -475 & -475 & 475 & 0.583 & 0.668 \\
\hline & \multirow[t]{2}{*}{ 8-inch } & 3-point & -998 & -998 & 1069 & 1 & 1.18 \\
\hline & & 4-point & -712 & -712 & 712 & 0.874 & 1 \\
\hline \multirow[t]{4}{*}{ 11.5-foot } & \multirow[t]{2}{*}{ 12-inch } & 3-point & -499 & -499 & 546 & 0.305 & 0.36 \\
\hline & & 4-point & -364 & -364 & 364 & 0.266 & 0.305 \\
\hline & \multirow[t]{2}{*}{ 8-inch } & 3-point & -748 & -748 & 820 & 0.457 & 0.541 \\
\hline & & 4-point & -546 & -546 & 546 & 0.399 & 0.399 \\
\hline \multirow[t]{4}{*}{ 8-foot } & \multirow[t]{2}{*}{ 12-inch } & 3-point & -333 & -333 & 380 & 0.105 & 0.126 \\
\hline & & 4-point & -253 & -253 & 253 & 0.092 & 0.105 \\
\hline & \multirow[t]{2}{*}{ 8-inch } & 3-point & -561 & -561 & 571 & 0.158 & 0.189 \\
\hline & & 4-point & -403 & -403 & 380 & 0.139 & 0.158 \\
\hline \multirow[t]{2}{*}{ 5.5-foot } & 12-inch & 3-point & -214 & -214 & 261 & 0.036 & 0.044 \\
\hline & 8-inch & 3-point & -321 & -321 & 393 & 0.055 & 0.66 \\
\hline
\end{tabular}

Table 4.8 Strains and Deflection Predictions of Transverse Samples using the Equivalent Plate Finite Element Model

\begin{tabular}{|c|c|c|c|c|c|c|c|}
\hline Span & Width & $\begin{array}{c}\text { Bending } \\
\text { Type }\end{array}$ & \multicolumn{3}{|c|}{$\begin{array}{c}\text { Strains, } \\
\text { microstrain/kip }\end{array}$} & \multicolumn{2}{c|}{$\begin{array}{c}\text { Deflection, } \\
\text { in/kip }\end{array}$} \\
\cline { 4 - 8 } & & & Top-w/4 & Top-w/2 & Bottom & L/3 of Span & L/2 of Span \\
\hline \multirow{3}{*}{ 8-foot } & \multirow{2}{*}{ 12-inch } & 3-point & -561 & -561 & 641 & 0.185 & 0.223 \\
\cline { 3 - 8 } & & 4-point & -403 & -403 & 403 & 0.154 & 0.174 \\
\cline { 3 - 8 } & \multirow{2}{*}{ 8-inch } & 3-point & -793 & -793 & 907 & 0.262 & 0.315 \\
\cline { 3 - 8 } & & 4-point & -604 & -604 & 604 & 0.231 & 0.262 \\
\hline 5.5-foot & 12-inch & 3-point & -361 & -361 & 441 & 0.066 & 0.081 \\
\cline { 3 - 8 } & 8-inch & 3-point & -510 & -510 & 624 & 0.094 & 0.115 \\
\hline
\end{tabular}




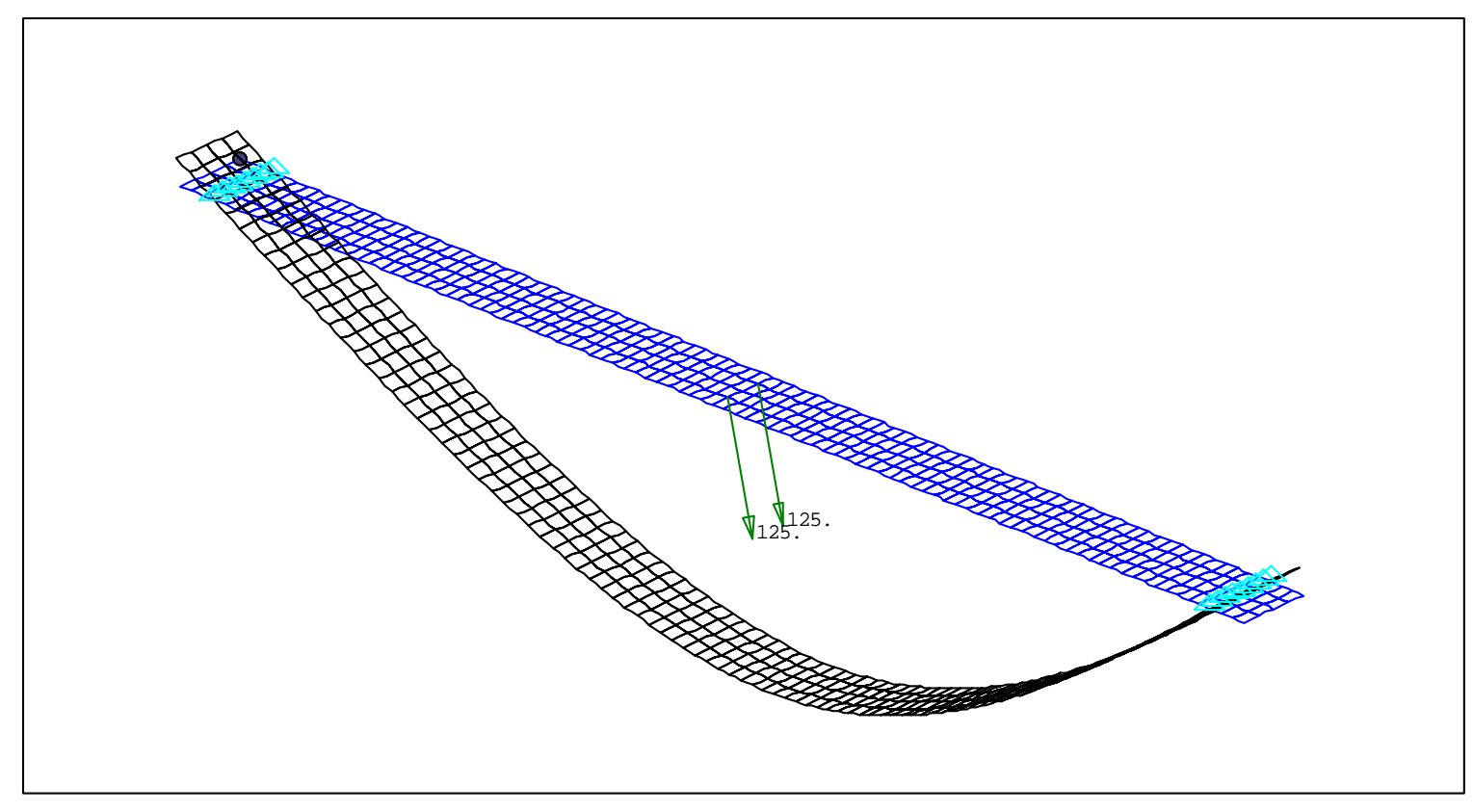

Figure 4.6 Deformed Shape of Equivalent Plate Model of 8' Longitudinal Sample Under 3-point Bending with 15' Span

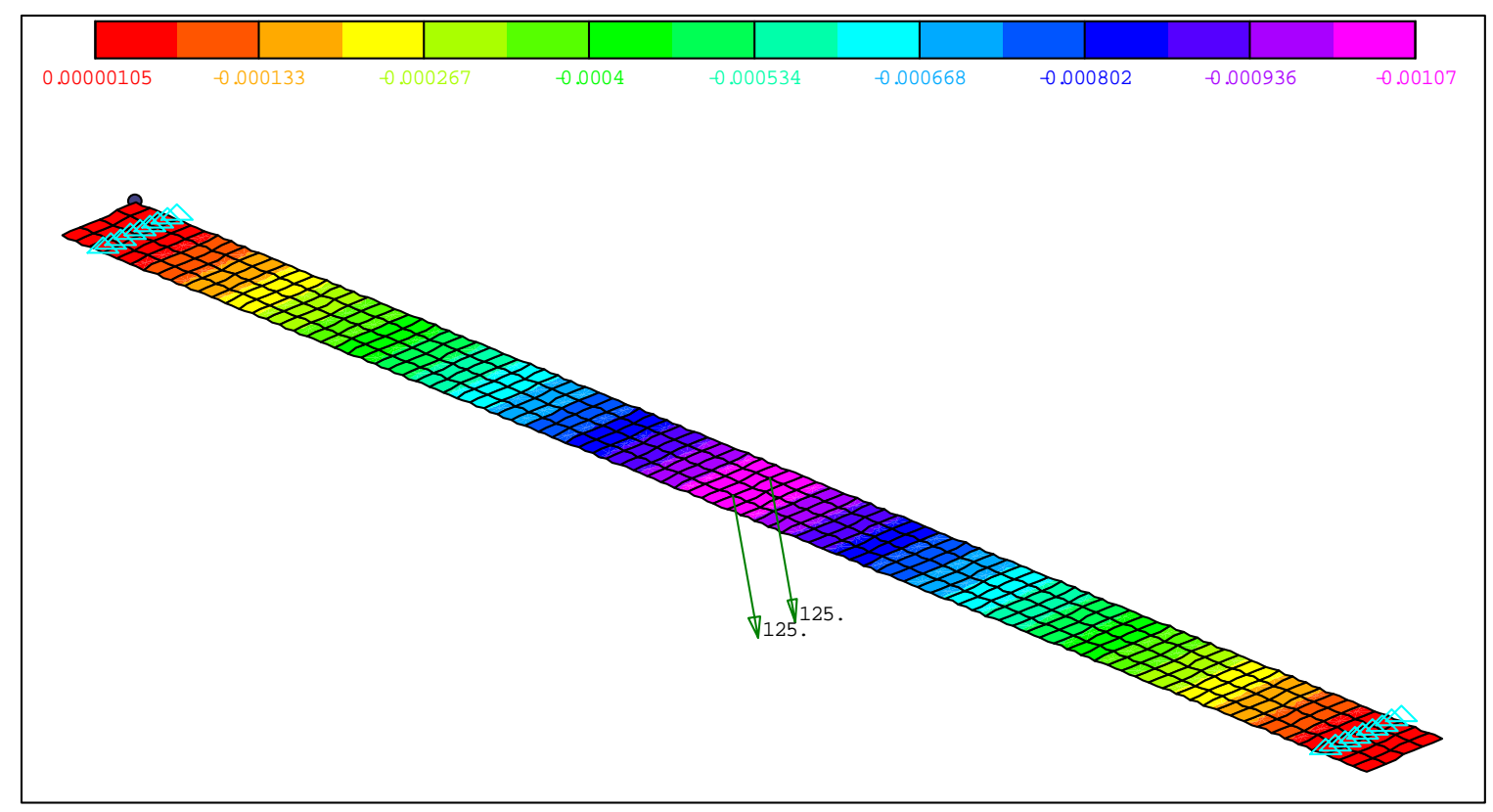

Figure 4.7 Strain Distribution of Equivalent Plate Model of 8' Longitudinal Sample using 3-point bending with a 15' Span 


\subsection{Analytical Solutions}

The equivalent panel properties that are found in Chapter 2 are now used to predict responses of the three and four-point bending tests. These responses will be compared with the predictions of the finite element models, as well as the experimental results. A good correlation of values can verify the accuracy of the equivalent panel properties.

In order to find responses of bending tests, the stiffnesses of the beams must be defined in a rational way. Because shear deformation is significant in FRP sandwich beams, due to the relatively low shear stiffness of composites and possible short spans in actual applications, both the bending and shear stiffnesses are formulated using beam theory.

The beam bending stiffness $\mathrm{D}$ consists of face in-plane tensile stiffness and the core bending stiffness, and is expressed as

$D=b\left[\frac{(d-t)^{2} t}{2} E_{f}+\frac{(d-2 t)^{3}}{12} E_{c}\right]$

where $b$ is the beam width, $d$ is the beam depth, $t$ is the face thickness, and subscripts $f$ and $c$ are associated with face and core properties.

The shear stiffness of the beam can be simplified by neglecting the face shear deformation, and thus can be expressed as

$(\kappa G A)=G^{e}{ }_{x z} b d$ 
where $G_{x z}^{e}$ is the out-of-plane shear modulus of the core and given in Chapter 2. The shear correction factor, , is approximated as 1.0 for this study.

The responses of interest are the maximum strain at center span, the deflection at halfspan and the deflection at one-third span. The analytical results are based on the firstorder shear deformation theory. It is reasonable to assume that the transverse shear strain is constant throughout the thickness of the beam, thus using Timoshenko beam theory, the governing differential equations are as follows:

$$
\begin{aligned}
& D \frac{d^{2} \psi}{d x^{2}}+(\kappa G A)\left(\frac{d w}{d x}-\psi\right)=0 \\
& \kappa G A\left(\frac{d \psi}{d x}-\frac{d^{2} w}{d x^{2}}\right)=q(x)
\end{aligned}
$$

where $w$ denotes the deflection, and represents the first derivative of the deflection due to bending.

Combining the two previous equations, the maximum mid-span deflections for 3-point $\left(\delta_{3}\right)$ and 4-point $\left(\delta_{4}\right)$ loading can be written as

$$
\begin{aligned}
& \delta_{3}=\frac{P L^{3}}{48 D}+\frac{P L}{4(\kappa G A)} \\
& \delta_{4}=\frac{23 P L^{3}}{1296 D}+\frac{P L}{6(\kappa G A)}
\end{aligned}
$$


where $P$ is the total applied load and $L$ is the span length. The results of the closed-form solution are given in Tables 4. through 4.12, in which all values of the comparable bending studies are shown.

Table 4.9 Comparison of Deflections for Longitudinal Beam Samples

\begin{tabular}{|c|c|c|c|c|c|c|c|c|c|c|}
\hline \multirow{4}{*}{$\begin{array}{c}\text { Span, } \\
\text { feet }\end{array}$} & \multirow{4}{*}{$\begin{array}{l}\text { Width, } \\
\text { inches }\end{array}$} & \multirow{4}{*}{$\begin{array}{c}\text { Bending } \\
\text { Type }\end{array}$} & \multicolumn{8}{|c|}{ Deflection, in./kip } \\
\hline & & & \multicolumn{4}{|c|}{ FE Model } & \multirow{2}{*}{\multicolumn{2}{|c|}{ Analytical }} & \multicolumn{2}{|c|}{ Experimental } \\
\hline & & & \multicolumn{2}{|c|}{ Actual } & \multicolumn{2}{|c|}{ Eq uivalent } & & & & \\
\hline & & & $\begin{array}{c}1 / 2 \\
\text { Span }\end{array}$ & $\begin{array}{c}1 / 3 \\
\text { Span }\end{array}$ & $\begin{array}{c}1 / 2 \\
\text { Span }\end{array}$ & $\begin{array}{c}1 / 3 \\
\text { Span }\end{array}$ & $\begin{array}{c}1 / 2 \\
\text { Span }\end{array}$ & $\begin{array}{c}1 / 3 \\
\text { Span }\end{array}$ & $\begin{array}{c}1 / 2 \\
\text { Span }\end{array}$ & $\begin{array}{c}1 / 3 \\
\text { Span }\end{array}$ \\
\hline \multirow[t]{4}{*}{$15.0^{\prime}$} & \multirow[t]{2}{*}{$12 "$} & point & 0.701 & 0.645 & 0.788 & 0.668 & 0.753 & 0.639 & 0.684 & 0.557 \\
\hline & & 4-point & 0.645 & 0.562 & 0.668 & 0.583 & 0.639 & 0.557 & 0.572 & 0.479 \\
\hline & \multirow[t]{2}{*}{ 8" } & 3-point & 1.087 & 0.921 & 1.180 & 1.000 & 1.130 & 0.958 & 1.000 & 0.824 \\
\hline & & 4-point & 0.921 & 0.803 & 1.000 & 0.874 & 0.958 & 0.835 & 0.836 & 0.711 \\
\hline \multirow[t]{4}{*}{$11.5^{\prime}$} & \multirow[t]{2}{*}{$12 "$} & 3-point & 0.348 & 0.294 & 0.360 & 0.305 & 0.344 & 0.291 & 0.321 & 0.262 \\
\hline & & 4-point & 0.294 & 0.257 & 0.305 & 0.266 & 0.291 & 0.254 & 0.263 & 0.224 \\
\hline & \multirow[t]{2}{*}{$8 "$} & 3-point & 0.498 & 0.421 & 0.541 & 0.457 & 0.517 & 0.437 & 0.466 & 0.386 \\
\hline & & 4-point & 0.421 & 0.368 & 0.399 & 0.399 & 0.437 & 0.381 & 0.385 & 0.331 \\
\hline \multirow[t]{4}{*}{$8.0^{\prime}$} & \multirow[t]{2}{*}{$12^{\prime \prime}$} & 3-point & 0.122 & 0.103 & 0.126 & 0.105 & 0.120 & 0.101 & 0.115 & 0.092 \\
\hline & & 4-point & 0.103 & 0.090 & 0.105 & 0.092 & 0.101 & 0.088 & 0.097 & 0.082 \\
\hline & \multirow[t]{2}{*}{$8 "$} & 3-point & 0.184 & 0.155 & 0.189 & 0.158 & 0.180 & 0.151 & 0.161 & 0.134 \\
\hline & & 4-point & 0.155 & 0.136 & 0.158 & 0.139 & 0.151 & 0.133 & 0.136 & 0.117 \\
\hline \multirow[t]{2}{*}{$5.5^{\prime}$} & $12^{\prime \prime}$ & 3-point & 0.043 & 0.036 & 0.044 & 0.036 & 0.042 & 0.035 & 0.051 & 0.04 \\
\hline & $8 "$ & 3-point & 0.065 & 0.054 & 0.660 & 0.055 & 0.063 & 0.052 & 0.061 & 0.052 \\
\hline
\end{tabular}

Table 4.10 Comparison of Deflections for Transverse Beam Samples

\begin{tabular}{|c|c|c|c|c|c|c|c|c|c|c|}
\hline \multirow{4}{*}{$\begin{array}{c}\text { Span, } \\
\text { feet }\end{array}$} & \multirow{4}{*}{$\begin{array}{l}\text { Width, } \\
\text { inches }\end{array}$} & \multirow{4}{*}{$\begin{array}{c}\text { Bending } \\
\text { Type }\end{array}$} & \multicolumn{8}{|c|}{ Deflection, in./kip } \\
\hline & & & \multicolumn{4}{|c|}{ FE Model } & \multirow{2}{*}{\multicolumn{2}{|c|}{ Analytical }} & \multicolumn{2}{|c|}{ Experimental } \\
\hline & & & \multicolumn{2}{|c|}{ Actual } & \multicolumn{2}{|c|}{ Equiv. } & & & & \\
\hline & & & $\begin{array}{c}1 / 2 \\
\text { Span }\end{array}$ & $\begin{array}{c}1 / 3 \\
\text { Span }\end{array}$ & $\begin{array}{c}1 / 2 \\
\text { Span }\end{array}$ & $\begin{array}{c}1 / 3 \\
\text { Span }\end{array}$ & $\begin{array}{c}1 / 2 \\
\text { Span }\end{array}$ & $\begin{array}{c}1 / 3 \\
\text { Span }\end{array}$ & $\begin{array}{c}1 / 2 \\
\text { Span }\end{array}$ & $\begin{array}{c}1 / 3 \\
\text { Span }\end{array}$ \\
\hline \multirow[t]{4}{*}{$8.0^{\prime}$} & \multirow[t]{2}{*}{ 12" } & 3-point & 0.200 & 0.167 & 0.223 & 0.185 & 0.202 & 0.169 & 0.207 & 0.17 \\
\hline & & 4-point & 0.167 & 0.147 & 0.174 & 0.154 & 0.169 & 0.148 & 0.176 & 0.15 \\
\hline & \multirow[t]{2}{*}{$8 "$} & 3-point & 0.301 & 0.251 & 0.315 & 0.262 & 0.304 & 0.253 & 0.335 & 0.272 \\
\hline & & 4-point & 0.251 & 0.221 & 0.262 & 0.231 & 0.253 & 0.223 & 0.275 & 0.237 \\
\hline \multirow[t]{2}{*}{$5.5^{\prime}$} & $12^{\prime \prime}$ & 3-point & 0.073 & 0.060 & 0.081 & 0.066 & 0.073 & 0.060 & 0.08 & 0.066 \\
\hline & 8" & 3-point & 0.109 & 0.090 & 0.115 & 0.094 & 0.109 & 0.089 & 0.121 & 0.1 \\
\hline
\end{tabular}


Table 4.11 Strain Comparisons of Longitudinal Beam Samples

\begin{tabular}{|c|c|c|c|c|c|c|c|c|c|c|}
\hline \multirow{4}{*}{$\begin{array}{c}\text { Span, } \\
\text { feet }\end{array}$} & \multirow{4}{*}{$\begin{array}{l}\text { Width, } \\
\text { inches }\end{array}$} & \multirow{4}{*}{$\begin{array}{l}\text { Bending } \\
\text { Type }\end{array}$} & \multicolumn{8}{|c|}{ Strain @1/2 Span, microstrain/kip } \\
\hline & & & \multicolumn{4}{|c|}{ FE Models } & \multirow{2}{*}{\multicolumn{2}{|c|}{ Analytical }} & \multirow{2}{*}{\multicolumn{2}{|c|}{ Experimental }} \\
\hline & & & \multicolumn{2}{|c|}{ Actual } & \multicolumn{2}{|c|}{ Eq uivalent } & & & & \\
\hline & & & Comp. & Tens. & Comp. & Tens. & Comp. & Tens. & Comp. & Tens. \\
\hline \multirow[t]{4}{*}{$15.0^{\prime}$} & \multirow[t]{2}{*}{$12 "$} & 3-point & -666 & 659 & -665 & 713 & -637 & 683 & -521 & 570 \\
\hline & & 4-point & -477 & 435 & -475 & 475 & -455 & 455 & -378 & 373.5 \\
\hline & \multirow[t]{2}{*}{ 8" } & 3-point & -730 & 964 & -998 & 1069 & -956 & 1024 & -827 & 836 \\
\hline & & 4-point & -520 & 646 & -712 & 712 & -683 & 683 & -584 & 558 \\
\hline \multirow[t]{4}{*}{$11.5^{\prime}$} & \multirow[t]{2}{*}{$12^{\prime \prime}$} & 3-point & -500 & 507 & -499 & 546 & -478 & 524 & -388 & 438 \\
\hline & & 4-point & -366 & 334 & -364 & 364 & -349 & 349 & -291 & 288 \\
\hline & \multirow[t]{2}{*}{ 8" } & 3-point & -549 & 738 & -748 & 820 & -717 & 785 & -614 & 633 \\
\hline & & 4-point & -399 & 495 & -546 & 546 & -524 & 524 & -448 & 425 \\
\hline \multirow[t]{4}{*}{$8.0^{\prime}$} & \multirow[t]{2}{*}{$12^{\prime \prime}$} & 3-point & -317 & 354 & -333 & 380 & -319 & 364 & -252 & 303 \\
\hline & & 4-point & -240 & 233 & -253 & 253 & -243 & 243 & -204 & 200 \\
\hline & \multirow[t]{2}{*}{ 8" } & 3-point & -446 & 513 & -561 & 571 & -478 & 546 & -401 & 439 \\
\hline & & 4-point & -339 & 345 & -403 & 380 & -364 & 364 & -311 & 295 \\
\hline \multirow[t]{2}{*}{$5.5^{\prime}$} & $12 "$ & 3-point & -205 & 245 & -214 & 261 & -205 & 250 & -159 & 209 \\
\hline & 8" & 3-point & -289 & 352 & -321 & 393 & -307 & 376 & -259 & 298 \\
\hline
\end{tabular}

Table 4.12 Strain Comparisons of Transverse Beam Samples

\begin{tabular}{|c|c|c|c|c|c|c|c|c|c|c|}
\hline \multirow{4}{*}{$\begin{array}{c}\text { Span, } \\
\text { feet }\end{array}$} & \multirow{4}{*}{$\begin{array}{l}\text { Width, } \\
\text { inches }\end{array}$} & \multirow{4}{*}{$\begin{array}{l}\text { Bending } \\
\text { Type }\end{array}$} & \multicolumn{8}{|c|}{ Strain @1/2 Span, microstrain/kip } \\
\hline & & & \multicolumn{4}{|c|}{ FE Models } & \multirow{2}{*}{\multicolumn{2}{|c|}{ Analytical }} & \multicolumn{2}{|c|}{ Experimental } \\
\hline & & & \multicolumn{2}{|c|}{ Actual } & \multicolumn{2}{|c|}{ Eq uivalent } & & & & \\
\hline & & & Comp. & Tens. & Comp. & Tens. & Comp. & Tens. & Comp. & Tens. \\
\hline \multirow[t]{4}{*}{$8.0^{\prime}$} & \multirow[t]{2}{*}{$12 "$} & 3-point & -497 & 481 & -561 & 641 & -521 & 595 & -500 & 564 \\
\hline & & 4-point & -374 & 348 & -403 & 403 & -397 & 397 & -395 & 382 \\
\hline & \multirow[t]{2}{*}{$8 "$} & 3-point & -752 & 833 & -793 & 907 & -781 & 892 & -709 & 881 \\
\hline & & 4-point & -562 & 567 & -604 & 604 & -595 & 595 & -559 & 570 \\
\hline \multirow[t]{2}{*}{$5.5^{\prime}$} & $12 "$ & 3-point & -322 & 318 & -361 & 441 & -335 & 409 & -306 & 386 \\
\hline & $8 "$ & 3-point & -488 & 567 & -510 & 624 & -502 & 614 & -442 & 590 \\
\hline
\end{tabular}




\subsection{Discussion of Results}

A comparison of strain and displacement results is shown in Tables 4.9 through 4.12. It can be noted that experimental values correlate well with both actual geometry and equivalent plate finite element models, as well as analytical predictions.

The finite element values presented in the comparison tables are taken from Section 4.3. The compression strain values for the actual geometry model are taken as an average of the three locations on the top plate. The experimental values are also taken as an average of the three gauges on the top plate. Experimental samples of the same width and core orientation are averaged together as well. All strain values for the experimental analysis are given in Tables 4.1 through 4.4. Compressive strain values are taken six inches from the midspan of the beam, while the tensile strain readings are taken directly at the midspan. The experimental deflections at $L / 3$ as presented in the tables are taken as an average of the $L / 3$ and $2 L / 3$ readings for the beams. Each value given in Table 4.9 through 4.12 is for one kip of loading.

The finite element and analytical predictions of displacements for the longitudinal samples are generally higher than the experimental values. This is also the case with the strain values, although the percentage difference is somewhat larger. A possible reason for the differences between experimental values and analytical and numerical predictions may be due to geometric variations of the experimental samples. For example, the longitudinal 12" wide samples could have a width of almost 13" in some locations. The 
longitudinal 8" wide sample could be up to 9" in width in some locations. This is due to geometric imperfections in the manufacturing and fabrication process. Also, the longitudinal samples tended to delaminate the faceplates from the core, due to a weak interface bond. Since the bending resistance is mostly carried by the top and bottom faceplates, this delamination does not play a significant role.

The experimental deflection results of the transverse beams are generally higher than the predictions from analytical and numerical models. Also, the equivalent plate finite element models give larger deflection values than the actual geometry FE models and analytical predictions. Although there is some difference in values, there is a good correlation in the comparisons of experimental results with each model. The experimental strains in the transverse beams also compare well with both FE and analytical models.

An area of concern with analytical and finite element modeling of the beam samples is the core. It is assumed that the core is perfectly attached to the faceplates. As stated earlier, this is not true. However, the bonds between the core and face laminates of the transverse samples are generally better than that of the longitudinal samples. Basically, the transverse samples may have more contacts along the interface; whereas it is easy to introduce imperfection along the bonds for longitudinal samples, since the quality along the long bonding lines might be difficult to control. This may account for the fact that the transverse samples tend to have better correlations with predicted values. 


\section{Chapter 5}

\section{Evaluation of Sandwich Beams in Torsion}

\section{$5.1 \quad$ Introduction}

Analytical models are valuable for describing responses of the FRP honeycomb panel considered in this study, particularly explicit solutions that can be used in design. However, due to the complex geometry of the sandwich panel, a closed-form solution for torsion is not available at this time. Thus, an experimental study is presented, supplemented by a finite element analysis to evaluate the response of the samples in torsion. The calibration of the torsion machine to evaluate its accuracy is outlined in Section 5.2. The experimental investigation of the FRP sandwich beam samples is given in Section 5.3, while the finite element modeling of the samples in torsion is presented in Section 5.4.

\subsection{Calibration of the Torsion Testing Machine}

To validate the accuracy of the experimental torsion tests, it is necessary that the machine be calibrated using a sample with a known shear modulus. This section describes the torsion machine and experimental torsion method, followed by a combined analytical, experimental, and finite element evaluation of the torsional response of an aluminum bar. 


\subsubsection{Overview of Experimental Methods}

The machine used to experimentally test samples in torsion was designed by a former graduate student, James Brokaw in 1992, and subsequently used by doctoral student Hani Salim in 1996, among others. A diagram of the torsion machine is show in Figure 5.1.

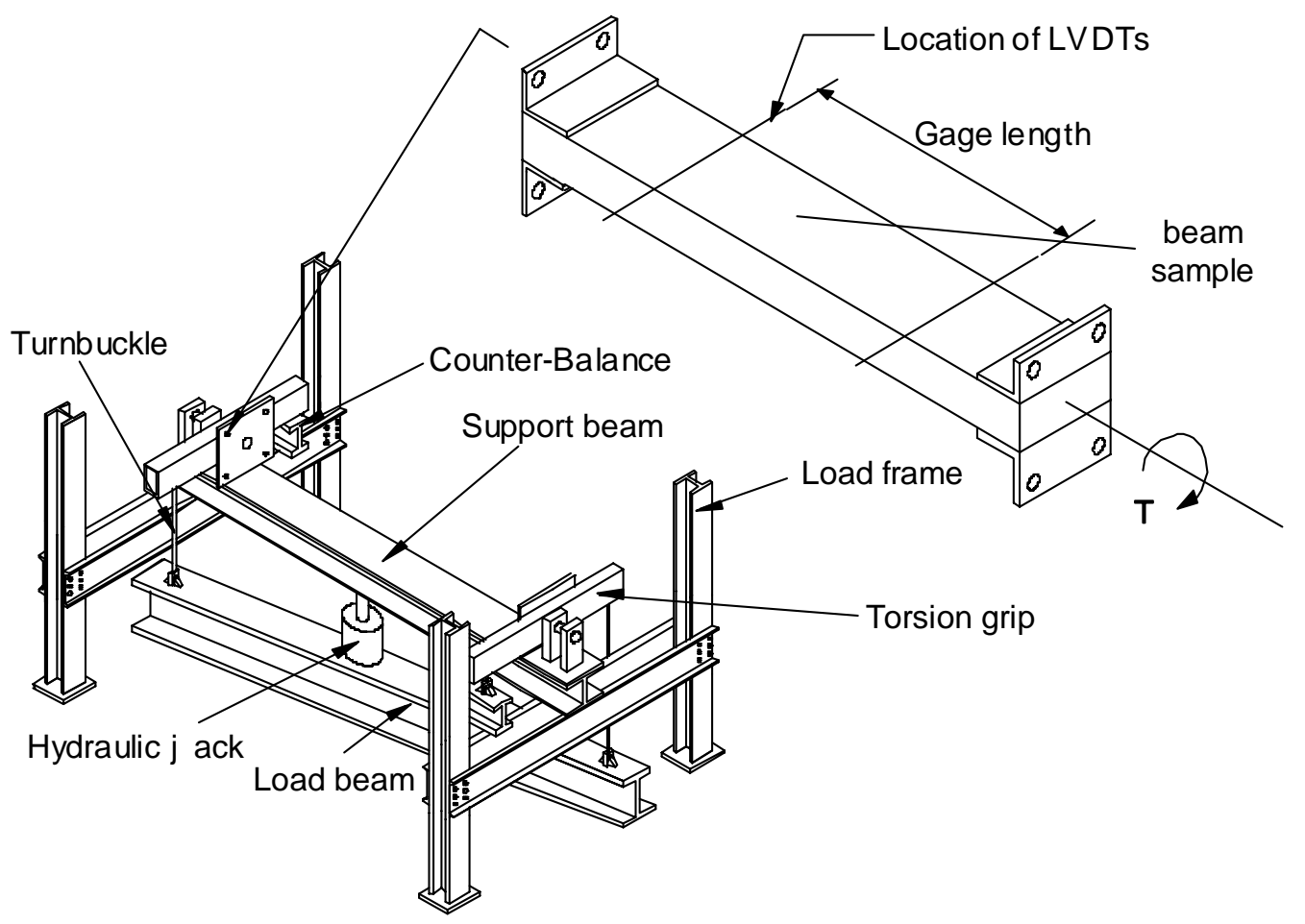

Figure 5.1 Torsion Machine

As shown in Figure 5.1, the test sample is placed between two grips, which hold the sample at the ends. A hydraulic jack applies a vertical load to a loading beam suspended diagonally from the moment arms at the ends. The load is transferred to turnbuckles, which in turn apply opposite loads to the moment arms at the grips. These loads applied to the moment arms cause the grips to rotate in opposite directions, thus applying a torque to the sample. The magnitude of the load transferred to each turnbuckle is approximately 
one-half the load applied by the hydraulic jack, and the load applied to the turnbuckle when multiplied by the length of the moment arm produces the torque applied to the sample. Because both ends of the sample rotate by about the same angle, the sample will rotate with respect to its mid-length, which will behave as a fixed boundary condition.

\subsubsection{Analytical Predictions for Aluminum Test Sample}

A 6061-T6 aluminum bar with dimension of 6" x 1" $\mathrm{x} 10$ ' is used for the calibration process. The aluminum bar was chosen because of its well-documented isotropic material properties. Using St. Venant's isotropic torsion solution, the published shear modulus and geometric properties can be used to find the angle of rotation, as well as the maximum shear strain for a given torque. Using the isotropic material constants, the shear modulus of the aluminum bar can be found as follows, for $\mathrm{E}=11,000 \mathrm{ksi}$ and $\quad=0.30$.

$$
G=\frac{E}{2(1+v)}=4,230 k s i
$$

Boresi, Schmidt and Sidebottom (1993) reported the St. Venant's solution for an isotropic rectangular cross-section as

$$
\begin{gathered}
\theta=\frac{\mathrm{T}}{k_{1} \mathrm{G} b h^{3}} \\
\tau_{\max }=\frac{\mathrm{T}}{k_{2} b h^{2}}
\end{gathered}
$$

where $=$ angle of rotation per unit length in radians; $\max =$ maximum shear stress at the center of the longest cross-sectional dimension at the fixed boundary. The values of 
$k_{1}$ and $k_{2}$ are based on the ratio of $b / h$ In this case, $\mathrm{k}_{1}=\mathrm{k}_{2}=0.299$. The predicted values

of and $\max$ from equations (5.2) and (5.3), respectively, are given in Table 5.1.

Table 5.1 Analytical Predictions using St. Venant's Solution

\begin{tabular}{|c|c|c|}
\hline $\begin{array}{c}\text { Distance from Midspan } \\
\text { of Sample, inches }\end{array}$ & $\begin{array}{c}\text { Strain, } \\
\text { Microstrains/kip-inch }\end{array}$ & $\begin{array}{c}\text { Angle of Rotation, } \\
\text { Radians/kip-inch }\end{array}$ \\
\hline 0" & 131.8 & 0.0 \\
\hline $24 "$ & -- & 0.00317 \\
\hline $36 "$ & -- & 0.00475 \\
\hline
\end{tabular}

\subsubsection{Experimental Results for Aluminum Bar}

The goal of the experimental testing is to find the rotational response of the aluminum sample. Based on the data, a corresponding shear modulus can be calculated using the St. Venant's solution. The instrumentation of the aluminum sample consists of four LVDT's. The core of each LVDT is suspended from an attached arm placed at 36 " from the midspan of the sample towards the end-grip. The length of the attached arm is 30 " from the mid-width of the sample. This instrumentation with attached arms is used to provide more accurate displacement readings of the LVDT's, as shown in Figure 5.2.

The displacements are used to calculate the angle of rotation of the sample. When the sample undergoes an applied torque, the LVDT's will measure the displacements at their specific locations. The deformed and undeformed cross-section of the sample, and the corresponding displacements are shown in Figure 5.3. 




Figure 5.2 LVDT Locations of Aluminum Sample

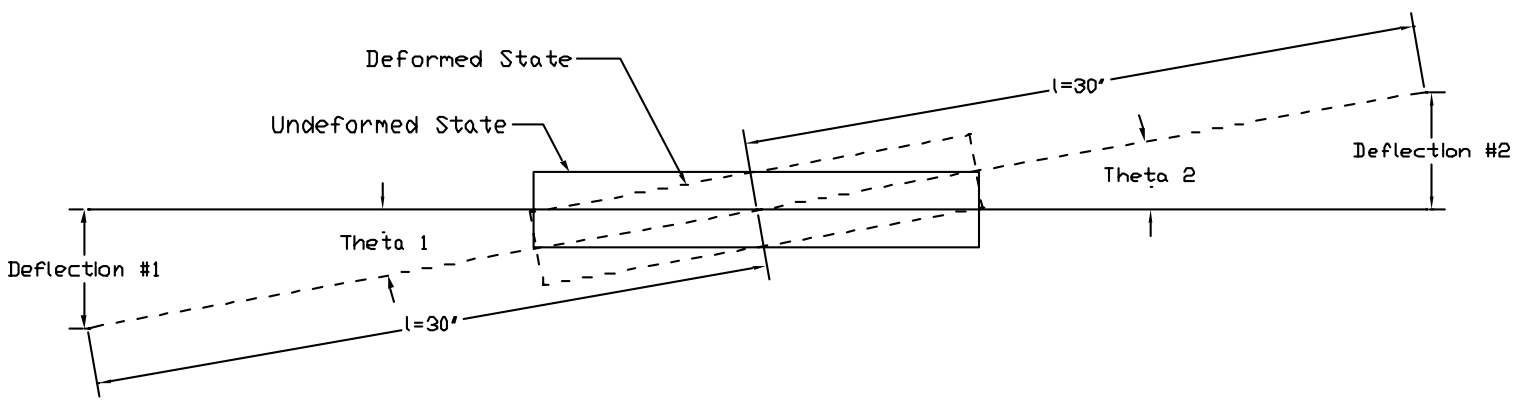

Figure 5.3 Deformed Shape of Aluminum Sample 
For each LVDT, the angle of rotation in radians is calculated by dividing the absolute value of the corresponding displacement by the arm length, $l$. Theoretically, the absolute value of the displacement should be the same for all LVDT locations. However, due to geometric variations in the testing setup and/or experimental errors, the angle of rotation values are not all identical.

It should be noted that the section of the bar that undergoes no rotation should be the midspan of the sample, but during the testing, this condition was not precisely satisfied. However, it would be tedious and to no advantage to try to find the neutral location along the bar. The angle of twist was found by averaging the corresponding values for all four LVDT's, and therefore, a fixed-free sample gauge length of 36 " can be used in the analysis.

The amount of force, P, applied to the load beam was measured using a 2-kip load cell, and the torque is calculated using the following equation:

$T=\frac{P}{2} \times r$

where, $\mathrm{T}=$ torque (kip-in), $\mathrm{P}=$ load (kip), $\mathrm{r}=$ moment arm length (36 in).

Once the data for the applied load and displacement measurements are recorded, they are used to find the experimental value of the shear modulus using Saint Venant's solution for an isotropic narrow rectangular bar as

$\frac{\mathrm{T}}{\theta}=\frac{\mathrm{Gbh}^{3} \mathrm{k}_{1}}{\mathrm{~L}}$ 
where $\mathrm{T}=$ applied Torque (kip-in); $\mathrm{b}=$ width of bar $(6 \mathrm{in}) ; \mathrm{h}=$ height of bar ( $1 \mathrm{in})$;

$\mathrm{k}_{1}=$ constant based on bar geometry $\left(\mathrm{k}_{1}=0.299\right.$ for 6 " x 1 " rectangular bar);

$\mathrm{L}=$ gauge length $(36 \mathrm{in}) ; \quad=$ angle of twist $(\mathrm{rad})$.

The experimental values for the shear modulus were found from three tests. The experimental results, along with the percent differences with respect to the theoretical value $(\mathrm{G}=4230 \mathrm{ksi})$ are given in Table 5.2.

Table 5.2 Experimental Results for Aluminum Bar

\begin{tabular}{|c|c|c|c|}
\hline Test Number & $\begin{array}{c}\text { Average Angle of Twist, } \\
\text { rad/kip-in }\end{array}$ & $\begin{array}{c}\text { Shear Modulus, } \\
\text { ksi }\end{array}$ & $\begin{array}{c}\text { Percentage Difference } \\
\text { From Theoretical } \\
\text { Value }\end{array}$ \\
\hline Test \#1 & .004582 & 4380 & $3.5 \%$ \\
\hline Test \#2 & .004534 & 4426 & $4.6 \%$ \\
\hline Test \#3 & .004506 & 4453 & $5.3 \%$ \\
\hline
\end{tabular}

An average percent difference of $4.5 \%$ is obtained from the calibration test, and such a small difference gives us the confidence to proceed with the torsion testing of the FRP composite beam samples. 


\subsubsection{Finite Element Modeling of Aluminum Bar}

A finite element analysis is used to provide additional verification of the experimental and analytical results for the calibration of the testing machine. Moreover, the finite element modeling of the aluminum bar will also serve as a first step to develop a finite element model for the torsion of the FRP honeycomb samples.

The 6061-T6 aluminum bar is modeled with ABAQUS, using FEMAP as a pre- and postprocessor. The mesh consists of 8-node shell elements, and each element is 3" x 3", with an aspect ratio of 1 . The cross-sectional data is input in the preprocessor, and the relevant geometric properties are calculated automatically. The material data used for linear elastic analysis is the same as for the explicit solution.

It is assumed that during the experimental testing, the same magnitude of torque is applied to each grip of the machine. Theoretically, this provides a location of no rotation, or point of fixity, at the midspan section of the sample, given that the sample tested has symmetric material and geometric properties about the midspan. Thus, a model with a length of 36 "is used, corresponding to the gauge length of the experimental tests (see Figure 5.2).

The boundary conditions used in the finite element analysis are fixed at one end of the bar and free at the opposite end, where the torque is apllied by means of a moment 
couple, consisting of two equal but opposite concentrated loads placed on the two edges of the model (Figure 5.4). The total applied torque was 1 kip-in.

From the finite element analysis, the shear strains and the nodal displacements are the quantities of interest and are given in Table 5.3.

Table 5.3 Finite Element Results for Aluminum Bar

\begin{tabular}{|c|c|c|}
\hline $\begin{array}{c}\text { Distance from Fixed } \\
\text { Support, inches }\end{array}$ & $\begin{array}{c}\text { Maximum Shear Strain, } \\
\text { microstrain/kip-in }\end{array}$ & $\begin{array}{c}\text { Angle of Rotation, } \\
\text { Radians/kip-in }\end{array}$ \\
\hline $24 "$ & 118 & 0.00294 \\
\hline $36 "$ & 121 & 0.00442 \\
\hline
\end{tabular}

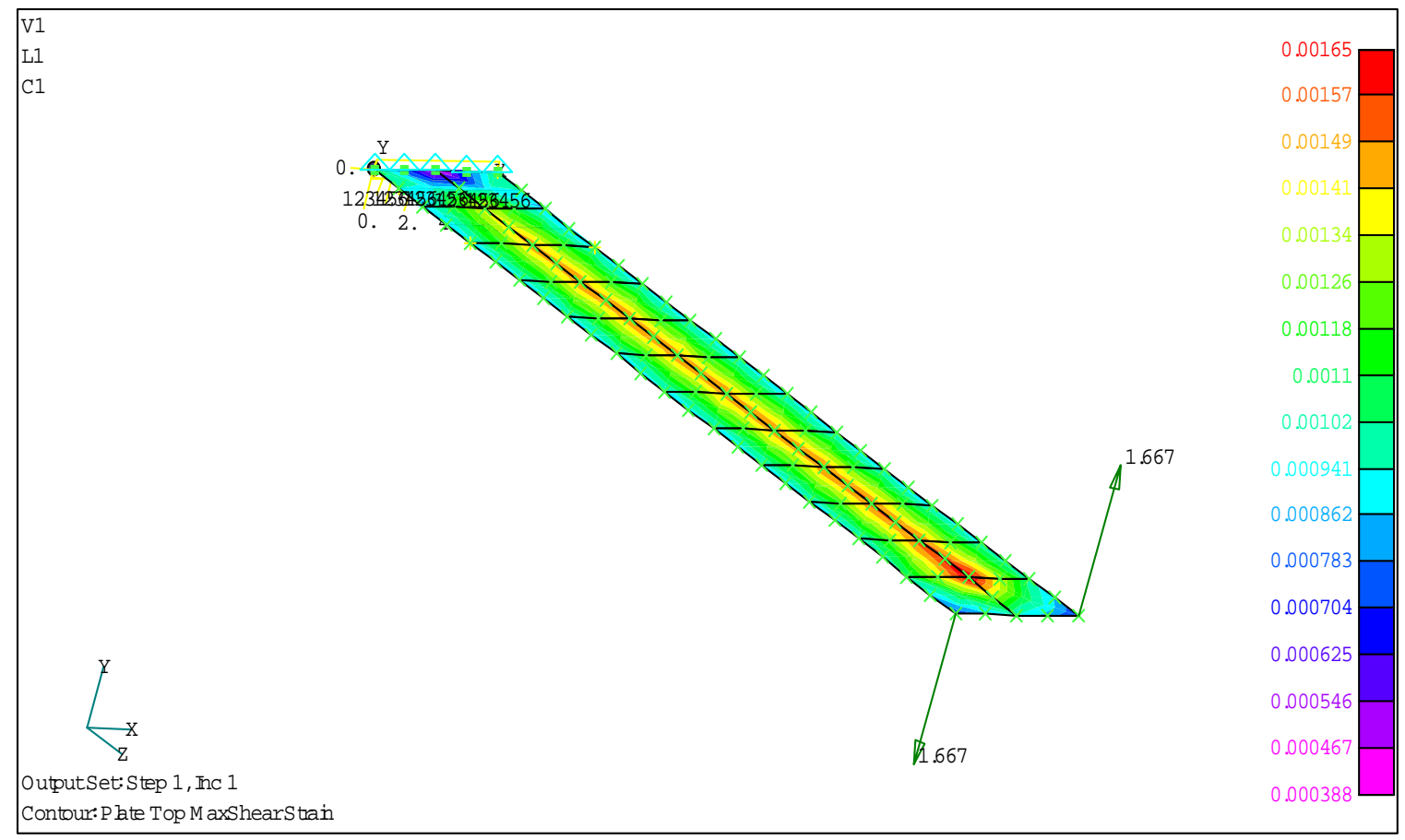

Figure 5.4 Finite Element Modeling of Aluminum Bar Showing Shear Strain Distribution 


\subsubsection{Discussion of Calibration Test}

Three different analyses are presented in the previous section. The results for angle of rotation at the gauge length of $\mathrm{L}=36$ " for all three analyses are given in Table 5.4.

Table 5.4 Summary of Angle of Rotation for the Aluminum Bar

\begin{tabular}{|c|c|c|c|}
\hline & $\begin{array}{c}\text { Analytical } \\
\text { Prediction }\end{array}$ & $\begin{array}{c}\text { Finite Element } \\
\text { Prediction }\end{array}$ & $\begin{array}{c}\text { Experimental } \\
\text { Results, Average }\end{array}$ \\
\hline $\begin{array}{c}\text { Angle of Rotation at } \\
\text { Gauge Length } \\
\text { L=36", } \\
\text { radians/kip-in }\end{array}$ & 0.00475 & 0.00442 & 0.00454 \\
\hline
\end{tabular}

From Table 5.4, the percent difference between the analytical prediction and the average experimental result is $7.5 \%$, while the difference between the finite element analysis and the average experimental result is $2.7 \%$. The small percent differences provide confidence to proceed with the FE modeling, as well as experimental testing (see Table 5.2), of the FRP honeycomb samples. 


\subsection{Experimental Evaluation of FRP Honeycomb Sandwich Beams in Torsion}

Through bending tests described in Chapter 4, bending behaviors in the longitudinal and transverse directions were characterized and successfully correlated with analytical and finite element analyses. The bending tests are also useful to indirectly evaluate the outof-plane shear stiffnesses in the longitudinal and transverse directions. However, a better test is required to study the shear behavior of the FRP honeycomb samples. Thus, in this chapter a torsion experimental method and finite element analysis are used to better characterize the in-plane and out-of-plane shear stiffnesses of the FRP honeycomb panel. The torsion tests are performed using the calibrated machine outlined in Section 5.2.2 and pictured in Figure 5.1. The samples that are used are outlined in Section 3.2.2, which include 4 longitudinal samples and 4 transverse samples with widths of 8 " and 12”. Two samples per each type were tested to provide more general data.

\subsubsection{Instrumentation and Setup}

The instrumentation of the test samples consists of two strain gauges $\left( \pm 45^{\circ}\right.$ to record shear strain) and four LVDT's. These sensors are positioned at the same locations on each beam specimen, regardless of sample type. This scheme allows for uniform testing results of all specimens.

The strain gauges used are intended for shear strain measurements. Manufactured by Micro-Measurements Group, each gauge contains two separated grids, which are oriented 
at $\pm 45^{\circ}$ with respect to the longitudinal axis of the sample. Each grid, or strain gauge leg, is independently connected to provide its own strain readings. The gauges are placed symmetrically, each at two feet away from the midspan towards the end-support and along the centerline of the beam width. In order to measure the angle of rotation of the sample, four LVDT's are used. Two LVDT's are placed on each side at three feet away from the midspan in the direction of the end-support. The placement of the LVDT's as well as the location of the strain gauges are shown in Figure 5.5.

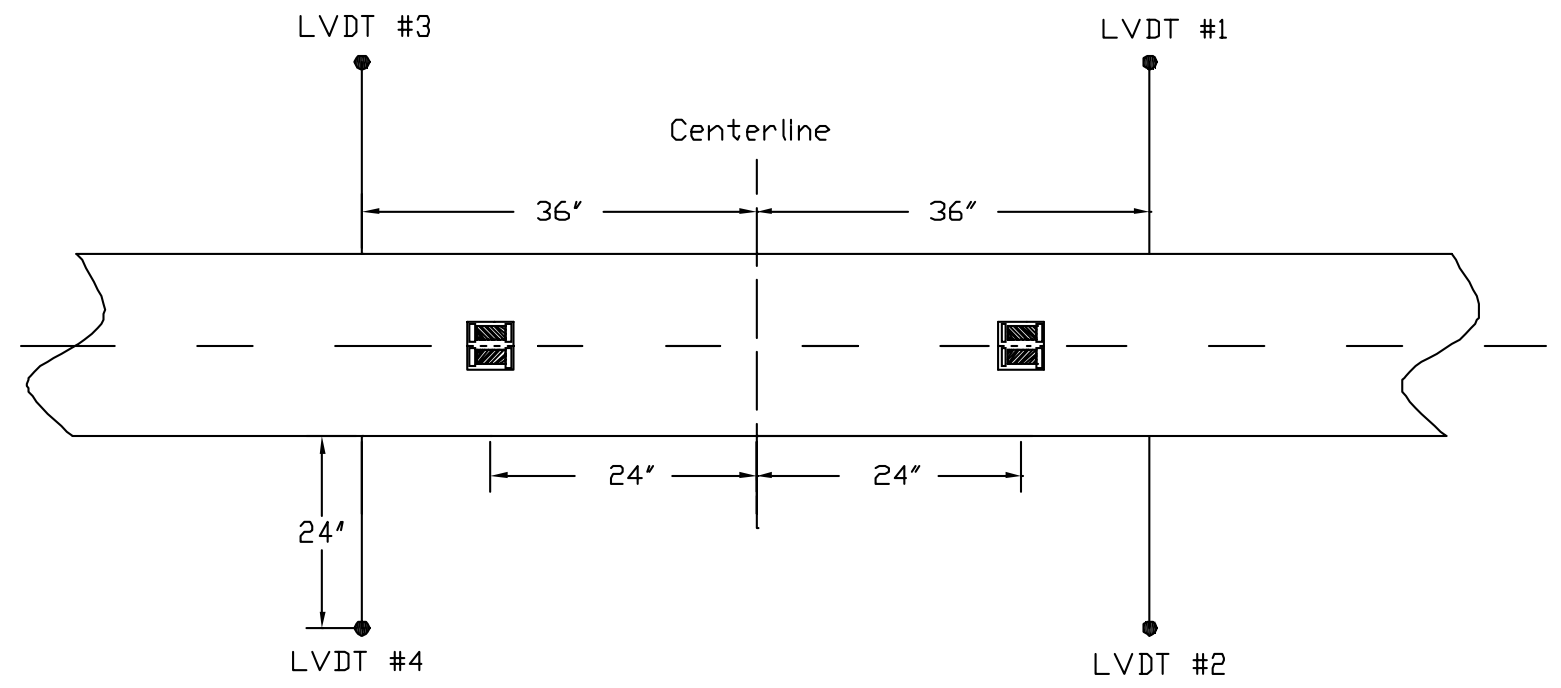

\section{Figure 5.5 Location of LVDT's and Strain Gauges}

Each LVDT is attached to the sample using an 8-inch steel channel section over the edge of the samples, with a 24 -inch steel rod welded normal to the outside face of the channel section. The channel slides over the edge of the FRP sample, and is held in place by setscrews drilled and tapped into the flanges of the channel. The channel section is set in such a way that the angle of rotation with respect to the mid-height of the beam is 
measured. This scheme is used to permit warping deformations while minimizing local effects. A picture of a transverse sample ready for testing in the machine is shown in Figure 5.6, and the details of the testing setup are shown in Figure 5.7.



Figure 5.6 Transverse Sample Prepared for Experimental Torsion Test 


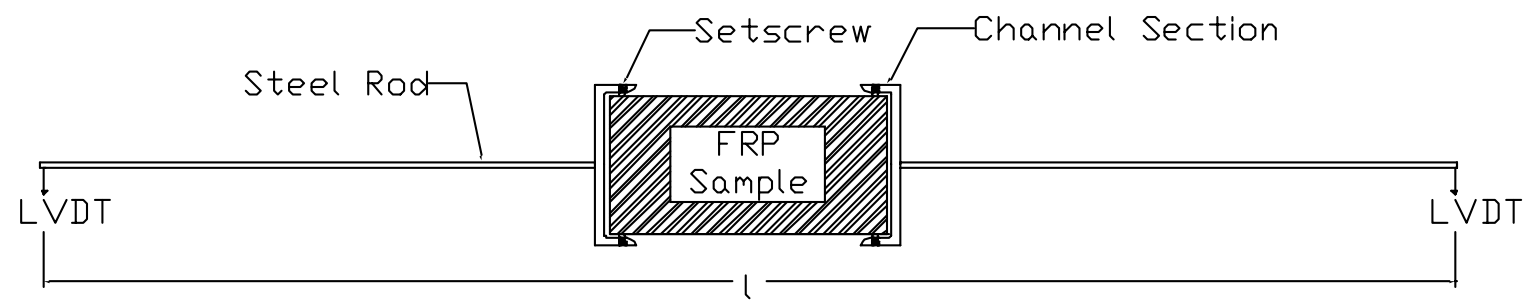

Fig 5.7 (a) Initial Cross-section of FRP Beam Sample



Fig 5.7 (b) Rotated Cross-section of FRP Beam Sample

Figure 5.7 Cross-sectional View of FRP Beam Sample in Torsion 


\subsubsection{Experimental Procedure}

Testing of the beam samples in torsion took place in two separate phases. The longitudinal samples were tested first because they could fit in the machine using the original grips. The transverse samples were tested second because specially made endclamps (shown in Figure 5.8) were needed to make up for the beams only being nine feet in length. However, for both sample orientations, the procedure is the same. The distance from the center of the beam sample to the LVDT location is determined by the half-width of the beam sample plus the 24" long steel rod (Figure 5.5).

Each sample was loaded and unloaded five times, and the first three tests were used to adjust the testing apparatus. For example, small adjustments in the placement of the load cell along the loading beam could cause a significant change in the location of the point of fixity along the sample. The goal is to try to place this point as close to the midspan of the sample as possible in order to induce nearly the same angle of rotation on each end of the sample. After checking the consistency of the results, each sample was tested twice and the data was collected for further analysis. 


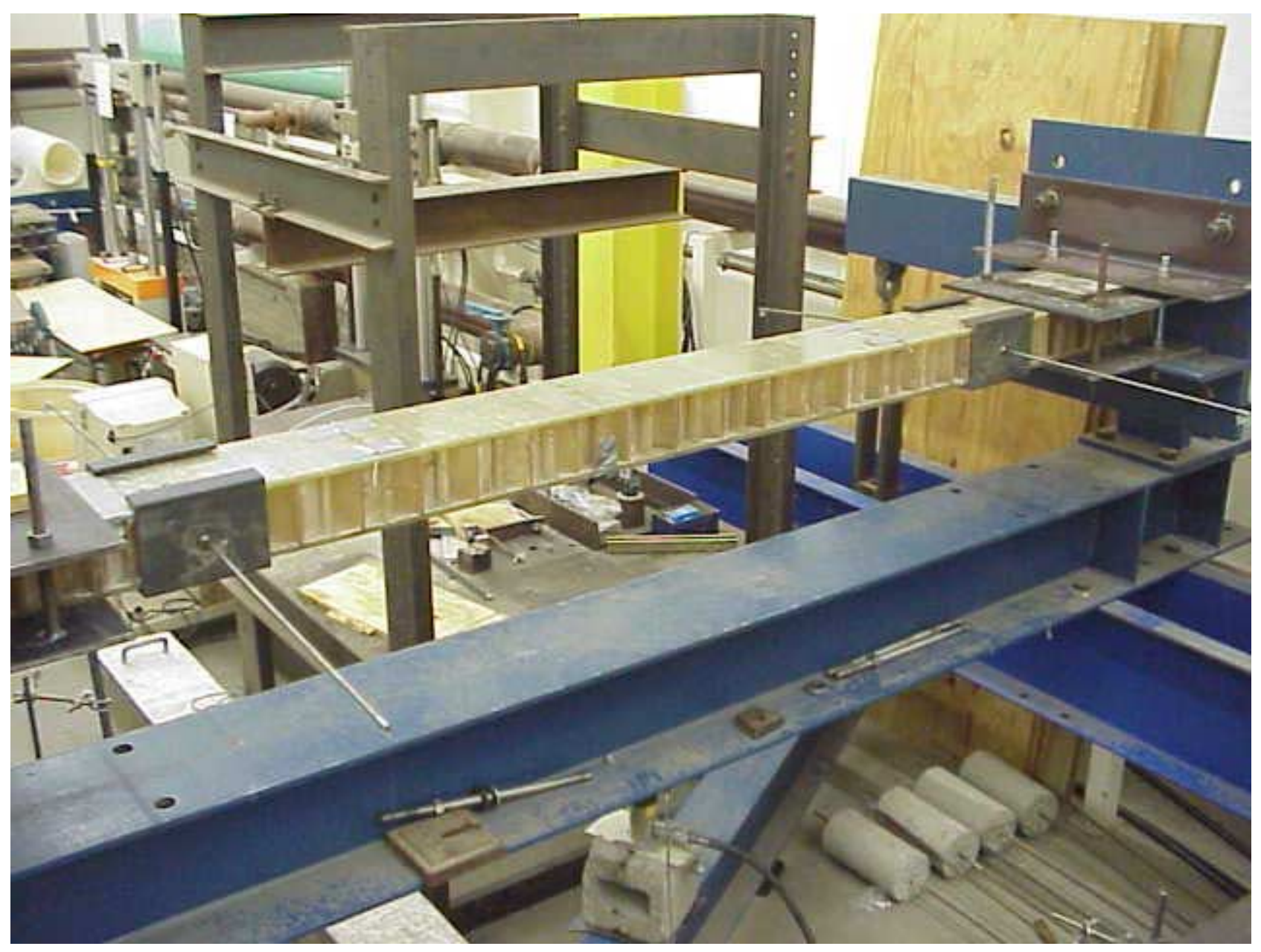

Figure 5.8 End-Clamps for Torsion Testing of Transverse Samples 
The LVDT's are used to measure the angle of rotation by recording the displacements at the ends of the steel rods. By using trigonometry and small angle assumption, the angle of rotation can be derived by a similar method as that used for the aluminum bar. The difference being that the total distance between two LVDT's at each location (distance $l$ in Figure 5.7) is measured directly and used in the calculations. The following equation is used to calculate the angle of rotation at one end of the sample (Figure 5.7):

$$
\theta=\frac{\left|\delta_{1}\right|+\left|\delta_{2}\right|}{l}
$$

where, $\quad 1=$ displacements at one end of the steel rod (inches); $\quad 2=$ displacement at the opposite end of steel rod (inches); $l=$ length between two LVDT's (inches); $\quad=$ angle of rotation (radians). The load is applied using a 2-kip load cell, and the torque applied to the sample is calculated using the same method as described in Section 5.2.3.

As stated before, each strain gauge has two grids oriented at 90 to each other. Each grid records an independent strain reading in its respective direction. The strain readings are then combined to obtain the maximum shear strain. The data acquisition system uses the individual strain readings to provide the shear strain at each gauge location. Using the Mohr's circle diagram shown in Figure 5.9, the process of obtaining the maximum shear strain can be explained. One grid of the strain gauge gives a positive strain reading, while the other grid gives a negative reading. The sum of the absolute value of the two strain gauge readings gives the maximum in-plane shear strain at the location of the gauge. 




Figure 5.9 Mohr's Circle Showing the Maximum Shear Strain

Once the loads, deflections and strains are recorded by the acquisition system, the data is then reduced into an Excel $^{\odot}$ spreadsheet. The torque, angles of rotations, and shear strains are then calculated using the methods described earlier.

\subsubsection{Results}

The applied torque versus the angles of rotation at each end of the specimen, as well as the average angle of rotation is shown for a typical sample in Figure 5.10. The torque is also plotted against the shear strain values recorded at the two symmetric locations from the specimen mid-length. A typical plot of torque vs. shear strain is shown in Figure 5.11 . 


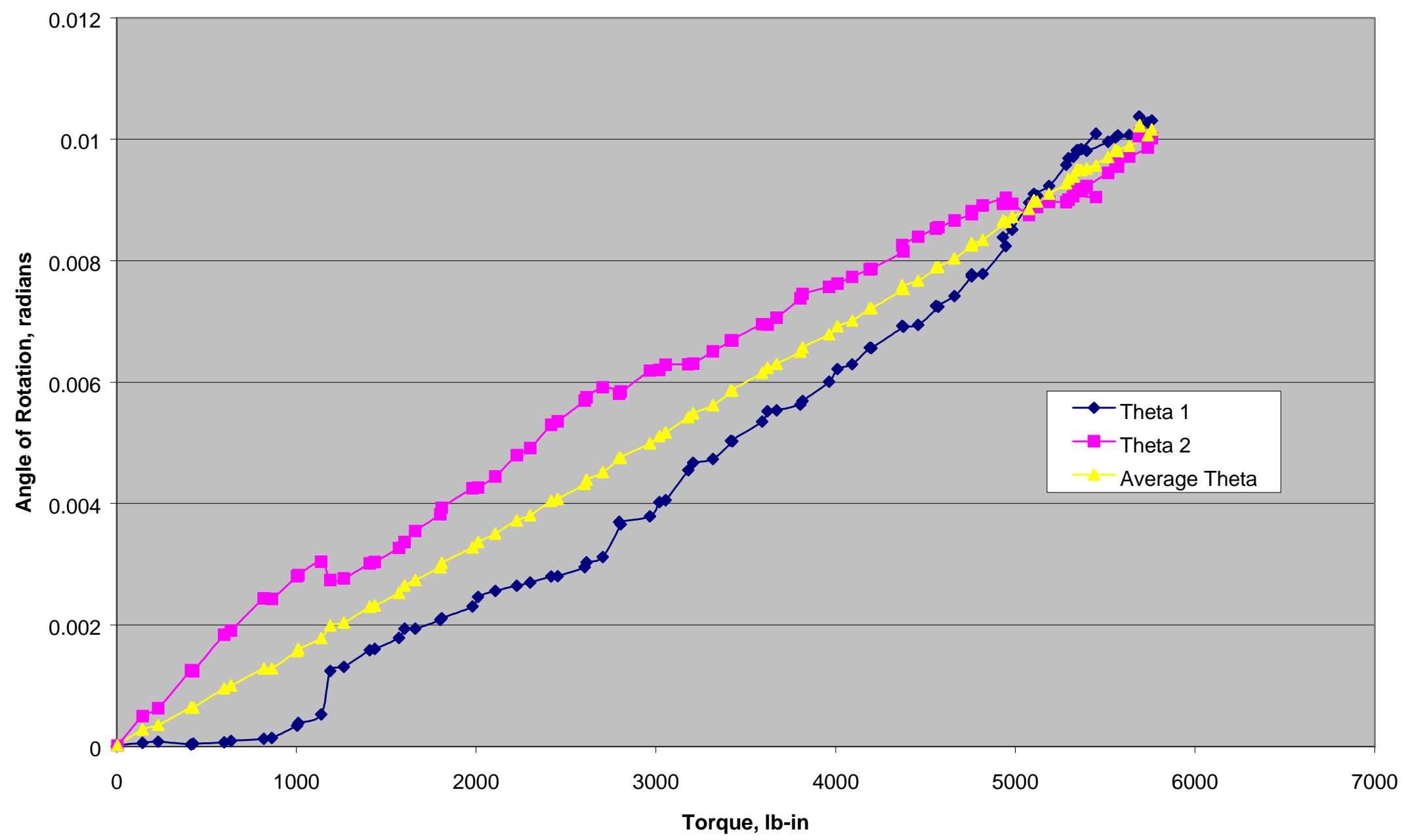

Figure 5.10 Typical Plot of Torque vs. Angle of Rotation (8” Longitudinal Sample \#1) 


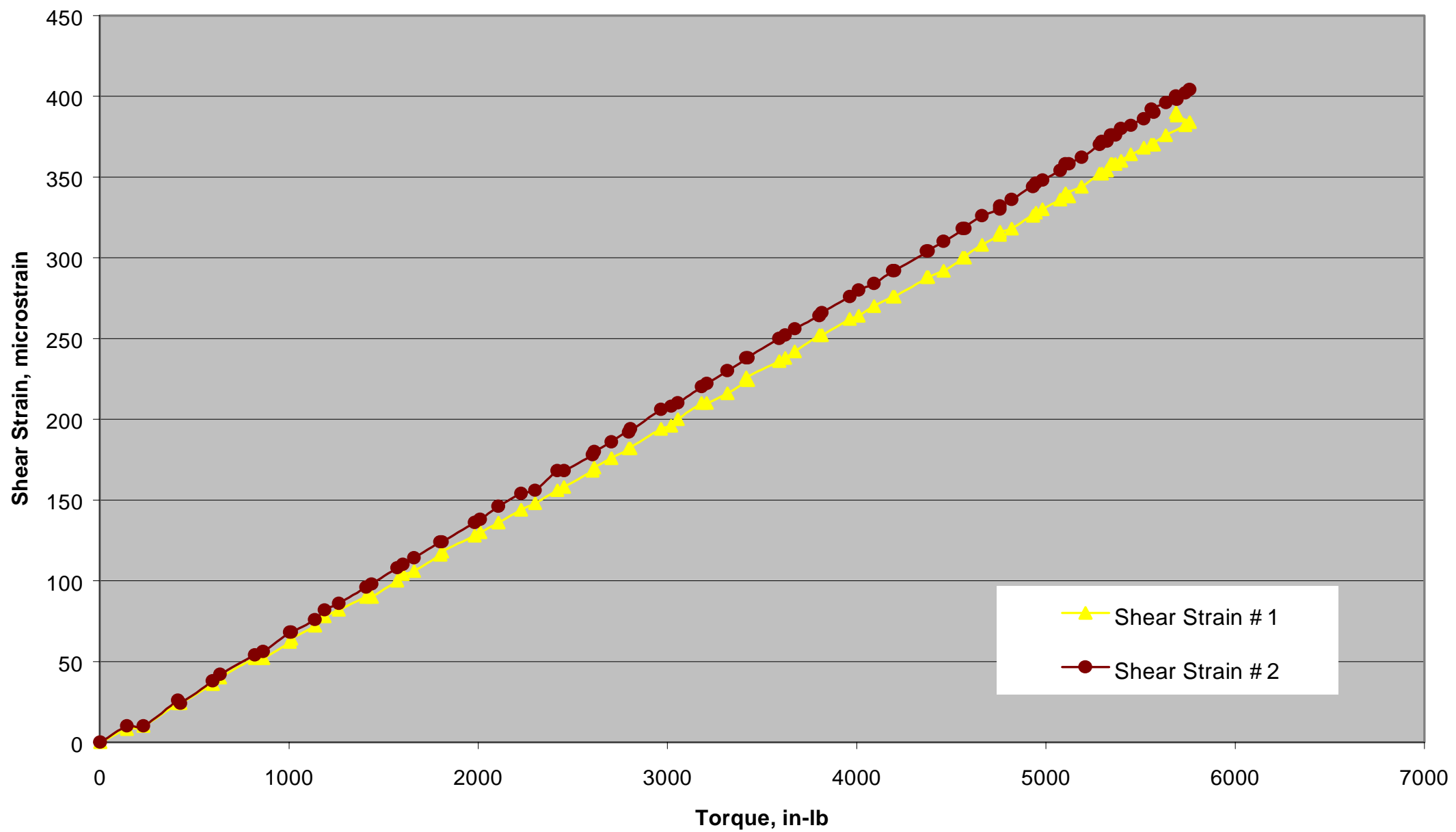

Figure 5.11 Typical Plot of Torque vs. Shear Strain (8” Longitudinal Sample \#1) 
A summary of the experimental data is shown in Table 5.5. The table provides the data for the longitudinal and transverse samples, with eight- and twelve-inch widths. A total of two samples were tested for each core material orientation and sample width. Two repetitions for each sample were recorded and reduced, and the corresponding data is averaged to give the values as shown in Table 5.5. The strain data is given in microstrains per kip-inch, while the angle of rotation data is given in radians per kip-inch.

\section{Table 5.5 Experimental Results for Torsion Tests}

\begin{tabular}{|c|c|c|c|c|c|c|}
\hline $\begin{array}{c}\text { Core Orientation } \\
\text { and Width }\end{array}$ & Sample \# & \multicolumn{2}{|c|}{ Shear Strain } & \multicolumn{3}{|c|}{ Angle of Rotation } \\
\cline { 2 - 7 } & & \multicolumn{2}{|c|}{ microstrain/kip-in } & \multicolumn{3}{|c|}{ radian/kip-in } \\
\cline { 2 - 7 } & $\# 1$ & $\# 2$ & 1 & 2 & Avg \\
\hline $\begin{array}{c}\text { Longitudinal } \\
\text { 12" width }\end{array}$ & 2 & 71 & 50 & 0.0014 & 0.00124 & 0.00132 \\
\cline { 2 - 7 } & 2 & 66 & 70 & 0.00165 & 0.00183 & 0.00174 \\
\hline $\begin{array}{c}\text { Longitudinal } \\
\text { 8" width }\end{array}$ & 1 & 81 & 71 & 0.00137 & 0.00105 & 0.00121 \\
\cline { 2 - 7 } & 2 & 55 & 58 & 0.00043 & 0.00152 & 0.00098 \\
\hline $\begin{array}{c}\text { Transverse } \\
\text { 12" width }\end{array}$ & 2 & 65 & 61 & 0.00103 & 0.00119 & 0.00111 \\
\hline $\begin{array}{c}\text { Transverse } \\
\text { 8" width }\end{array}$ & 1 & 83 & 99 & 0.0033 & 0.00282 & 0.00306 \\
\cline { 2 - 7 } & 2 & 100 & 89 & 0.00324 & 0.00295 & 0.0031 \\
\hline
\end{tabular}

While the torque versus angle of rotation plot in Figure 5.10 shows $\quad 1$ and $\quad 2$ relatively close to each other, this is sometimes not the case as can be seen in Table 5.5. In a few instances, the two angles of rotation can be as much as $350 \%$ difference (12" longitudinal sample \# 2 and 12" transverse sample \#1). As stated in the procedure, the sample is loaded and unloaded three times before the actual data collection starts. The purpose of this is to achieve the same angle of rotation on both sides of the beam by adjusting the torsion machine accordingly. However, symmetric readings are difficult to achieve due 
to the large amount of inertia the machine possesses. Thus, if it is not possible to achieve symmetric results during the unrecorded tests, the average angle of rotation is calculated, and if a good correlation is found, then the testing is completed. This is deemed sufficient since the total angle of rotation across the 6' span of the sample is being measured, and the average value is taken as a convenient experimental measurement.

\subsection{Finite Element Modeling of FRP Honeycomb Sandwich Beams in Torsion}

A finite element evaluation of the different beam samples in torsion is performed for comparison with the experimental testing. The description of the actual geometry FE model is given in Section 5.4.1, while the description of the equivalent plate FE model is given in Section 5.4.2. The response predictions for both analyses are discussed in Section 5.4.3.

\subsubsection{Actual Geometry Finite Element Model}

The model used in the formulation of the finite element torsion analysis consists of assemblies of the cell unit described in Section 3.3.1. The cell, shown in Figure 3.3, is the same one used in the FE bending analysis in Section 4.3.1, as well as the FE panel analysis in Section 6.3. Again, once this cell is defined, the sample can be generated for any specified width, length, and core orientation. For the torsion model, a three-foot long sample is generated, because this is one half of the gauge length used in the experimental testing. Thus, a total of four FE models, two transverse and two longitudinal is used, and 
two widths of eight-inch and twelve-inch for each sample orientation are defined. The analysis process used is similar to that for the aluminum sample described in Section 5.2.4.

Once the model is completed, the load and boundary conditions are specified. In the torsion model, a fixed-free boundary condition is utilized. All of the nodes at one end of the sample are completely fixed, while only the center node at the opposite free-end is constrained against translations along the geometric cross-sectional axis, but not rotations. This is to allow rotations and axial deformations of the cross-section, while preventing out-of-plane bending.

The torque is applied by defining a uniform line traction load on each side of the free edge of the sample. The nodes on the edges of the top and bottom plates are joined by continuous lines, over which the traction loads are applied. The uniform loads are discretized to the nodes and specified as concentrated loads. The loads on the top and bottom edges are equal in magnitude but opposite in direction, defining a couple, or torque at the free end of the beam. The amount of traction load applied is determined by using the following equation:

$p=\frac{1}{w \times h}$

where; $\mathrm{p}=$ uniform load per unit length, in kips per inch; $w=$ sample width, in inches; and $\mathrm{h}=$ distance between top and bottom nodes at the mid-surface of the face sheets, which is 4.554 inches. The applied load is determined by the width of the sample, but the 
resulting applied torque is always 1 kip-in. A finite element model of the 12-inch longitudinal sample is given in Figure 5.12.

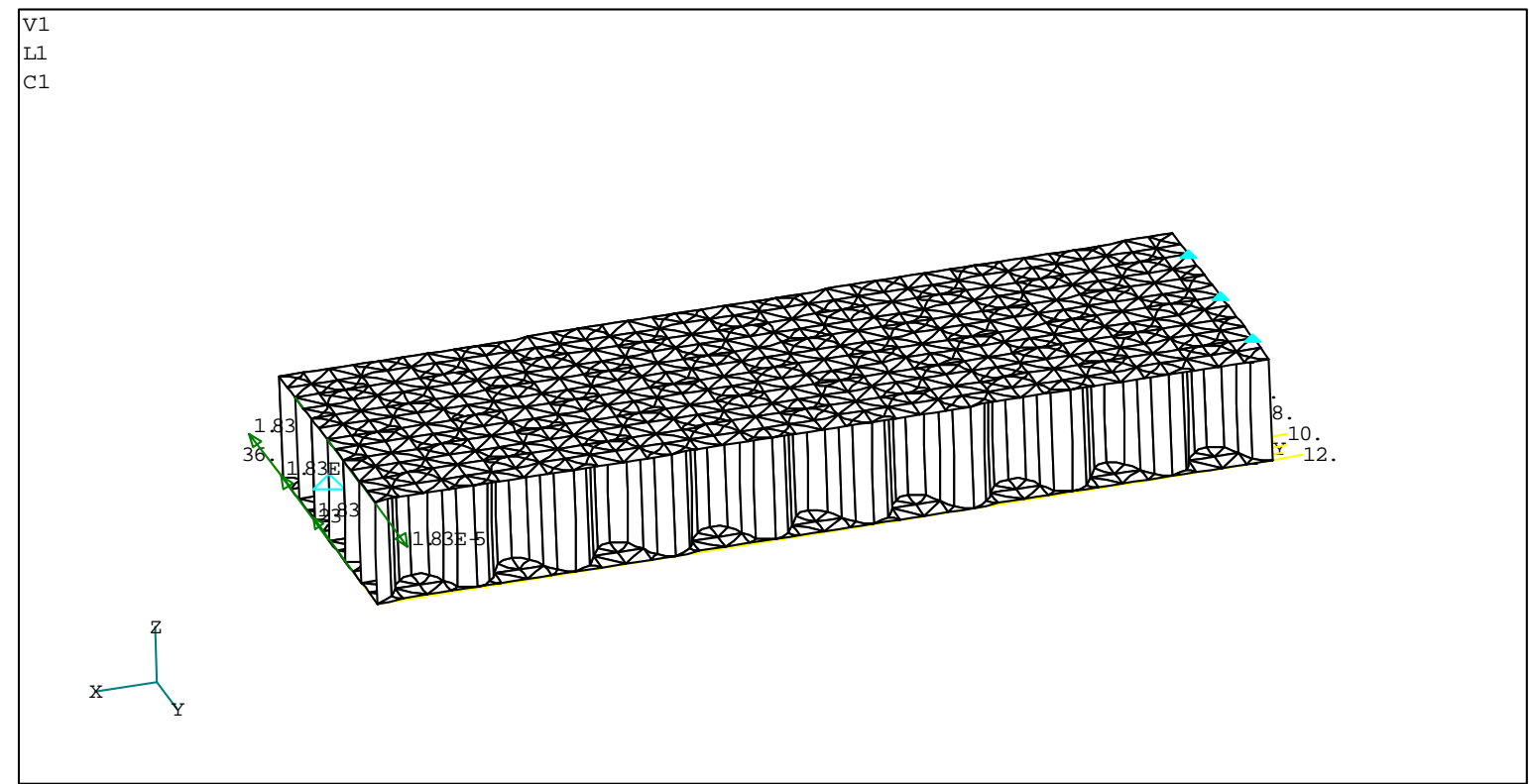

Figure 5.12 Finite Element Model for 12” Longitudinal Sample

\subsubsection{Equivalent Plate Finite Element Model}

The equivalent plate finite element model consists of 2"x 2" elements described in Section 3.3.3. The model is assembled exactly like the beam models used for modeling of bending behavior. The basic element can be copied to define any width and core orientation. For the torsion FE analyses, the length of the models is 36 ".

The boundary condition used in the equivalent plate model is fixed-free, with all the nodes at on edge of the model being fully constrained, and the center node at the other edge of the model constrained against axial translation. This is similar to the actual 
geometry finite element model. The torque is applied by a couple through forces placed on the free edge of the beam. The equal but opposite concentrated loads are applied on opposite corners of the free edge, to produce a total torque of one kip-in.

\subsubsection{Results}

The experimental data was collected for the angles of rotation at three feet from the midspan and for shear strains at two feet from the midspan, along the specimen centerline. Thus the finite element model is setup to collect the same data. Once the analysis is completed with ABAQUS, the results are imported back into FEMAP and analyzed. For the equivalent plate models, the angles of rotation and shear strain values can be obtained directly at the locations of interest. However, collecting data from the actual geometry model is more difficult and requires a defined procedure.

Examining the elements at the locations of interest can provide the shear strain data for the actual geometry model. The data for angle of twist is found using the geometry of the deformed shape. Because of the induced torque, warping will cause some local effects on the nodes. To minimize this effect, the nodes at the center of the width of the sample are used to find the angle of rotation. The lateral displacement of the center nodes on the top and bottom plates can be used to define a right triangle, and because of the small angle theory, the sum of their displacements can be divided by their vertical distance to give the angle of twist. Figure 5.13 shows a sketch of the rotation of the cross-section, which is used to calculate the angle of twist as, 


$$
\theta=\left(\delta_{1}\left|+\delta_{2}\right|\right) / h
$$

where, $\quad=$ angle of twist (radians); $1=$ lateral displacement of top-center node (in); ${ }_{2}=$ lateral displacement of bottom-center node (in); $\mathrm{h}=$ height of sample (4.554 in).

The total translation contour of a typical actual geometry sample is given in Figure 5.14, and Table 5.6 summarizes the values of shear strains on the top face plate at two feet away from the fixed support, as well as angles of rotation at the free end for all models.

The predictions of the equivalent plate models compared to the actual geometry models show a good correlation with respect to the angles of rotation. The shear strain comparisons are also good for the transverse samples. However, the shear strain comparisons for the longitudinal samples are not good, with a maximum discrepancy of $60 \%$ for the 8 " sample. The response of the FE models subjected to torsion is expected to be sensitive to the in-plane and out-of-plane shear strain evaluations, due primarily to the degree of accuracy of the shear moduli data used in the analysis The experimental results are used to evaluate both FE models by comparing rotations and strains.

Table 5.6 Results for Finite Element Models in Torsion

\begin{tabular}{|c|c|c|c|c|c|}
\hline \multirow{2}{*}{$\begin{array}{c}\text { Core } \\
\text { Orientation }\end{array}$} & \multirow{2}{*}{$\begin{array}{c}\text { Sample } \\
\text { Width }\end{array}$} & \multicolumn{2}{|c|}{$\begin{array}{c}\text { Angle of Rotation } \\
\text { rad/kip-in }\end{array}$} & \multicolumn{2}{c|}{$\begin{array}{c}\text { Shear Strain } \\
\text { microstrains/kip-in }\end{array}$} \\
\cline { 3 - 6 } & & Actual & Eq uiv. & Actual & Eq uiv. \\
\hline Longitudinal & 12 -inch & 0.0007 & 0.0006 & 44 & 68 \\
\cline { 2 - 6 } & 8 -inch & 0.0016 & 0.0013 & 66 & 105 \\
\hline Transverse & 12 -inch & 0.0009 & 0.0010 & 58 & 67 \\
\cline { 2 - 6 } & 8-inch & 0.0026 & 0.0028 & 96 & 103 \\
\hline
\end{tabular}






Figure 5.13 Rotated Cross-section of FRP Beam Sample in Torsion
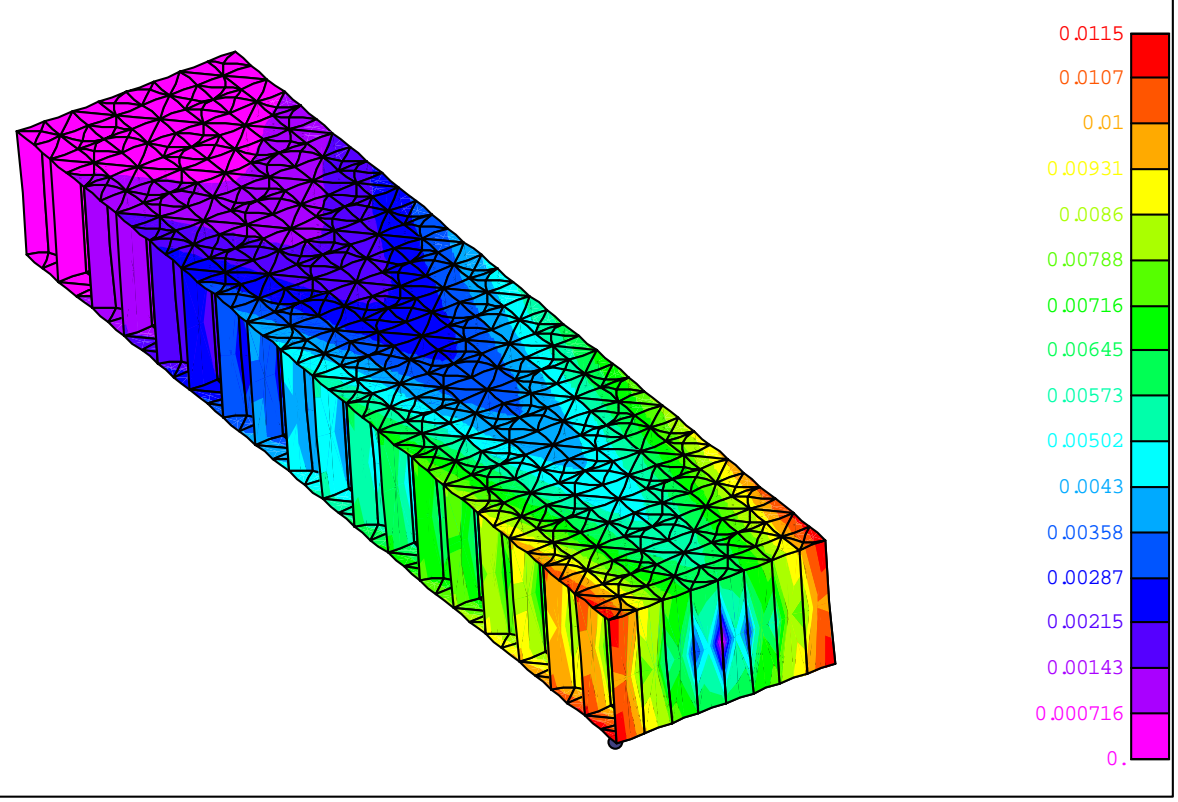

Figure 5.14 Total Translation Contour for 8" Transverse Sample in Torsion 


\subsection{Comparison of FE and Experimental Results}

The experimental and finite element data are compared to establish correlations of results. The comparisons of the angles of rotation between experimental and finite element analysis values are shown in Table 5.7, while the comparisons of shear strains are given in Table 5.8. The values presented are all for a load of one kip-inch.

Table 5.7 Comparison of FE and Experimental Values of Angles of Rotation

\begin{tabular}{|c|c|c|c|c|c|c|c|}
\hline \multirow[t]{2}{*}{ Core Orientation } & \multirow[t]{2}{*}{ Width } & \multirow[t]{2}{*}{ Sample } & \multicolumn{3}{|c|}{ Angle of Rotation, radians/kip-in } & \multirow{2}{*}{$\begin{array}{l}\text { \% Difference } \\
\text { from FE } \\
\text { Actual }\end{array}$} & \multirow{2}{*}{$\begin{array}{l}\text { \% Difference } \\
\text { from FE } \\
\text { Eq uiv. }\end{array}$} \\
\hline & & & FE Actual & FE Equiv. & Experimental & & \\
\hline \multirow[t]{4}{*}{ Longitudinal } & \multirow[t]{2}{*}{$12 "$} & $\overline{\# 1}$ & 0.0007 & 0.0006 & 0.00132 & 88.6 & 120.0 \\
\hline & & \#2 & 0.0007 & 0.0006 & 0.001 & 42.9 & 66.7 \\
\hline & \multirow[t]{2}{*}{$8 "$} & \#1 & 0.0016 & 0.0013 & 0.00174 & 8.7 & 33.8 \\
\hline & & \#2 & 0.0016 & 0.0013 & 0.00121 & 32.2 & 7.4 \\
\hline \multirow[t]{4}{*}{ Transverse } & \multirow[t]{2}{*}{$12 "$} & $\# 1$ & 0.0009 & 0.001 & 0.00098 & 8.9 & 2.0 \\
\hline & & \#2 & 0.0009 & 0.001 & 0.00111 & 23.3 & 11.0 \\
\hline & \multirow[t]{2}{*}{$8 "$} & \#1 & 0.0026 & 0.0028 & 0.00306 & 17.7 & 9.3 \\
\hline & & $\# 2$ & 0.0026 & 0.0028 & 0.0031 & 19.2 & 10.7 \\
\hline
\end{tabular}

Table 5.8 Comparison of FE and Experimental Values of Shear Strains

\begin{tabular}{|c|c|c|c|c|c|c|c|c|c|c|}
\hline \multirow[t]{3}{*}{ Core Orientation } & \multirow[t]{3}{*}{ Width } & \multirow[t]{3}{*}{ Sample } & \multicolumn{4}{|c|}{ Shear Strain, microstrain } & \multirow{2}{*}{\multicolumn{2}{|c|}{$\begin{array}{l}\text { \% Difference } \\
\text { from FE Actual }\end{array}$}} & \multirow{2}{*}{\multicolumn{2}{|c|}{$\begin{array}{l}\text { \% Difference } \\
\text { from FE Eq uiv. }\end{array}$}} \\
\hline & & & \multicolumn{2}{|c|}{ FE Model } & \multicolumn{2}{|c|}{ Experimental } & & & & \\
\hline & & & Actual & Equiv. & $\# 1$ & $\# 2$ & $\# 1$ & $\# 2$ & $\# 1$ & $\# 2$ \\
\hline \multirow[t]{4}{*}{ Longitudinal } & \multirow[t]{2}{*}{$12 "$} & $\# 1$ & 44 & 68 & 71 & 50 & 61.4 & 13.6 & 4.4 & 36.0 \\
\hline & & $\# 2$ & 44 & 68 & 47 & 50 & 6.8 & 13.6 & 44.7 & 36.0 \\
\hline & \multirow[t]{2}{*}{$8 "$} & $\# 1$ & 66 & 105 & 66 & 70 & 0.0 & 6.1 & 59.1 & 50.0 \\
\hline & & $\# 2$ & 66 & 105 & 81 & 71 & 22.7 & 7.6 & 29.6 & 47.9 \\
\hline \multirow[t]{4}{*}{ Transverse } & \multirow[t]{2}{*}{$12 "$} & $\# 1$ & 58 & 67 & 55 & 58 & 5.5 & 0.0 & 21.8 & 15.5 \\
\hline & & $\# 2$ & 58 & 67 & 65 & 61 & 12.1 & 5.2 & 3.1 & 9.8 \\
\hline & \multirow[t]{2}{*}{ 8" } & $\# 1$ & 96 & 103 & 83 & 99 & 15.7 & 3.1 & 24.1 & 4.0 \\
\hline & & $\# 2$ & 96 & 103 & 100 & 89 & 4.2 & 7.9 & 3.0 & 15.7 \\
\hline
\end{tabular}


The comparisons of the longitudinal samples reveal a large percent difference between the finite element modeling and experimental evaluation. There are several possible reasons for this discrepancy. First, it could be due to testing inaccuracies. The test procedures is difficult to implement, and slight errors could influence the results greatly. Second, the lack of consistency in the manufacturing quality of the samples could affect the testing results. A serious problem that was observed during the torsion tests was the delamination of the face-sheet from the core. This problem was particularly evident for the 12" wide longitudinal samples; thus the measured torsional responses for these samples are likely to be in error with respect to the FE results.

Another possible source of error in the analysis could be the inaccuracy of the in-plane and out-of-plane shear moduli material constants. As can be seen in Table 5.7, the actual and equivalent plate finite element models for the longitudinal 12" wide samples predict a stiffer response than experimentally achieved. While for the transverse samples there are reasonable percent differences, the discrepancies are higher for the longitudinal samples. The worst cases of high percent differences are for the 12-inch longitudinal samples, each sample showing a higher angle of twist value in relation to the $\mathrm{FE}$ predictions; these differences are due to the face-to-core delaminations, particularly for sample \#1, which exhibited the worst delamination condition.

While it is difficult to predict the shear strain values of the samples because of their complex geometry, it can be seen from Table 5.8 that the actual FE models provide better correlations to experimental values than the equivalent plate models. With the exception 
of the 12" longitudinal sample \#1 (stated before as having some degree of delamination), relatively small percent differences are found between the actual FE models and the experimental results. However, the equivalent plate FE models show high percent differences, especially for the longitudinal samples. Again, this could be due to either manufacturing irregularities, or inaccurate estimations of the shear stiffness properties.

The quality of manufacturing plays an important role in the bond between the top and/or bottom face plates and the core. This bond is critical in this specific loading condition. It was noticed that some delamination between the core and plates had occurred prior to, as well as during torsional loading. This delamination could cause the torsional stiffness to decrease. However, the finite element model assumes a perfect contact between core and face plates, and thus gives a higher stiffness.

It should also be noted that during bending, the shear effects are small. Even if some portion of the core had delaminated from the face plates, the top and bottom face plates, which act as beam flanges, are still held at the same locations away from the neutral axis, thus still effectively carrying the bending moment. In contrast, during torsional loading of the FRP sandwich beams, the dominant properties that influence torsional rigidity are the in-plane and out-of-plane shear stiffnesses which are obviously quite sensitive to delamination effects. Thus, a further study of shear effects with a closed-form solution and using better estimates of shear moduli properties should be a topic of further research. 


\section{Chapter 6}

\section{Evaluation of Panel Sample}

\subsection{Introduction}

A FRP honeycomb panel, approximately $8^{\prime} \times{ }^{\prime}$ ' $16^{\prime}$ in size, is experimentally tested in bending and analyzed using the finite element method. The experimental investigation is presented in Section 6.2, and a description of the finite element analysis and results is presented in Section 6.3. The experimental and FE results are compared in Section 6.4.

\subsection{Experimental Evaluation of the Panel}

The test panel is subjected to static concentrated loads and strains and deflections are recorded. The following sections discusses the instrumentation of the panel, test procedures, and results for concentric and eccentric loading conditions.

\subsubsection{Instrumentation and Testing Setup}

The testing setup corresponds to bending of a simply-supported plate, with a pin-roller boundary condition, as for the bending tests of the beam samples. The supports for the panel are two large concrete blocks with steel plates resting on top. For each support, a steel cylinder rests on top of the plate. To achieve the pin condition, one of the cylinders 
has a steel plate welded to it. The other roller has the plate just resting atop, allowing for axial displacement and simulating the roller condition. The deck is placed over the supports, which extend transversely across the width. Loads are applied at the midspan of the deck and also at two feet on each side from the midspan, as shown in Figure 6.2.

The displacements are measured using LVDT's at 15 locations on the bottom face of the panel. Figure 6.1 (a) shows the location of each LVDT, which is numbered for reference. For the case of midspan loading condition, readings are taken only along the midspan and also mid-width of the panel, which corresponds with LVDT \#3, \#13 and \#6 through \#10.

The panel is instrumented using 18 strain gauges, nine of which are oriented longitudinally and the other nine oriented transversely with respect to the deck. Figure 6.1 (b) shows the location and orientation of the strain gauges. A longitudinal and transverse gauge is bonded at each location. The gauges are numbered for reference, and labeled either $\mathrm{L}$ for longitudinal or $\mathrm{T}$ for transverse. For the midspan loading condition, only the gauges along the midspan are used, which are gauges\# 4 through 6 in both longitudinally and transverse directions.

The load is recorded using a 10-kip load cell and is applied with a hydraulic jack. The applied load is transferred through a swivel onto a steel loading plate placed at a specified location. The load plate is two inches thick, with an area of 24"x 9.5". This specific size is chosen to approximately simulate a wheel load of a dual-wheel truck. The 24" 
direction of the plate is placed in the longitudinal direction of the deck. The basic load setup is shown in Figure 6.3.

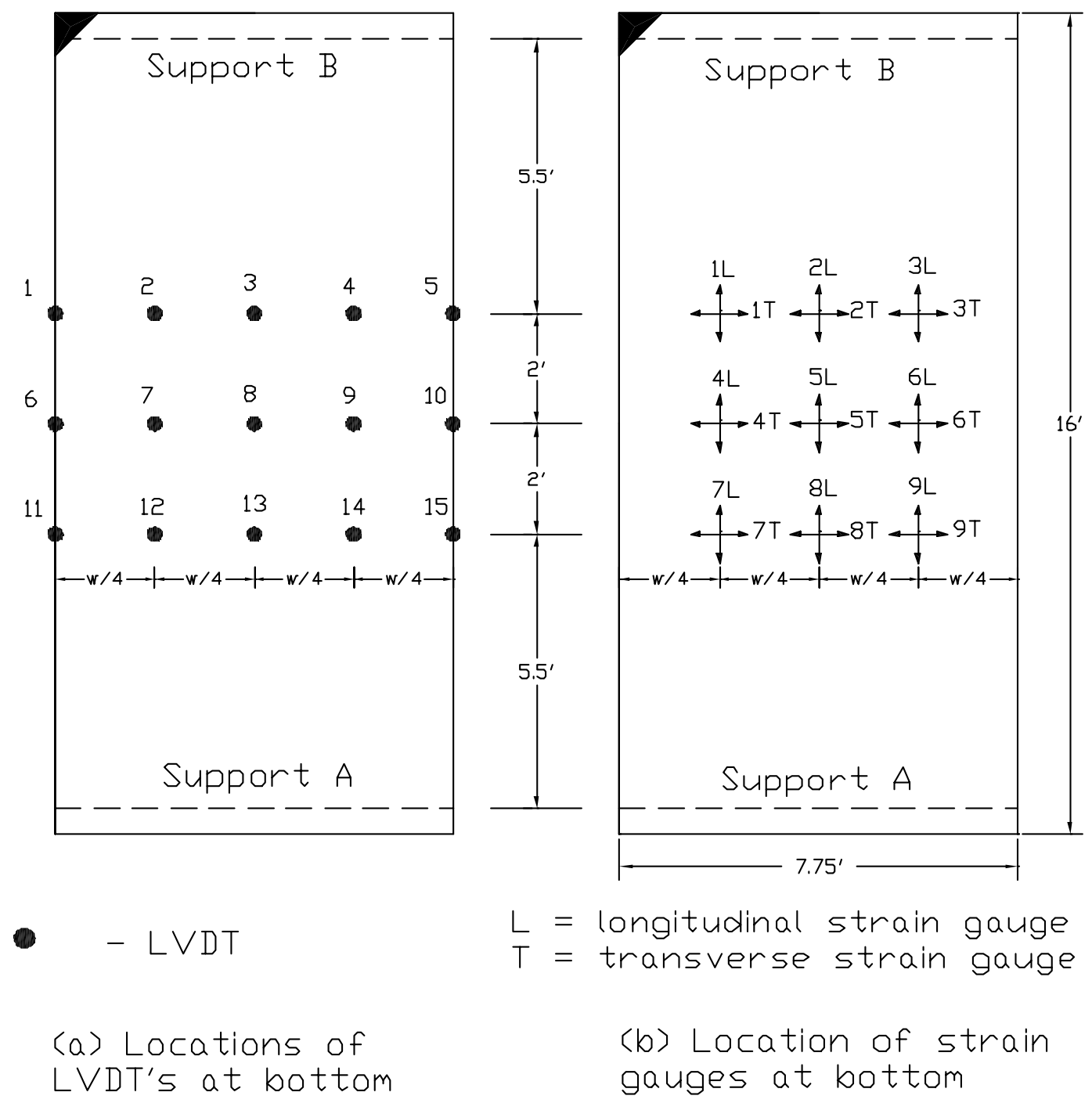

Note: The dark corner triangle refers to corresponding locations of the sample for Figures 6.1 and 6.2.

Figure 6.1 Location of LVDT's and Strain Gauges 




Figure 6.2 Load Placements for Panel Tests

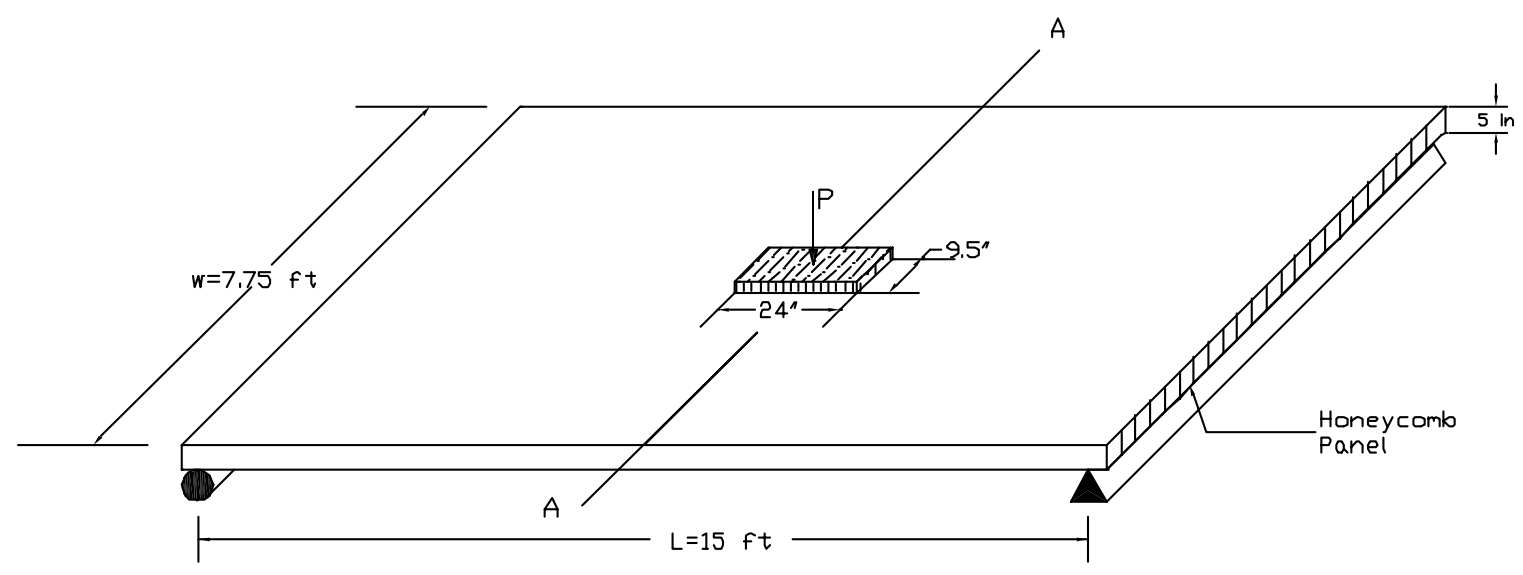

Figure 6.3 Basic Setup for Midspan Concentric Load Case 


\subsubsection{Procedure}

The experimental tests are performed in two phases. First, the load was applied along the midspan, corresponding to locations 1,2, and 3 in Figure 6.2. Second, the panel and supports were aligned so that the loading would be placed two feet away from the midspan toward one support (simulating an eccentric loading), corresponding to locations 4, 5, and 6 in Figure 6.2. In order to apply the loads on the opposite side, locations 7, 8, and 9 in Figure 6.2, the panel is rotated 180 degrees. Altogether, nine patch loading locations are studied (Figure 6.2).

Once all the gauges and LVDT's are in place, a load is applied to the panel. Because the testing frame used to hold the hydraulic jack is stationary, the jack must be moved to achieve each load case. The data acquisition system used only has the capability of processing five LVDT readings at one time. Thus each load case must be loaded and unloaded several times to collect the necessary data. For data collection, the deck is loaded to 10 kips. However, the deflection results are given in inch per kip as to provide uniform data. The load was applied a minimum of three times before data is recorded for reduction.

For the midspan loading condition, the supports and panel are aligned so that the jack can be located along the midspan. These loading conditions are represented by LC \#1, \#2 and \#3 in Figure 6.2. The three independent midspan load cases are implemented by moving the hydraulic jack to the correct location for each case. Each of these three cases 
required seven displacement readings (see Figure 6.1 (a)). During the tests, the data was analyzed to assure that each test was giving a consistent response. The results for the midspan load tests are shown in Table 6.1.

For the other loading conditions, the supports were moved such that the load will be applied at locations two feet from the midspan. Again, the hydraulic jack must be moved in order to place loads at different locations with respect to the width. After all three load cases were completed on one side of the panel, the panel was then lifted and rotated. This allows the other load placements to be tested. For each of these cases 15 different displacements were recorded, so the LVDT's were moved three times for each case. The results for these tests are shown in Tables 6.2 and 6.3.

\subsubsection{Results for Midspan Loading Conditions}

There are three midspan loading cases, which are shown in Figure 6.2 as Case \#1, \#2, and \#3. As described in Figure 6.1, the displacements measured are displacement \#3, \#6 through \#10, and \#13, and the strains recorded at the midspan correspond to gauge locations 4 through 6 , both longitudinal and transverse. The results for each midspan load case are shown in Table 6.1. 
Table 6.1 Results for Midspan Loading, LC \#1 through LC \#3

\begin{tabular}{|c|c|c|c|c|c|c|c|}
\hline \multirow{2}{*}{ Load Placement } & \multicolumn{7}{|c|}{ Deflection at Given Location, inch/kip } \\
\cline { 2 - 8 } & 6 & 7 & 8 & 9 & 10 & 3 & 13 \\
\hline Case \# 1 & 0.1325 & 0.1151 & 0.0975 & 0.0819 & 0.0708 & 0.0815 & 0.0834 \\
\hline Case \# 2 & 0.097 & 0.0976 & 0.1 & 0.0972 & 0.0973 & 0.0819 & 0.0833 \\
\hline Case \# 3 & 0.0703 & 0.082 & 0.099 & 0.1175 & 0.1356 & 0.0815 & 0.0836 \\
\hline & \multicolumn{7}{|c|}{ Strain Value at Given Location, microstrain/kip } \\
\cline { 2 - 9 } & $4 \mathrm{~L}$ & $5 \mathrm{~L}$ & $6 \mathrm{~L}$ & $4 \mathrm{~T}$ & $5 \mathrm{~T}$ & $6 \mathrm{~T}$ & \\
\hline Case \# 1 & 106.9 & 79.9 & 66.7 & 19.8 & -12 & -16.1 & \\
\hline Case \# 2 & 82.5 & 85.5 & 82.6 & -11.3 & 28.3 & -4.8 & \\
\hline Case \# 3 & 66.4 & 84.4 & 101.9 & -18.9 & -11.2 & 10.3 & \\
\hline
\end{tabular}

For load Case \#2, the load is applied at the center of the panel, thus the results for this load case should theoretically be symmetric about the center along the length and width, assuming the material properties and geometry are the same throughout the panel. Experimentally this was found to be the case.

For load Cases \#1 and \#3, the results should be antisymmetric with respect to each other. For example, deflections at locations 9 and 10 (Figure 6.1 (a)) for Case \#3 should give the same results as deflections at the respective locations 7 and 6 for Case \#1. The strain data should show the same response. Table 6.2 provides a ratio of displacement data in which each value shown for Load Case \#1 should correspond with the value shown for load Case \#3. The same data is given for strain values in Table 6.3. A perfect correlation would give a ratio of 1 . As is shown in the tables, a fairly good correlation exists, thus showing uniform material properties and little experimental variability. 
Table 6.2 Displacement Ratios for Symmetric Load Cases

\begin{tabular}{|c|c|c|}
\hline $\begin{array}{c}\text { Displacement } \\
\text { Load Case \#1 }\end{array}$ & $\begin{array}{c}\text { LC1/LC3 } \\
\text { Ratio }\end{array}$ & $\begin{array}{c}\text { Displacement } \\
\text { Load Case \#3 }\end{array}$ \\
\hline 6 & 0.977 & 10 \\
\hline 7 & 0.980 & 9 \\
\hline 8 & 0.985 & 8 \\
\hline 9 & 0.999 & 7 \\
\hline 10 & 1.007 & 3 \\
\hline 3 & 1 & 13 \\
\hline 13 & 0.998 & \\
\hline
\end{tabular}

Table 6.3 Strain Ratios for Symmetric Load Cases

\begin{tabular}{|c|c|c|}
\hline $\begin{array}{c}\text { Displacement } \\
\text { Load Case \#1 }\end{array}$ & $\begin{array}{c}\text { LC1/LC3 } \\
\text { Ratio }\end{array}$ & $\begin{array}{c}\text { Displacement } \\
\text { Load Case \#3 }\end{array}$ \\
\hline $4 \mathrm{~L}$ & 1.050 & $6 \mathrm{~L}$ \\
\hline $4 \mathrm{~T}$ & 1.922 & $6 \mathrm{~T}$ \\
\hline $5 \mathrm{~L}$ & 0.947 & $5 \mathrm{~L}$ \\
\hline $5 \mathrm{~T}$ & 1.071 & $5 \mathrm{~T}$ \\
\hline $6 \mathrm{~L}$ & 1.005 & $4 \mathrm{~L}$ \\
\hline $6 \mathrm{~T}$ & 0.852 & $4 \mathrm{~T}$ \\
\hline
\end{tabular}




\subsubsection{Results for Eccentric Loading Conditions}

In addition to the midspan loading conditions, the deck is loaded at six more locations. Table 6.4 shows the strain values for load Cases \#4 through \#9. Table 6.5 shows the deflection values for the same load cases. For these tests, all the strain gauges and LVDT's shown in Figure 6.1 were recorded.

It is important that the locations of the load cases and the locations of the deflection and strain readings are not misinterpreted. To avoid this, a small triangle is shown in the corner of the deck for Figure 6.1 and for Figure 6.2, and the proper orientation of the deck is achieved by superimposing the corner triangles. Thus it is possible to get the proper values for the corresponding test.

Table 6.4 Strain Values for LC \#4 to LC \#9

\begin{tabular}{|c|c|c|c|c|c|c|c|c|c|}
\hline \multirow[t]{2}{*}{ Load Case } & \multicolumn{9}{|c|}{ Longitudinal Strain at Given Location, microstrain/kip } \\
\hline & $1 \mathrm{~L}$ & $2 \mathrm{~L}$ & $3 \mathrm{~L}$ & $4 \mathrm{~L}$ & $5 \mathrm{~L}$ & $6 \mathrm{~L}$ & $7 \mathrm{~L}$ & $8 \mathrm{~L}$ & 9L \\
\hline \#4 & 154.95 & 66.75 & 58.65 & 76.7 & 69.95 & 60.35 & 50.9 & 48.75 & 43.1 \\
\hline \#5 & 73.05 & 115.6 & 75.85 & 70.5 & 61.95 & 68.65 & 45.1 & 43.15 & 45.1 \\
\hline$\# 6$ & 55.65 & 62.15 & 112.3 & 60.2 & 65.85 & 74.15 & 38.9 & 44.05 & 47.65 \\
\hline$\# 7$ & 52.7 & 37 & 47.1 & 79.8 & 72.8 & 59.25 & 167.65 & 86.75 & 54.75 \\
\hline$\# 8$ & 47.9 & 38 & 49.6 & 71.15 & 62.7 & 69.5 & 72.2 & 156.75 & 71.85 \\
\hline$\# 9$ & 45.15 & 45.5 & 52.9 & 60.3 & 66.05 & 78.95 & 50.75 & 68.15 & 88.15 \\
\hline \multirow[t]{2}{*}{ Load Case } & \multicolumn{9}{|c|}{ Transverse Strain at Given Location, microstrain/kip } \\
\hline & $1 \mathrm{~T}$ & $2 T$ & 3T & $4 \mathrm{~T}$ & 5T & 6T & 7T & $8 \mathrm{~T}$ & 9T \\
\hline \#4 & 48.15 & -7.05 & -18.65 & -2.4 & -8.05 & -18.35 & -10.15 & 0.05 & -13.7 \\
\hline \#5 & -4.3 & 47.3 & -12.35 & -1.55 & 9.65 & -8.6 & -4.65 & -1.9 & -7 \\
\hline \#6 & -13.75 & -26.7 & 25.15 & -10.95 & -13.95 & 0.9 & -8.55 & -9.4 & -6.5 \\
\hline$\# 7$ & -11.7 & -9.2 & -14.05 & -6.2 & -7.3 & -20.15 & 70.35 & -16.75 & -22.8 \\
\hline \#8 & -5.05 & -2.3 & -7.35 & -3.15 & 12.35 & -11.15 & -0.55 & 110.4 & -17.9 \\
\hline$\# 9$ & -10.25 & -13.05 & -7.15 & -13.25 & -22.25 & 1.45 & -13.45 & -21.35 & 52.35 \\
\hline
\end{tabular}


Table 6.5 Deflection Values for LC \#4 to LC \#9

\begin{tabular}{|c|c|c|c|c|c|}
\hline \multirow[t]{2}{*}{ Load Case } & \multicolumn{5}{|c|}{ Deflection at Given Locations, in/kip } \\
\hline & 1 & 2 & 3 & 4 & 5 \\
\hline$\# 4$ & 0.127354 & 0.111575 & 0.088312 & 0.075993 & 0.066451 \\
\hline \#5 & 0.085283 & 0.093394 & 0.095445 & 0.088877 & 0.092489 \\
\hline \#6 & 0.048578 & 0.065827 & 0.086546 & 0.119302 & 0.139616 \\
\hline$\# 7$ & 12215 & 0.112004 & 0.085106 & 0.061931 & 0.049991 \\
\hline \#8 & 0.084235 & 0.089688 & 0.081633 & 0.075944 & 0.082017 \\
\hline \#9 & 59355 & 0.068858 & 0.080815 & 0.090992 & 0.108439 \\
\hline \multirow[t]{2}{*}{ Load Case } & \multicolumn{5}{|c|}{ Deflection at Given Locations, in/kip } \\
\hline & 6 & 7 & 8 & 9 & 10 \\
\hline$\# 4$ & 0.132368 & 0.113443 & 0.094466 & 0.077862 & 0.065626 \\
\hline$\# 5$ & 09139 & 0.091931 & 0.094543 & 0.090552 & 0.092717 \\
\hline \#6 & 0.054658 & 070699 & 0.095262 & 0.114657 & 0.140648 \\
\hline$\# 7$ & 15214 & 0.130085 & 0.096932 & 0.067309 & 0.049775 \\
\hline \#8 & 0.1007 & 0.102838 & 0.096612 & 0.085377 & 0.088568 \\
\hline$\# 9$ & 25 & 078379 & 0.090993 & 0.106577 & 0.127358 \\
\hline \multirow[t]{2}{*}{ Load Case } & \multicolumn{5}{|c|}{ Deflection at Given Locations, in/kip } \\
\hline & 11 & 12 & 13 & 14 & 15 \\
\hline$\# 4$ & 0.11617 & 0.098354 & 0.082608 & 0.066927 & 0.05164 \\
\hline \#5 & 0.083343 & 0.08289 & 0.080621 & 0.075142 & 0.083593 \\
\hline$\# 6$ & 0.049486 & 0.064468 & 0.081375 & 0.094718 & 0.117564 \\
\hline$\# 7$ & 0.156795 & 0.132065 & 0.091973 & 0.060116 & 0.042462 \\
\hline$\# 8$ & 4 & 0. & 0.0 & 0.08 & 0.085497 \\
\hline$\# 9$ & 0.058495 & 0.074408 & 0.084363 & 0.102003 & 0.122538 \\
\hline
\end{tabular}


The data provided in Tables 6.4 and 6.5 are given in unit of measure per kip of loading. Each value is recorded twice, and the average of these values is shown. Each test was loaded to ten kips, and the linear regression of the data points are used to find the reported value. The procedure for the linear regression is the same used for the bending tests of beam samples.

There is a lot of data to interpret, since there are nine load cases with 15 deflection values and 18 strain values. However, many of these cases have either symmetry or antisymmetry response compared to other cases. For example, Case \#4 and Case \#9 should have similar values. Deflections at Location \#2 for Case \#4 should coincide with the deflection at Location \#14 of Case \#9 (see Figures 6.1 and 6.2). Thus, Tables 6.6 and 6.7 give ratios of comparisons for Load Case \# 4 and Load Case \#9 for selected deflection and strain values.

The deflection ratios from Table 6.6 show good correlations, with a maximum difference of around $10 \%$. The strain data shows sufficient correlation, however certain values have large differences. With exception of one pair of readings ( $1 \mathrm{~L}$ of Case \#4 and 9L of Case \#9), the longitudinal strain ratios are close to 1.0. The transverse strain, on the other hand, shows more variability. This is attributed to the fact that the transverse strains are much smaller and more erratic. However, after reviewing the data from these tables, it can be concluded that the material properties of the panel are approximately uniform, just as shown by the concentric loading cases. 
Table 6.6 Displacement Ratios for Asymmetric Load Cases

\begin{tabular}{|c|c|c|}
\hline $\begin{array}{c}\text { Displacement } \\
\text { Load Case \#4 }\end{array}$ & $\begin{array}{c}\text { LC4/LC9 } \\
\text { Ratio }\end{array}$ & $\begin{array}{c}\text { Displacement } \\
\text { Load Case \#9 }\end{array}$ \\
\hline 2 & 1.098 & 14 \\
\hline 3 & 1.046 & 13 \\
\hline 4 & 1.02 & 12 \\
\hline 7 & 1.064 & 9 \\
\hline 8 & 1.038 & 8 \\
\hline 9 & 0.993 & 7 \\
\hline 12 & 1.081 & 4 \\
\hline 13 & 0.935 & 3 \\
\hline 14 & 0.972 & 2 \\
\hline
\end{tabular}

Table 6.7 Strain Ratios for Asymmetric Load Cases

\begin{tabular}{|c|c|c|}
\hline $\begin{array}{c}\text { Displacement } \\
\text { Load Case \#4 }\end{array}$ & $\begin{array}{c}\text { LC4/LC9 } \\
\text { Ratio }\end{array}$ & $\begin{array}{c}\text { Displacement } \\
\text { Load Case \#9 }\end{array}$ \\
\hline $1 \mathrm{~L}$ & 1.758 & $9 \mathrm{~L}$ \\
\hline $1 \mathrm{~T}$ & 0.920 & $9 \mathrm{~T}$ \\
\hline $3 \mathrm{~L}$ & 1.156 & $7 \mathrm{~L}$ \\
\hline $3 \mathrm{~T}$ & 1.387 & $7 \mathrm{~T}$ \\
\hline $5 \mathrm{~L}$ & 1.059 & $5 \mathrm{~L}$ \\
\hline $5 \mathrm{~T}$ & 0.362 & $5 \mathrm{~T}$ \\
\hline $7 \mathrm{~L}$ & 0.962 & $3 \mathrm{~L}$ \\
\hline $7 \mathrm{~T}$ & 1.420 & $3 \mathrm{~T}$ \\
\hline $9 \mathrm{~L}$ & 0.955 & $1 \mathrm{~L}$ \\
\hline $9 \mathrm{~T}$ & 1.337 & $1 \mathrm{~T}$ \\
\hline
\end{tabular}




\subsection{Finite Element Evaluation of the Panel}

The finite element modeling of the panel is performed by two separate approaches. First, the panel is evaluated using the actual core geometry model. Secondly, the equivalent material properties model is used. Both methods are presented herein, and results for each are shown and compared.

\subsubsection{Finite Element Modeling}

As previously stated, the finite element evaluation of the panel is accomplished using two different models. The actual core geometry model will be described first. This model is made using the 4"x 4" cell described in Chapter 3, Section 3.3.1. The size of the model when using this actual geometry for the entire panel is so large that symmetry is applied to decrease the number of elements, and a part of the panel is modeled. However, this limits the flexibility of the model.

Symmetric boundary conditions are exploited for the actual geometry model, such that only one-quarter of the deck panel is modeled, and the number of nodes and elements are reduced by approximately three-quarters. However this limits the possibilities for different load cases. It is possible to model eccentric load cases by superposition of symmetric and antisymmetric substructures, but this was deemed too complex and therefore, only the midspan concentric loading is modeled. Figure 6.4 shows a diagram of the loading and boundary conditions of one quarter of the deck. The patch loading 
consists of one-quarter of the loading plate, which represents one-quarter of the actual applied load. The symmetric boundary conditions used are represented by shear release. The translations and rotations allowed at these boundary conditions are defined to conform to symmetric conditions.

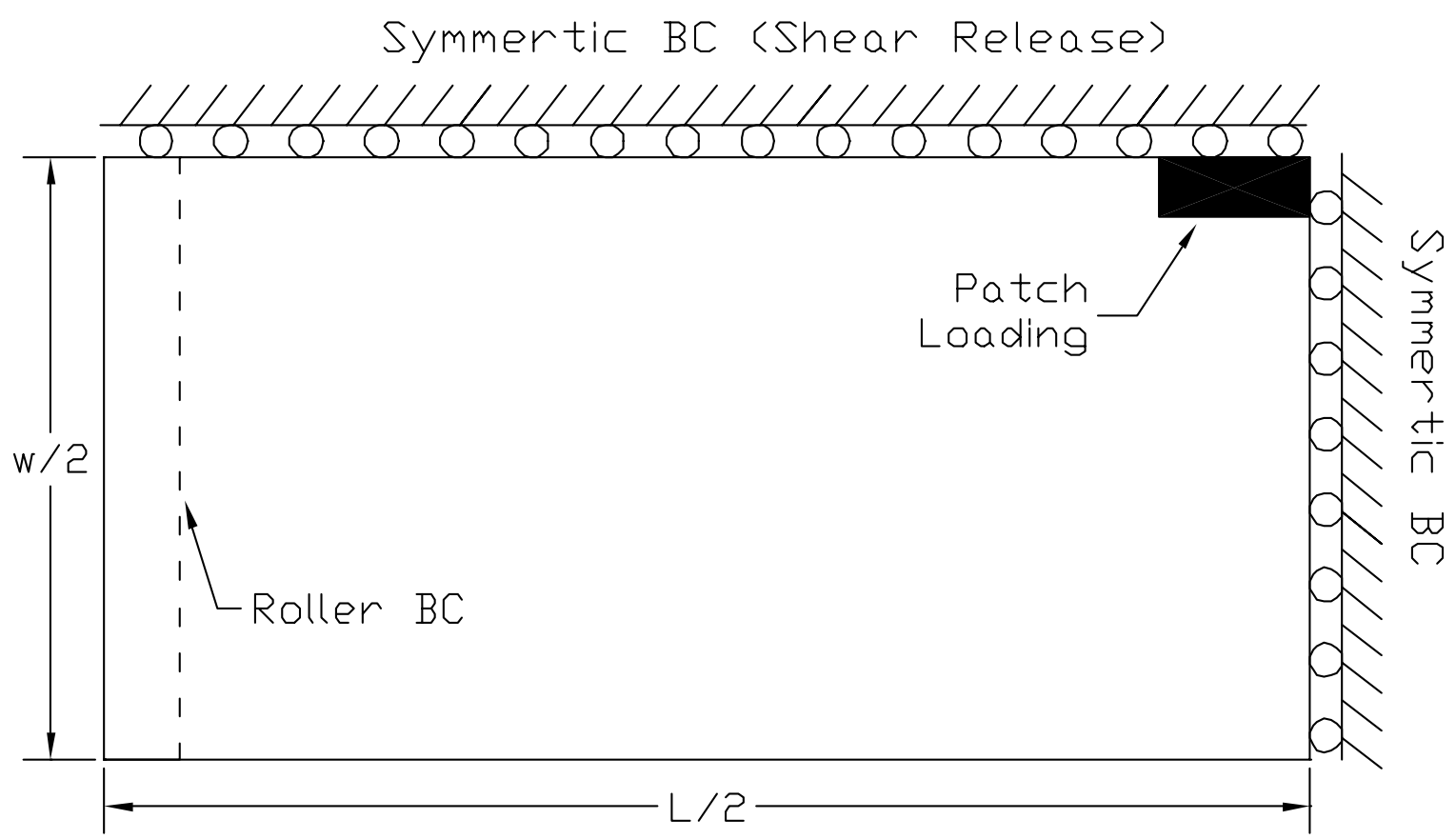

Figure 6.4 Conditions of Finite Element Model for Actual Geometry

A finite element model using equivalent panel properties is also made. The formulation of the elements used for this model is described in Chapter 3, Section 3.3.3. The equivalent plate model has very few elements compared to the actual panel model. Thus, the entire deck is modeled, instead of just one quarter as in the actual panel model. The boundary conditions used are pin-roller, just as the experimental setup. Also, all loading conditions are applied. These loads are applied using an attached surface, with a load per unit area applied to this surface. When the input file is created, the loads are 
automatically discretized to the correct and corresponding nodes. A total of one kip loading is used for each model.

\subsubsection{Actual Panel Geometry Finite Element Modeling Results}

The finite element results of the concentric load condition using the actual panel geometry are shown in Table 6.8. These values are later compared with the finite element predictions using the equivalent panel properties, as well as experimental results. These results are reported according to the methods outlined in Section 3.3.2.

\section{Table 6.8 Finite Element Predictions of Concentric Loading using The Actual Panel Geometry}

\begin{tabular}{|c|c|c|c|}
\hline $\begin{array}{c}\text { Deflection } \\
\text { Location }\end{array}$ & $\begin{array}{c}\text { Deflection, } \\
\text { in/kip }\end{array}$ & $\begin{array}{c}\text { Strain } \\
\text { Location }\end{array}$ & $\begin{array}{c}\text { Strain, } \\
\text { microstrain/kip }\end{array}$ \\
\hline $1,5,11,15$ & 0.082 & 1L,3L,7L,9L & 48.7 \\
\hline $2,4,12,14$ & 0.081 & $1 \mathrm{~T} .3 \mathrm{~T}, 7 \mathrm{~T}, 9 \mathrm{~T}$ & -9.9 \\
\hline 3,13 & 0.083 & $2 \mathrm{~L}, 8 \mathrm{~L}$ & 57.8 \\
\hline 6,10 & 0.091 & $2 \mathrm{~T}, 8 \mathrm{~T}$ & 7.7 \\
\hline 7,9 & 0.09 & $4 \mathrm{~L}, 6 \mathrm{~L}$ & 70.5 \\
\hline 8 & 0.094 & $4 \mathrm{~T}, 6 \mathrm{~T}$ & -10.1 \\
\hline--- & --- & $5 \mathrm{~L}$ & 109 \\
\hline--- & --- & $5 \mathrm{~T}$ & 29.4 \\
\hline
\end{tabular}

\subsubsection{Finite Element Results using the Equivalent Plate Properties}

The finite element predictions using the equivalent plate model are reported using the methods outlined in Section 3.3.4. The responses that are requested are longitudinal and 
transverse strains on the bottom layer of the plate and vertical translations. Each of these responses for the required locations is presented in Tables 6.9 and 6.10 .

The strain and displacement locations are shown in Figure 6.1. These locations correspond to the experimental instrumentation locations. The loads that are applied to the panel represent the experimental loading conditions. The nine load conditions shown in Figure 6.2 can be represented in the analysis by simply four cases: Case \#2, Case \#3, Case \#5, and Case \#6.

Both, deflection and strain contours obtained from the finite element analyses are shown for the equivalent deck panel. The deflection contours for each of the four loading cases are shown in Figures 6.5 through 6.8. The longitudinal and transverse strain contours for the concentric midspan loading case are shown in Figures 6.9 and 6.10, respectively. 
Table 6.9 Translations Using Equivalent Plate Model

\begin{tabular}{|c|c|c|c|c|}
\hline \multirow{2}{*}{ Location } & \multicolumn{4}{|c|}{ Displacement at Given Locations, inch/kip } \\
\cline { 2 - 5 } & Case \# 2 & Case \# 3 & Case \# & Case \# \\
\hline 1 & 0.095 & 0.058 & 0.08 & 0.054 \\
\hline 2 & 0.094 & 0.069 & 0.081 & 0.065 \\
\hline 3 & 0.096 & 0.085 & 0.084 & 0.081 \\
\hline 4 & 0.094 & 0.103 & 0.081 & 0.101 \\
\hline 5 & 0.095 & 0.123 & 0.08 & 0.118 \\
\hline 6 & 0.105 & 0.064 & 0.085 & 0.058 \\
\hline 7 & 0.104 & 0.076 & 0.085 & 0.069 \\
\hline 8 & 0.108 & 0.093 & 0.086 & 0.085 \\
\hline 9 & 0.104 & 0.116 & 0.085 & 0.103 \\
\hline 10 & 0.105 & 0.136 & 0.085 & 0.122 \\
\hline 11 & 0.095 & 0.058 & 0.076 & 0.052 \\
\hline 12 & 0.094 & 0.069 & 0.074 & 0.061 \\
\hline 13 & 0.096 & 0.085 & 0.074 & 0.074 \\
\hline 14 & 0.094 & 0.103 & 0.074 & 0.088 \\
\hline 15 & 0.095 & 0.123 & 0.076 & 0.105 \\
\hline
\end{tabular}

\subsection{Strains Using Equivalent Plate Model}

\begin{tabular}{|c|c|c|c|c|}
\hline \multirow{2}{*}{ Location } & \multicolumn{4}{|c|}{ Strains at Given Locations, microstrain/kip } \\
\cline { 2 - 5 } & Case \# 2 & Case \# 3 & Case \# 5 & Case \# \\
\hline 1L & 71.2 & 52 & 70.7 & 52.5 \\
\hline 1T & -10.8 & -18.1 & -11.5 & -19.3 \\
\hline 2L & 65.3 & 63.8 & 90.1 & 70.7 \\
\hline 2T & 12.2 & -14.4 & 31.5 & -17 \\
\hline 3L & 71.2 & 72.1 & 70.7 & 105.8 \\
\hline 3T & -10.8 & -1.9 & -11.5 & 16.5 \\
\hline 4L & 85.8 & 58.4 & 63.8 & 52 \\
\hline 4T & -14.6 & -21.2 & -9.7 & -18.1 \\
\hline 5L & 107.2 & 77 & 58.6 & 63.8 \\
\hline 5T & 33.6 & -18.7 & 10.9 & -14.4 \\
\hline 6L & 85.8 & 112.4 & 63.8 & 72.2 \\
\hline 6T & -14.6 & 14.7 & -9.7 & -2 \\
\hline 7L & 71.2 & 52 & 46.8 & 42.1 \\
\hline 7T & -10.8 & -18.1 & -7.7 & -13.5 \\
\hline 8L & 65.3 & 63.8 & 42.7 & 46.7 \\
\hline 8T & 12.2 & -14.4 & -0.9 & -10.7 \\
\hline 9L & 71.2 & 72.1 & 46.8 & 51.4 \\
\hline 9T & -10.8 & -1.9 & -7.7 & -9 \\
\hline
\end{tabular}




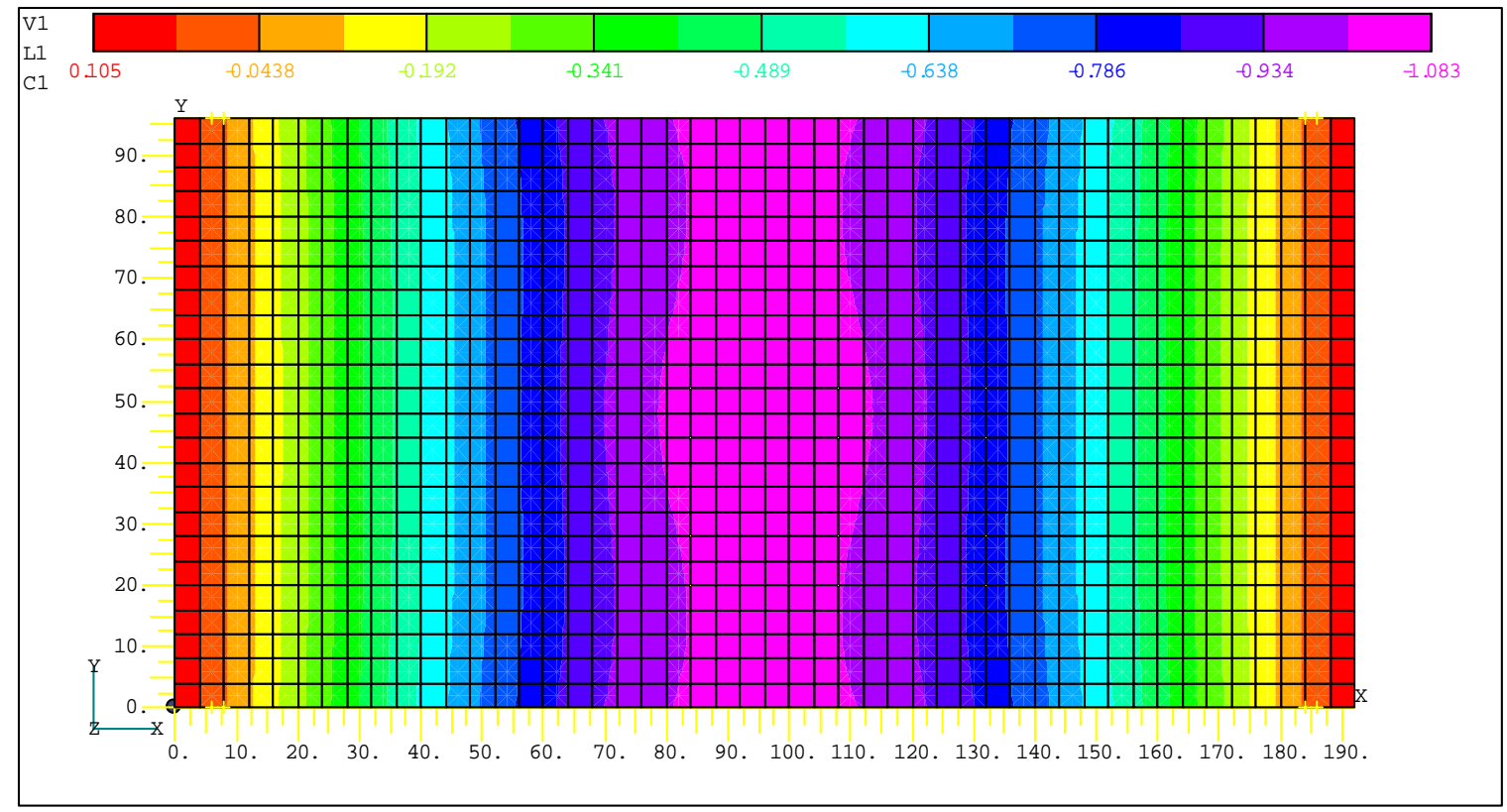

Figure 6.5 Deflection Contour for Equivalent Panel under Load Condition \#2

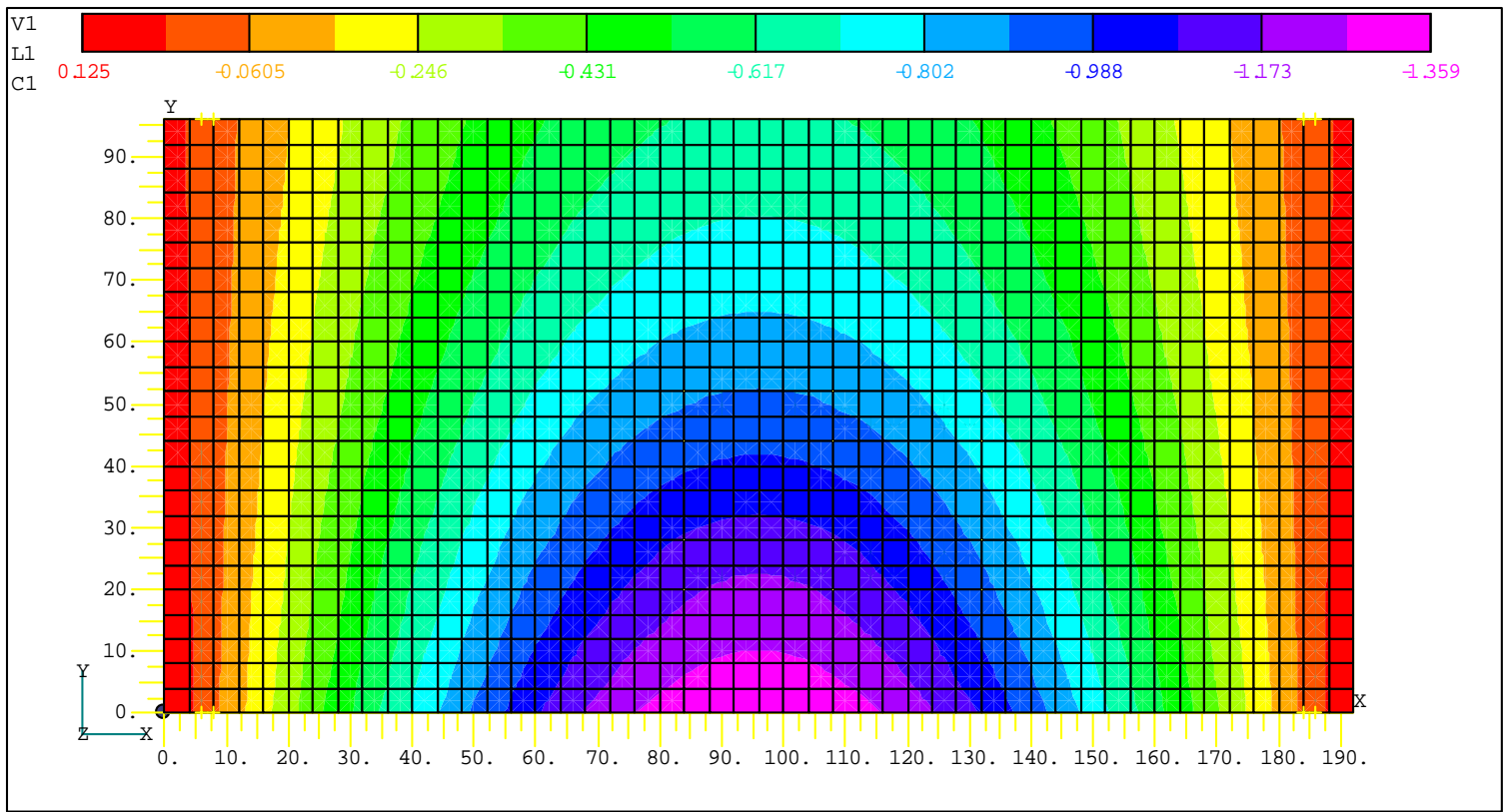

Figure 6.6 Deflection Contour for Equivalent Panel under Load Condition \#3 




Figure 6.7 Deflection Contour for Equivalent Panel under Load Condition \#5

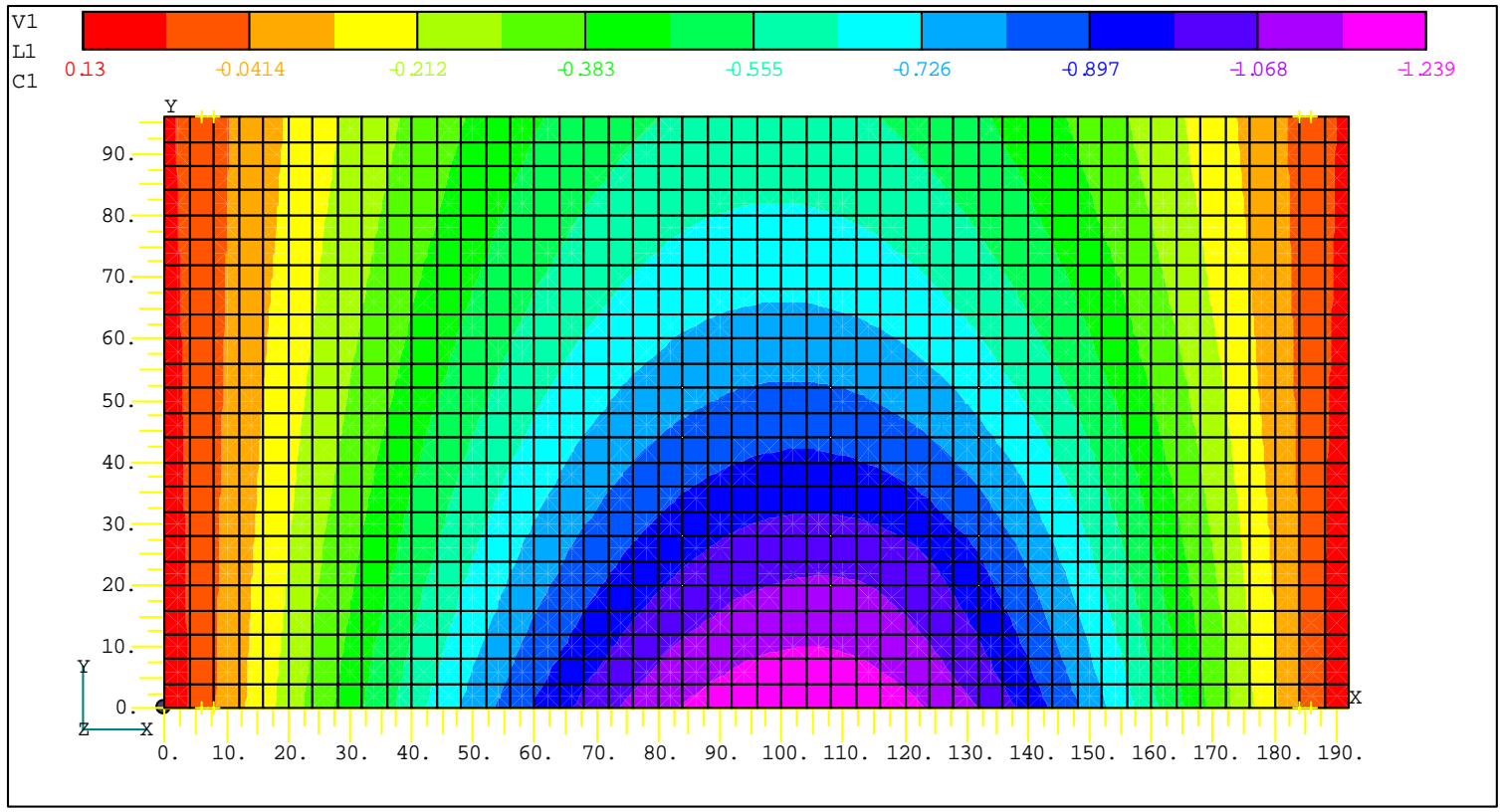

Figure 6.8 Deflection Contour for Equivalent Panel under Load Condition \#6 


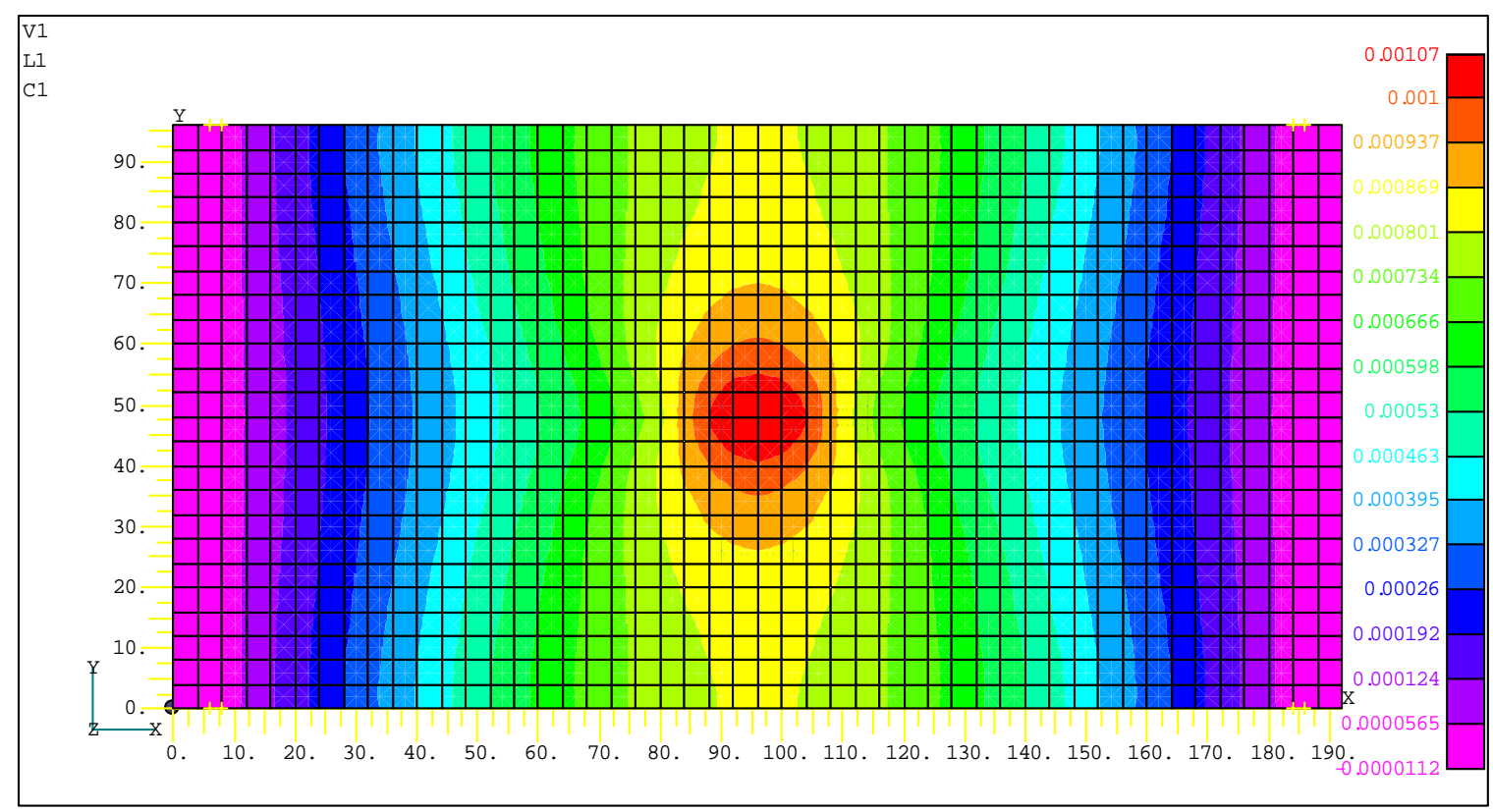

Figure 6.9 Longitudinal Strain Contour for Load Case \#2

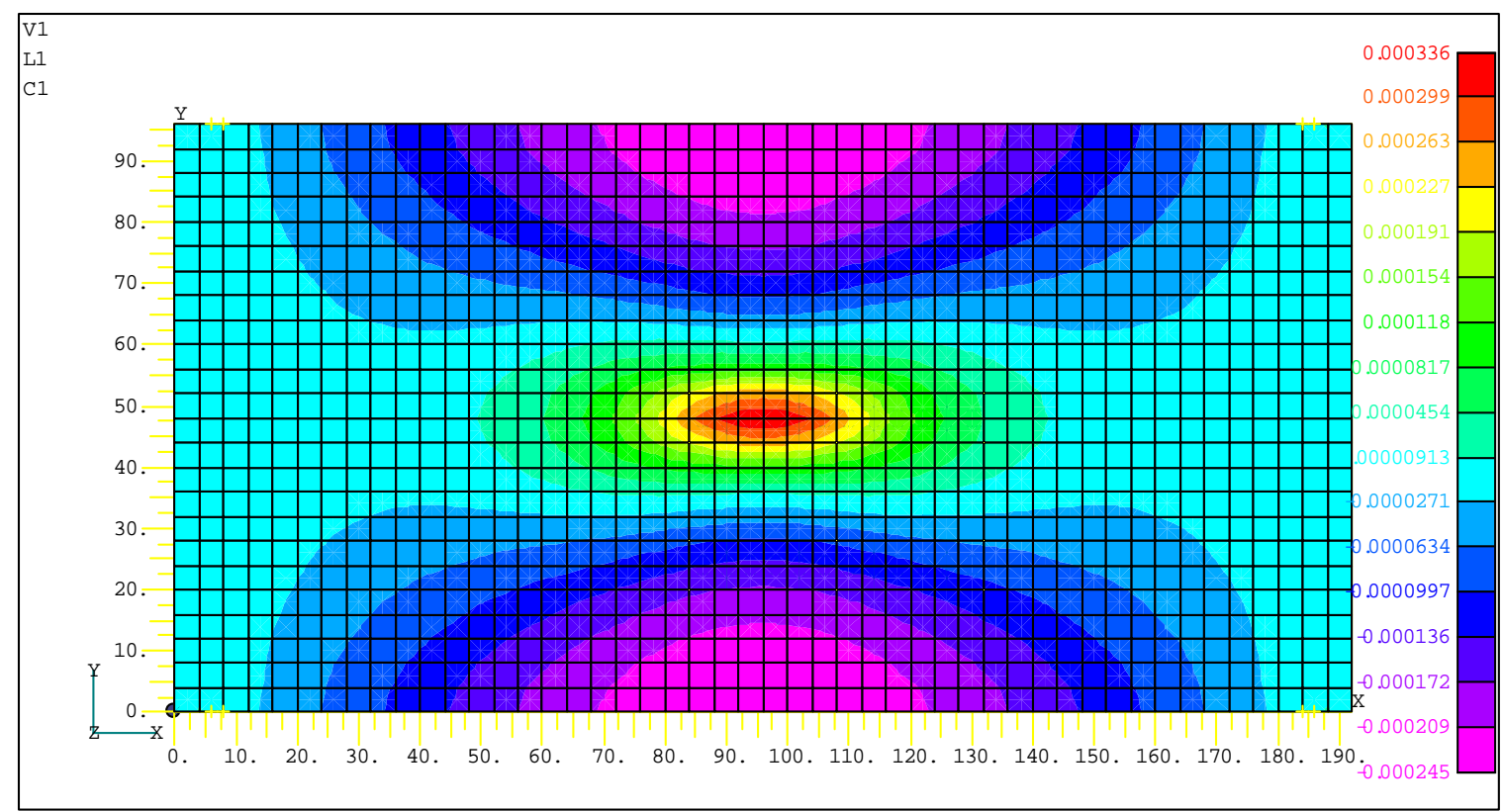

Figure 6.10 Transverse Strain Contour for Load Case \#2 


\subsection{Comparison of Results}

Correlations of strains and displacements between the two finite element models, and also between the FE models and the experimental results are important for evaluating the accuracy of the equivalent panel properties obtained from the explicit solution. Thus, tables are given in this section that show comparisons for all loading conditions.

Theoretically, many of the experimental loading conditions are duplicated, and would show identical results given perfect orthotropic material and geometric properties, ideal testing conditions, and no experimental errors. Unfortunately these conditions are not always achievable; thus some inconsistencies exist. This was discussed in part in Sections 6.2.3 and 6.2.4.

In order to compare the experimental data with the finite element predictions, the experimental load cases which should give duplicated results are averaged, and the average as well as the range of values are given. For example, load case \#1 and load case \#3 should give identical responses (Figure 6.2), and although this is not exactly the case, as shown in Tables 6.2 and 6.3 , the corresponding values can be averaged and then compared with the finite element predictions. The displacement and strain correlations are shown in Tables 6.11 and 6.12, respectively. 
Table 6.11 Displacement Correlation of Experimental Results and FE Models

\begin{tabular}{|c|c|c|c|c|c|c|c|c|c|c|c|c|c|c|c|}
\hline \multirow{3}{*}{$\begin{array}{l}\text { Disp. } \\
\text { Loc. }\end{array}$} & \multicolumn{3}{|c|}{ Case \# 2} & \multicolumn{4}{|c|}{ Case \# 3} & \multicolumn{4}{|c|}{ Case \# 5} & \multicolumn{4}{|c|}{ Case \# 6} \\
\hline & \multirow[t]{2}{*}{ Exp. } & \multicolumn{2}{|c|}{ FE } & \multicolumn{3}{|c|}{ Exp. Load Cases } & \multirow{2}{*}{$\begin{array}{c}\mathrm{FE} \\
\text { Eq uiv. }\end{array}$} & \multicolumn{3}{|c|}{ Exp. Load Cases } & \multirow{2}{*}{$\begin{array}{c}\mathrm{FE} \\
\text { Eq uiv. }\end{array}$} & \multicolumn{3}{|c|}{ Exp. Load Cases } & \multirow{2}{*}{$\begin{array}{c}\mathrm{FE} \\
\text { Equiv. }\end{array}$} \\
\hline & & Actual & Equiv. & Min & Max & Avg & & Min & Max & Avg & & Min & Max & Avg & \\
\hline 1 & $x x x$ & 0.082 & 0.095 & $x x x$ & $x x x$ & $x x x$ & 0.058 & 0.0853 & 0.0855 & 0.0854 & 0.08 & 0.042 & 0.066 & 0.054 & 0.054 \\
\hline 2 & $x x x$ & 0.081 & 0.094 & $x x x$ & $x x x$ & $x x x$ & 0.069 & 0.0828 & 0.0934 & 0.0881 & 0.081 & 0.06 & 0.076 & 0.069 & 0.065 \\
\hline 3 & 0.0819 & 0.083 & 0.096 & 0.0815 & 0.0815 & 0.0815 & 0.085 & 0.0911 & 0.0954 & 0.09325 & 0.084 & 0.084 & 0.092 & 0.088 & 0.081 \\
\hline 4 & $x x x$ & 0.081 & 0.094 & $x x x$ & $x x x$ & $x x x$ & 0.103 & 0.0889 & 0.0956 & 0.09225 & 0.081 & 0.102 & 0.132 & 0.116 & 0.101 \\
\hline 5 & $x x x$ & 0.082 & 0.095 & $x x x$ & $x x x$ & $x x x$ & 0.123 & 0.09194 & 0.0925 & 0.09222 & 0.08 & 0.122 & 0.157 & 0.137 & 0.118 \\
\hline 6 & 0.097 & 0.091 & 0.105 & 0.0703 & 0.0708 & 0.07055 & 0.064 & 0.0886 & 0.0914 & 0.09 & 0.085 & 0.05 & 0.066 & 0.059 & 0.058 \\
\hline 7 & 0.0976 & 0.09 & 0.104 & 0.0819 & 0.082 & 0.08195 & 0.076 & 0.0854 & 0.0919 & 0.08865 & 0.085 & 0.067 & 0.078 & 0.074 & 0.069 \\
\hline 8 & 0.1 & 0.094 & 0.108 & 0.0975 & 0.099 & 0.099 & 0.093 & 0.0945 & 0.0966 & 0.09555 & 0.086 & 0.091 & 0.097 & 0.094 & 0.085 \\
\hline 9 & 0.0972 & 0.09 & 0.104 & 0.1151 & 0.1175 & 0.1163 & 0.116 & 0.0906 & 0.1028 & 0.0967 & 0.085 & 0.107 & 0.13 & 0.116 & 0.103 \\
\hline 10 & 0.0973 & 0.091 & 0.105 & 0.1325 & 0.1356 & 0.13405 & 0.136 & 0.0927 & 0.1007 & \begin{tabular}{|l|}
0.0967 \\
\end{tabular} & 0.085 & 0.127 & 0.152 & 0.138 & 0.122 \\
\hline 11 & $x x x$ & 0.082 & 0.095 & $x x x$ & $x x x$ & $x x x$ & 0.058 & 0.082 & 0.0833 & 0.08265 & 0.076 & 0.049 & 0.058 & 0.052 & 0.052 \\
\hline 12 & $x x x$ & 0.081 & 0.094 & $x x x$ & $x x x$ & $x x x$ & 0.069 & 0.0759 & 0.0829 & 0.0794 & 0.074 & 0.062 & 0.074 & 0.067 & 0.061 \\
\hline 13 & 0.0833 & 0.083 & 0.096 & 0.0834 & 0.0836 & 0.0835 & 0.085 & 0.0806 & 0.0816 & \begin{tabular}{|l|}
0.0811 \\
\end{tabular} & 0.074 & 0.081 & 0.085 & 0.083 & 0.074 \\
\hline 14 & $x x x$ & 0.081 & 0.094 & $x x x$ & $x x x$ & $x x x$ & 0.103 & 0.0751 & 0.0897 & 0.0824 & 0.074 & 0.095 & 0.112 & 0.102 & 0.088 \\
\hline 15 & $x x x$ & 0.082 & 0.095 & $x x x$ & $x x x$ & $x x x$ & 0.123 & 0.0836 & 0.0842 & 0.0839 & 0.076 & 0.116 & 0.122 & 0.119 & 0.105 \\
\hline
\end{tabular}

Note: The symbol xxx indicates values not recorded for midspan loading conditions, LC \#1 through LC\#3, as shown in Table 6.1. 
Table 6.12 Strain Correlation of Experimental Results and FE Models

\begin{tabular}{|c|c|c|c|c|c|c|c|c|c|c|c|c|c|c|c|}
\hline \multirow{3}{*}{$\begin{array}{l}\text { Strain } \\
\text { Loc. }\end{array}$} & \multicolumn{3}{|c|}{ Case \# 2} & \multicolumn{4}{|c|}{ Case \# 3} & \multicolumn{4}{|c|}{ Case \# 5} & \multicolumn{4}{|c|}{ Case \# 6} \\
\hline & \multirow[t]{2}{*}{ Exp. } & \multicolumn{2}{|c|}{ FE } & \multicolumn{3}{|c|}{ Exp. Load Cases } & \multirow{2}{*}{$\begin{array}{c}\mathrm{FE} \\
\text { Equiv. }\end{array}$} & \multicolumn{3}{|c|}{ Exp. Load Cases } & \multirow{2}{*}{$\begin{array}{c}\mathrm{FE} \\
\text { Eq uiv. }\end{array}$} & \multicolumn{3}{|c|}{ Exp. Load Cases } & \multirow{2}{*}{$\begin{array}{c}\mathrm{FE} \\
\text { Eq uiv. }\end{array}$} \\
\hline & & Actual & Equiv. & Min & Max & Avg & & Min & Max & Avg & & Min & Max & $A v g$ & \\
\hline$\overline{1 \mathrm{~L}}$ & $x x x$ & 48.7 & 71.2 & $x x x$ & $x x x$ & $x x x$ & 52 & 72 & 73 & 72.5 & 70.7 & 51 & 59 & 55.3 & 52.5 \\
\hline$\overline{1 T}$ & $\overline{x x x}$ & -9.9 & -10.8 & $x x x$ & $x x x$ & $x x x$ & -18.1 & -18 & -4 & -11 & -11.5 & -23 & -13 & -17.3 & -19.3 \\
\hline $2 \mathrm{~L}$ & $x x x$ & 57.8 & 65.3 & $x x x$ & $x x x$ & $x x x$ & 63.8 & 116 & 157 & 136.5 & 90.1 & 62 & 87 & 71.0 & 70.7 \\
\hline $2 T$ & $x x x$ & 7.7 & 12.2 & $x x x$ & $x x x$ & $x x x$ & -14.4 & 47 & 110 & 78.5 & 31.5 & -27 & -7 & -18.0 & -17 \\
\hline $3 \mathrm{~L}$ & $x x x$ & 48.7 & 71.2 & $x x x$ & $x x x$ & $x x x$ & 72.1 & 72 & 76 & 74 & 70.7 & 88 & 168 & 130.8 & 105.8 \\
\hline $3 \mathrm{~T}$ & $x x x$ & -9.9 & -10.8 & $x x x$ & $x x x$ & $x x x$ & -1.9 & -12 & -1 & -6.5 & -11.5 & 25 & 70 & 48.8 & 16.5 \\
\hline $4 \mathrm{~L}$ & 82.5 & 70.5 & 85.8 & 66.4 & 66.7 & 66.55 & 58.4 & 70 & 70 & 70 & 63.8 & 59 & 60 & 59.8 & 52 \\
\hline $4 \mathrm{~T}$ & $\begin{array}{l}-11.3 \\
\end{array}$ & -10.1 & -14.6 & -18.9 & -16.1 & -17.5 & -21.2 & -11 & -2 & -6.5 & -9.7 & -20 & -11 & -15.5 & -18.1 \\
\hline $5 \mathrm{~L}$ & 85.5 & 109 & 107.2 & 79.9 & 84.4 & 82.15 & 77 & 62 & 63 & 62.5 & 58.6 & 66 & 73 & 68.8 & 63.8 \\
\hline $5 \mathrm{~T}$ & 28.3 & 29.4 & 33.6 & -12 & -11.2 & -11.6 & -18.7 & 10 & 12 & 11 & 10.9 & -22 & -7 & $\begin{array}{l}-12.8 \\
\end{array}$ & -14.4 \\
\hline $6 \mathrm{~L}$ & 82.6 & 70.5 & 85.8 & 101.9 & 106.9 & 104.4 & 112.4 & 69 & 71 & 70 & 63.8 & 74 & 80 & 77.5 & 72.2 \\
\hline $6 \mathrm{~T}$ & -4.8 & -10.1 & -14.6 & 10.3 & 19.8 & 15.05 & 14.7 & -9 & -3 & -6 & -9.7 & -6 & 1 & -1.5 & -2 \\
\hline $7 \mathrm{~L}$ & $x x x$ & 48.7 & 71.2 & $x x x$ & $x x x$ & $x x x$ & 52 & 45 & 50 & 47.5 & 46.8 & 39 & 47 & 43.5 & 42.1 \\
\hline $7 \mathrm{~T}$ & $\overline{x x x}$ & -9.9 & -10.8 & $x x x$ & $x x x$ & $x x x$ & -18.1 & -7 & -5 & -6 & $\begin{array}{l}-7.7 \\
\end{array}$ & -14 & -9 & $\begin{array}{l}-11.8 \\
\end{array}$ & -13.5 \\
\hline $8 \mathrm{~L}$ & $x x x$ & 57.8 & 65.3 & $x x x$ & $x x x$ & $x x x$ & 63.8 & 38 & 44 & 41 & 42.7 & 37 & 49 & 44.0 & 46.7 \\
\hline $8 \mathrm{~T}$ & $x x x$ & 7.7 & 12.2 & $x x x$ & $x \mathrm{XXX}$ & $x x x$ & -14.4 & -2 & -2 & -2 & -0.9 & -13 & 0 & -7.8 & -10.7 \\
\hline 9L & $x x x$ & 48.7 & 71.2 & $x x x$ & $x x x$ & $x x x$ & 72.1 & 45 & 48 & 46.5 & 46.8 & 48 & 53 & 51.3 & 51.4 \\
\hline $9 \mathrm{~T}$ & $x x x$ & -9.9 & -10.8 & $x x x$ & $x x x$ & $x x x$ & -1.9 & -7 & -5 & -6 & -7.7 & -12 & -7 & -9.0 & -9 \\
\hline
\end{tabular}

Note: The symbol xxx indicates values not recorded for midspan loading conditions, LC \#1 through LC\#3, as shown in Table 6.1. 
The finite element models for Case \#2 indicate that the FE actual geometry model usually underestimates deflections and strains compared to the FE equivalent plate model. The experimental values seem to fall somewhere between the predictions of the two models.

For Case \#3, a good correlation for both strain and deflection values is obtained. For strain values, the experimental results are generally lower than the FE predictions. The discrepancy may be caused by the load placement where localized effects influence the strain value of the FE model. The FE models for Cases \#5 and \#6 show lower strain and deflection values in relation to the experimental results. Since twist of the panel is more prevalent in the eccentric loading conditions, the overestimation of the shear stiffness in the FE model could be a direct result in smaller deformations (as described in Chapter 5). Despite this, a good correlation is shown for all load cases. Thus it can be concluded that the equivalent orthotropic material properties analytically predicted for the core and face laminates (given in Chapter 2) and used in the FE models are relatively accurate. This further implies that the explicit solution for equivalent properties can be confidently used in design applications for bridge decks. 


\section{Chapter 7}

\section{Conclusions and Recommendations}

\subsection{Overview}

In this study, a FRP honeycomb sandwich panel, produced by KSCI for highway bridge applications, is evaluated in the linear range under bending and torsional loads. Analytical procedures for this sandwich panel were developed in conjunction with this research work (Davalos et al. 2001) to determine equivalent orthotropic properties of the core and face laminates. The equivalent properties of the core, which consists of in-plane sinusoidal cells extending vertically between the top and bottom faceplates, are obtained using a combined energy method and mechanics of materials approach. A combination of micro/macromechanics is used to predict the properties of the face laminates.

Experimental results and finite element analyses are used to obtain responses of sandwich beam samples in bending and torsion. The experimental strains and displacements are correlated with analytical predictions for bending from Timoshenko's beam theory. The finite element models are formulated using layered shell elements with ABAQUS, and the models consist of equivalent three-layer plate assemblies as well as simulations of actual core geometries and face-sheet lay-up using ply properties of individual layers found by micromechanics. Beam samples of two widths and either longitudinal or 
transverse core orientations are tested under three and four-point bending, as well as in torsion. Finally, a panel is experimentally tested under midspan and eccentric patch loads, and its response is then correlated with results obtained by finite element analyses.

\subsection{Conclusions}

The results of the finite element modeling and experimental testing indicate that equivalent panel properties can be utilized to correctly predict responses of the FRP honeycomb sandwich structure. The results for the beam samples tested in bending and torsion showed indirectly that equivalent bending and shear stiffness properties can be efficiently used with confidence, both in the explicit solution for bending and the FE modeling in bending and torsion. The tests of the beam samples indicated that material properties for the sandwich structure were predicted with a good degree of accuracy.

Applying equivalent orthotropic material properties can allow for modeling of the FRP honeycomb sandwich structure as an equivalent layered plate. Thus the complex geometry of the honeycomb core and the laminated face plates can be reduced to a few material constants. This provides an economic yet effective method of modeling the otherwise complex panel.

The experimental testing and finite element evaluation of the panel under patch loading provided reassurance that the predictions can correctly correlate with the responses of the panel section under symmetric and asymmetric loadings. Generally, the equivalent 
properties give conservative predictions, but in general a good correlation was shown. Thus, the development of future design procedures for the KSCI honeycomb panel can be carried out confidently using the equivalent material properties.

\subsection{Recommendation}

It was observed in the experimental investigation that delamination of the core from the face plates can be a critical failure mode under torsional loading. This delamination severely decreases the sample's out-of-plane shear stiffness. Further research to improve the manufacturing process with respect to the core-to-faceplate bond is suggested. It would be beneficial to perform torsion tests in subsequent studies in which delamination could be an issue to be evaluated. While the effects of delamination show up slightly on bending tests, the torsion tests showed high sensitivity to capture the delamination of the face sheet.

As a further study, Schlussel (1996) has shown in his thesis that it is possible to obtain shear moduli through experimental procedures. Thus a study using the experimental and/or finite element analysis results presented in this thesis could be used to find the inplane and out-of-plane equivalent shear moduli of the FRP honeycomb sandwich panel. 


\section{References}

ABAQUS, Standard Users Manual, 1998, version 5.8. Hibbitt, Karlsson and Sorensen, Inc., USA.

Bathe, K.J., 1982. Finite element procedures in engineering analysis, Prentic-Hall.

Brokaw, J.T., 1992. Test methods to determine strength and stiffness properties for stress-laminated timber bridge decks. M.S. Thesis, West Virginia University, Morgantown, WV.

Christensen, R.M., 1991. Mechanics of Composite Materials. Malabar: Krieger.

Cook, R.D., Malkus, D.S. and Plesha, M.E., 1989. Concepts and applications of finite element analysis, $3^{\text {rd }}$ Edition, Johnson Wiley and Sons, USA.

Davalos, J.F., Qiao, P.Z., Xu, X.F., Robinson, J.M., Barth, K.E. 2001. "Modeling and characterization of fiber-reinforced plastic honeycomb sandwich panels for highway bridge applications," J . Composite Structurex2 (2001): 441-452.

FEMAP Users Manual, 1999, version 7.1. Enterprise Software Products, Inc., Exton, PA.

Lesko, J.J. 2001. "Overview of FRP Bridge Decks," presented at WVU ASCE $37^{\text {th }}$ Annual Spring Technical Conference. April 19, 2001.

Lesko, J.J. and Davalos, J.F. 2001. "Fiber-reinforced Polymer Decks for Bridge Systems." ASCE J ournal of Composites for Construction Special $150^{\text {th }}$ Anniversary Publication. To Appear.

Luciano, R. and Barbero, E. J. (1994). "Formulas for the stiffness of composites with periodic microstructure," I nt. J ournal of Solids and StructurBd(21): 2933-2944.

Market Development Alliance (MDA). 2000. "Product Selection Guide: FRP Composites for Bridge Applications," $1{ }^{\text {st }}$ edition, Eds. J.P. Busel and J.D. Lockwood.

Noor, A., Burton, W.S. and Bert, C.W. March 1996. "Computational models for sandwich panels and shells." A ppl Mech Rev, 49(3): 155-99.

Plunkett. J.D. November, 1997. "Fiber-Reinforcement Polymer Honeycomb Short Span Bridge for Rapid Installation," NCHRP-IDEA Project 46, Report.

Salim, H.A., 1997, Modeling and application of thin-walled composite beams in bending and torsion, Ph.D. Dissertation, West Virginia University, Morgantown, WV.

Schlussel, J., 1996. A nalytical and experimental evaluation of stiffnesses for FRP laminates, M.S. Thesis, West Virginia University, Morgantown, WV. 